\title{
Molten Salt Reactor Fundamental Safety Function PIRT
}

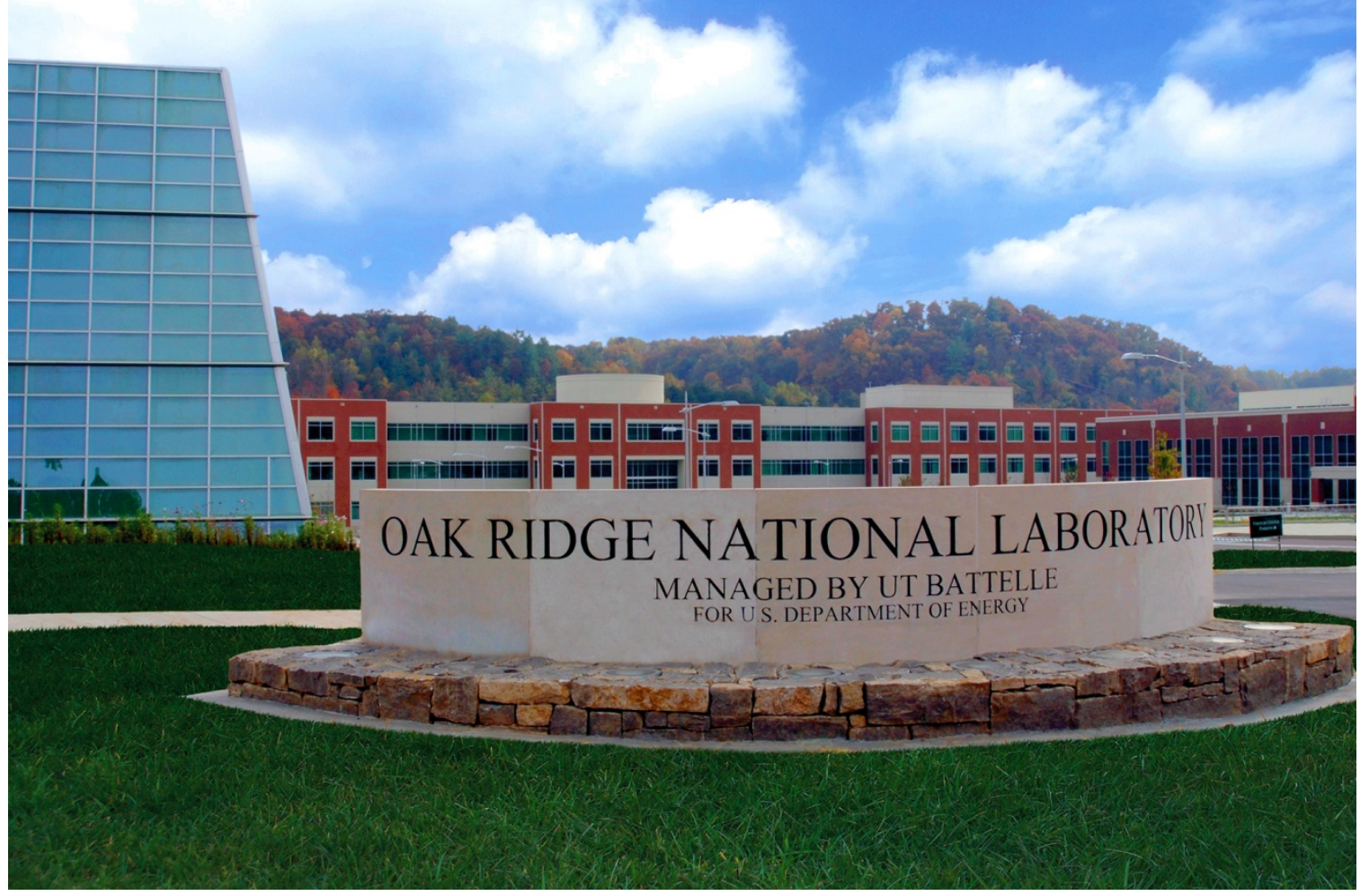

David E. Holcomb Alexander J. Huning Michael D. Muhlheim Richard S. Denning George F. Flanagan

September 2021 


\title{
DOCUMENT AVAILABILITY
}

Reports produced after January 1, 1996, are generally available free via US Department of Energy (DOE) SciTech Connect.

\section{Website www.osti.gov}

Reports produced before January 1, 1996, may be purchased by members of the public from the following source:

\author{
National Technical Information Service \\ 5285 Port Royal Road \\ Springfield, VA 22161 \\ Telephone 703-605-6000 (1-800-553-6847) \\ TDD 703-487-4639 \\ Fax 703-605-6900 \\ E-mail info@ntis.gov \\ Website http://classic.ntis.gov/
}

Reports are available to DOE employees, DOE contractors, Energy Technology Data Exchange representatives, and International Nuclear Information System representatives from the following source:

Office of Scientific and Technical Information

PO Box 62

Oak Ridge, TN 37831

Telephone 865-576-8401

Fax 865-576-5728

E-mail reports@osti.gov

Website https://www.osti.gov/

\begin{abstract}
This report was prepared as an account of work sponsored by an agency of the United States Government. Neither the United States Government nor any agency thereof, nor any of their employees, makes any warranty, express or implied, or assumes any legal liability or responsibility for the accuracy, completeness, or usefulness of any information, apparatus, product, or process disclosed, or represents that its use would not infringe privately owned rights. Reference herein to any specific commercial product, process, or service by trade name, trademark, manufacturer, or otherwise, does not necessarily constitute or imply its endorsement, recommendation, or favoring by the United States Government or any agency thereof. The views and opinions of authors expressed herein do not necessarily state or reflect those of the United States Government or any agency thereof.
\end{abstract}


Nuclear Energy and Fuel Cycle Division

\title{
MOLTEN SALT REACTOR FUNDAMENTAL SAFETY FUNCTION PIRT
}

\author{
David E. Holcomb \\ Alexander J. Huning \\ Michael D. Muhlheim \\ Richard S. Denning \\ George F. Flanagan
}

September 2021

\author{
Prepared by \\ OAK RIDGE NATIONAL LABORATORY \\ Oak Ridge, TN 37831-6283 \\ managed by \\ UT-BATTELLE LLC \\ for the \\ US DEPARTMENT OF ENERGY \\ under contract DE-AC05-00OR22725
}





\section{CONTENTS}

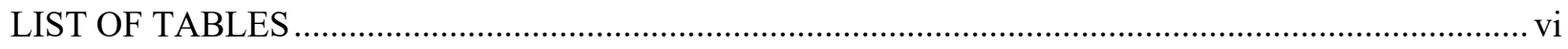

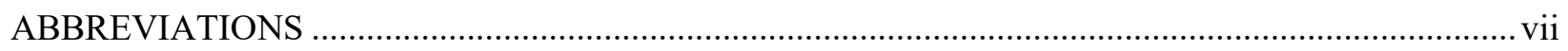

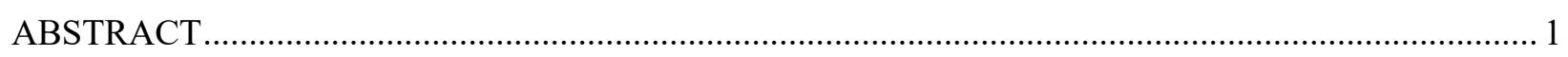

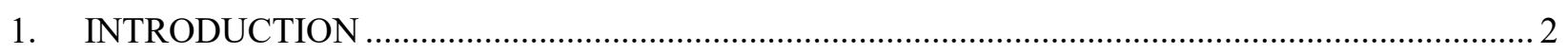

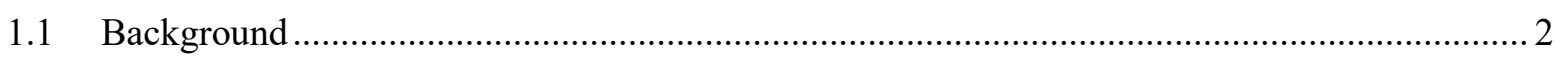

1.2 The Origin and Application of the Phenomena Identification and Ranking Table (PIRT) ........ 2

1.3 Application of the PIRT Process as a Guide to Research Prioritization .................................... 3

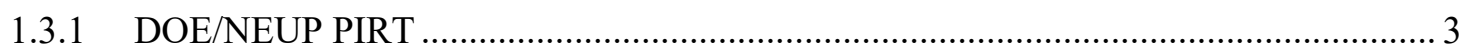

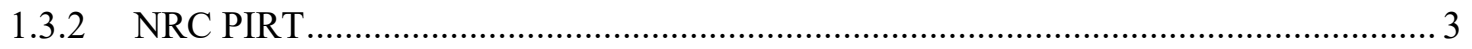

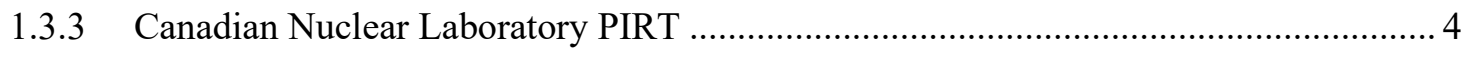

2. PIRT OBJECTIVES, PROCESS, AND SCOPE ...................................................................... 5

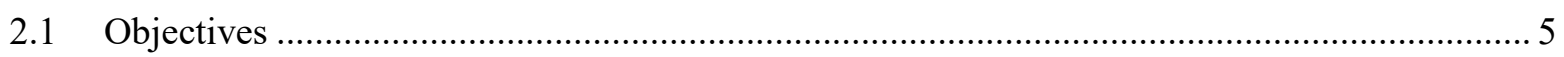

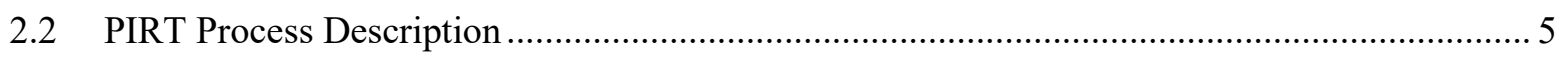

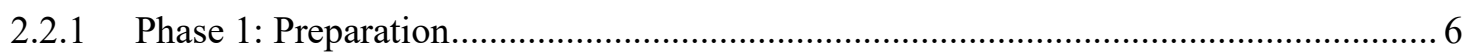

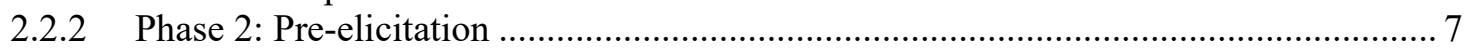

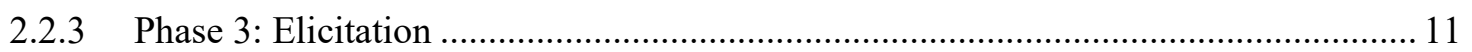

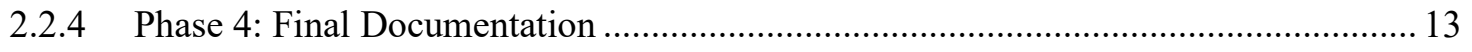

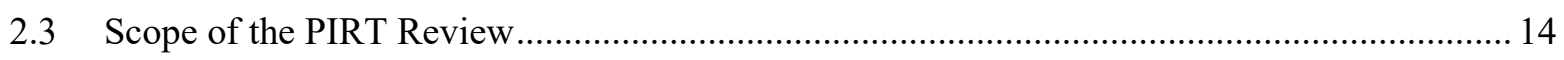

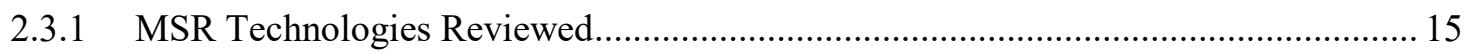

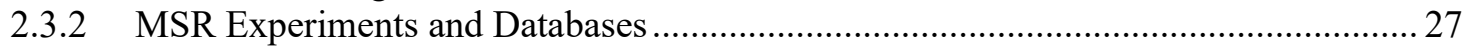

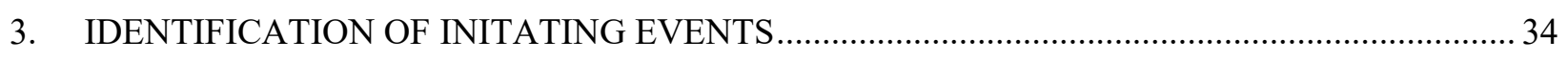

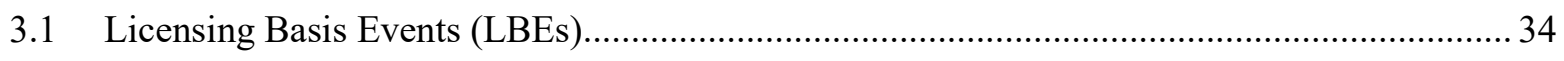

3.2 Aggregation of Initiating Events into Generic Scenario Categories ................................... 34

3.2.1 Scenario Category I: Salt Spill Accident .................................................................. 35

3.2.2 Scenario Category II: Dynamic System Thermal/Hydraulic/Power Response............. 37

3.2.3 Scenario Category III: Water-Molten Salt Interactions............................................. 38

3.2.4 Scenario Category IV: Accidental Criticality External to the Core Region or in

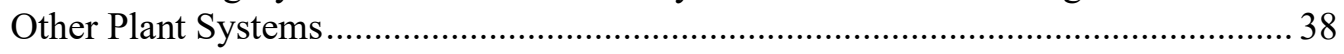

3.2.5 Scenario Category V: Emergency Response System Failures .................................. 38

3.2.6 Scenario Category VI: Radwaste Management System............................................ 38

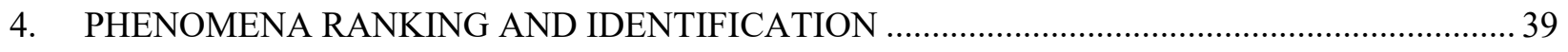

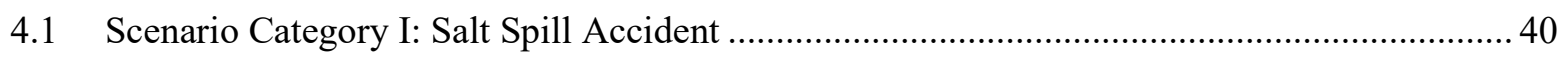

4.2 Scenario Category II: Dynamic system thermal/hydraulic/power response .......................... 47

4.3 Scenario Category III: Water-Molten Salt Interactions.................................................... 49

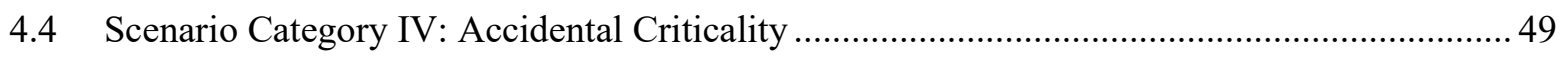

4.5 Scenario Category V: Emergency response system failures ............................................... 51

4.6 Scenario Category VI: Radwaste management system.................................................... 51 


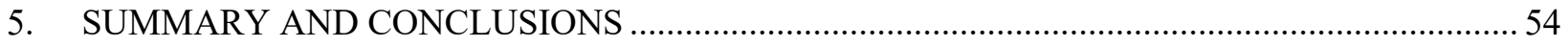

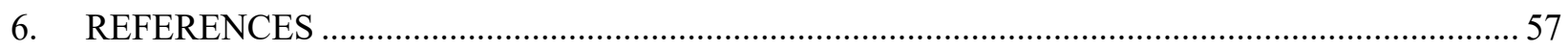

APPENDIX A. SCENARIO CATEGORY WORKSHEETS ............................................................ A-1

APPENDIX B. PHENOMENA RANKING WORKSHEETS ............................................................... B-1

APPENDIX C. PANEL COMPOSITION AND PRESENTERS .......................................................... C-1 


\section{LIST OF FIGURES}

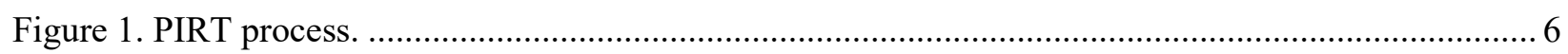

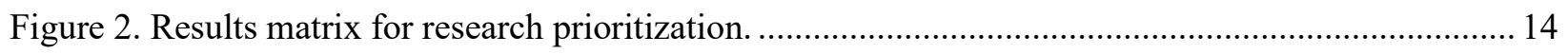

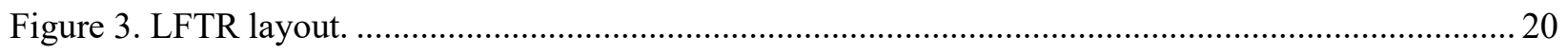

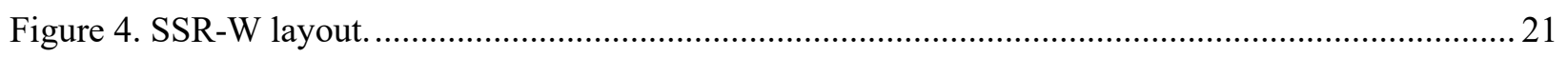

Figure 5. 100MW Copenhagen Atomics Wasteburner...................................................................... 22

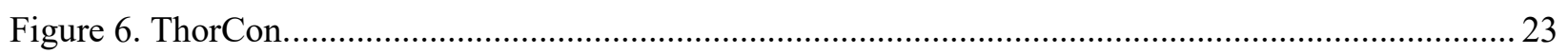

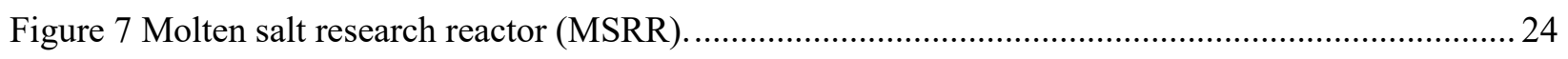

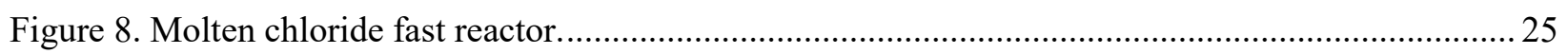

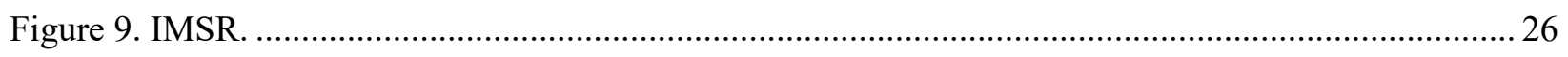

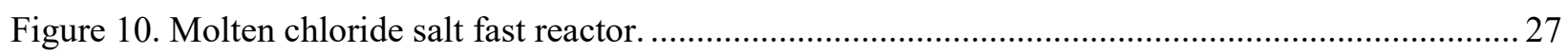

Figure 11. Schematic diagram of example radionuclide transport and release paths for liquid-

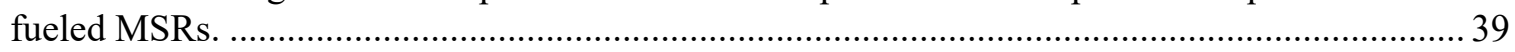

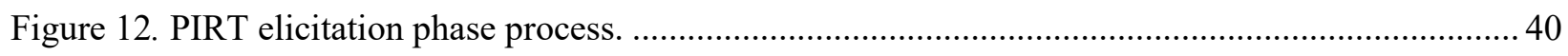




\section{LIST OF TABLES}

Table 1. Three fundamental safety functions (FSFs) for a liquid-fueled MSR ....................................... 5

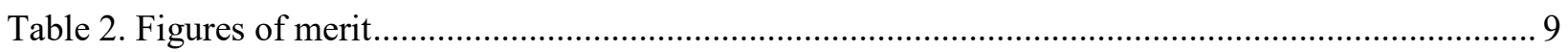

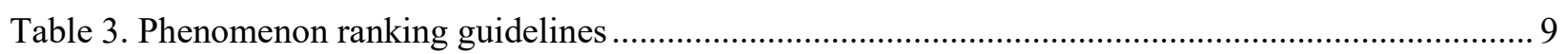

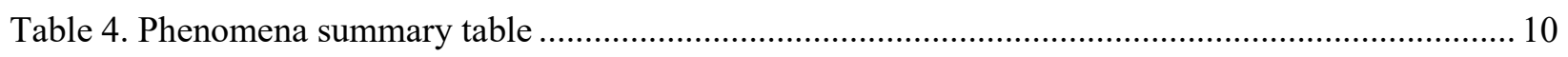

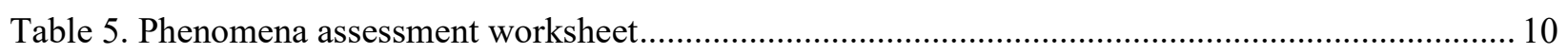

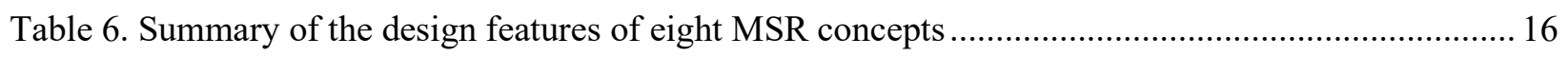

Table 7. Scenario Category I: Salt spill accident, identified phenomena ............................................... 41

Table 8. Scenario Category I: Salt spill accident ranked research priorities............................................ 45

Table 9. Scenario Category II: Dynamic system thermal/hydraulic/power response, identified

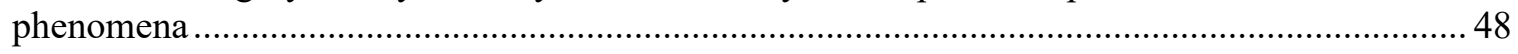

Table 10. Scenario Category II: Dynamic system thermal/hydraulic/power response, ranked

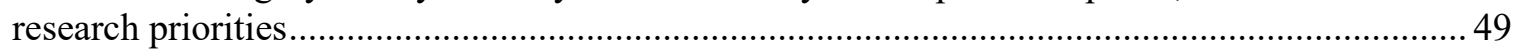

Table 11. Scenario Category VI: Accidental criticality, identified phenomena .................................... 50

Table 12. Scenario Category IV: Accidental criticality, ranked phenomena research priorities .............. 50

Table 13. Scenario Category VI: Radwaste management system failures, identified phenomena ............ 53

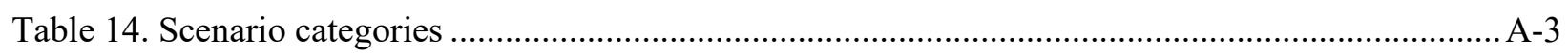

Table 15. Ranked phenomena and page location............................................................................... B-4

Table 16. Figure of merit definitions (repeated for Appendix B) ........................................................ B-4

Table 17. Figure of merit ranking definitions (repeated for Appendix B) ........................................... B-5

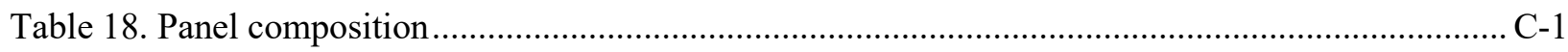

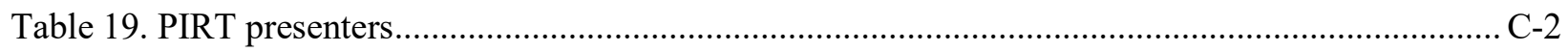




\begin{tabular}{|c|c|}
\hline & ABBREVIATIONS \\
\hline 1 (knowledge ranking) & models exist supported by validation \\
\hline 2 (knowledge ranking) & models exist but need additional data \\
\hline 3 (knowledge ranking) & models either do not exist, are simplistic, or have insufficient data \\
\hline AEC & US Atomic Energy Commission \\
\hline Argonne & Argonne National Laboratory \\
\hline $\mathrm{AOO}$ & anticipated operational occurrence \\
\hline ATF & accident-tolerant fuel \\
\hline BDBE & beyond design basis event \\
\hline $\mathrm{BFP}$ & boiler feedwater pump \\
\hline BNL & Brookhaven National Laboratory \\
\hline CFD & computational fluid dynamics \\
\hline CFR & US Code of Federal Regulations \\
\hline $\mathrm{CNL}$ & Canadian Nuclear Laboratory \\
\hline DBE & design basis event \\
\hline DOE & Department of Energy \\
\hline DU & depleted uranium \\
\hline EM & evaluation model \\
\hline EMDAP & evaluation model development and evaluation process \\
\hline EPRI & Electric Power Research Institute \\
\hline FEM & finite element method \\
\hline FHS & fuel handling system \\
\hline $\mathrm{FLiBe}$ & lithium beryllium fluoride with composition $2 \mathrm{LiF}^{-\mathrm{BeF}_{2}}$ \\
\hline FMEA & failure modes and effects analysis \\
\hline FMU & functional mockup \\
\hline FOM & figure of merit \\
\hline FSF & fundamental safety functions \\
\hline GEMS & Gibbs Energy Minimization Software \\
\hline H (Importance ranking) & high importance \\
\hline HALEU & high-assay low-enriched uranium \\
\hline HAZOP & hazard and operability \\
\hline HEU & highly enriched uranium \\
\hline HTGR & high-temperature gas-cooled reactor \\
\hline I (Importance ranking) & insignificant or no impact \\
\hline
\end{tabular}


ID

IE

$\mathrm{IMSR}^{\circledR}$

L (Importance ranking)

LBE

LEU

LFTR

LIBS

LTI

LWR

M (Importance ranking)

MACCS

MCRE

MCFR

MCFSR

MOF

MSR

MSRE

MSRR

MSTDB

MWe

MWt

N/A

NEAMS

NEI

NEUP

NQA

NRC

NPP

ORNL

PIRT

PHX

PLP

PMOD

PRA identifying event

initiating event

Terrestrial Energy Inc.'s integral MSR

low importance

licensing basis event

low enriched uranium

Lithium fluoride thorium reactor

laser-induced breakdown spectroscopy

lead technical integrator

light water reactor

medium importance

MELCOR Accident Consequence Code System

molten chloride reactor experiment

molten chloride fast reactor

molten chloride salt fast reactor

metal organic framework

Molten salt reactor

Molten Salt Reactor Experiment

molten salt research reactor

Molten Salt Thermal Properties Database

megawatt electric

megawatt thermal

not applicable

Nuclear Energy Advanced Modeling and Simulation

Nuclear Energy Institute

Nuclear Energy University Programs

nuclear quality assurance

US Nuclear Regulatory Commission

nuclear power plant

Oak Ridge National Laboratory

phenomena identification and ranking tables

primary heat exchanger

primary loop pump

power module

probabilistic risk assessment 
PRACS

PSI

QA

RAVEN

$\mathrm{RGPu}$

SAM

$\mathrm{SC}$

$\mathrm{sCO} 2$

SHX

SNF

SNL

SRH

SSR-W

SWP

TLP

TRANSFORM

TRISO

TRL

Unat

$\mathrm{V} \& \mathrm{~V}$

WGPu pool reactor auxiliary cooling system

Paul Scherrer Institute

quality assurance

Risk Analysis and Virtual Environment

reactor-grade plutonium

Systems Analysis Module

scenario categories

supercritical $\mathrm{CO}_{2}$

secondary heat exchanger

spent nuclear fuel

Sandia National Laboratories

steam reheater

stable salt reactor-waste burner

steam water pump

tertiary loop pump

Transient Simulation Framework of Reconfigurable Modules

tristructural isotropic

technology readiness level

natural uranium

verification and validation

weapons-grade plutonium 


\begin{abstract}
The phenomenon identification and ranking table (PIRT) process was employed to evaluate the current capability to assess the ability of liquid-salt-fueled molten salt reactors to achieve their fundamental safety functions (FSFs). The PIRT process provides a structured mechanism to elicit and document expert opinions on the most important phenomena and the corresponding level of knowledge with regard to achieving the FSFs. The PIRT panel included reactor developers, accident progression evaluation tool developers, US Department of Energy (DOE) national laboratory technical staff, university researchers, and US Nuclear Regulatory Commission (NRC) staff. The information-gathering process concentrated on phenomena related to accidents in which the fuel salt - including any in the cover gas - has been released from the first barrier layer. This information-gathering process included identifying all potential accidents that could result in the release of a substantial amount of radionuclides that could breach or bypass the first barrier. The PIRT did not identify any previously unrecognized systemic vulnerabilities. However, the elicitation process identified several areas with low levels of knowledge and significant potential impact on accident progression. These areas either require additional research to improve the state of knowledge or additional design conservatism to accommodate the remaining unknowns.
\end{abstract}




\section{INTRODUCTION}

\subsection{Background}

Molten salt reactor (MSR) designs use liquid fuel, so they have safety characteristics that are uniquely different from the solid-fuel nuclear power plant (NPP) designs licensed to operate worldwide. Although the Molten Salt Reactor Experiment (MSRE) was a demonstration reactor, it operated successfully and safely for five years: it was not a licensed commercial NPP. A key safety measure used in the regulation of NPPs, core damage frequency, has no relevance for a liquid-fueled MSR. Therefore, an applicant seeking to deploy an MSR in the United States must be able to demonstrate adequate plant safety without the advantage of the established regulatory framework for solid-fuel light water reactors (LWRs). Plant safety is evaluated based on models that illustrate the plant's response to accident scenarios. The accident scenarios are developed based on a combination of expert judgement, postulated initiating events (IEs), and accident progression models. Developing the accident progression models begins with postulating the IEs that could challenge plant safety systems or that could lead to a release of radioactive material. Expert judgement is employed to create a detailed list of possible scenarios that might start an accident sequence. Models of the accident sequences are then developed based on the plant's configuration and the phenomena that lead to the accident. Accident consequences are evaluated based on a mechanistic evaluation of the potential for radionuclide release. Accident progression models support vendor design activities to mitigate or prevent accidents, regulator evaluation of the potential accident consequences to the public or the environment, and US Department of Energy (DOE)'s allocation of developmental resources. Therefore, it is crucial that there be adequate understanding of the phenomena involved with accident progression to inform development of the accident progression model.

\subsection{The Origin and Application of the Phenomena Identification and Ranking Table (PIRT)}

The 1967 US Atomic Energy Commission (AEC) task force report on fuel cooling systems NPPs (Ergen Report) [1] which indicated limitations in the state of knowledge of emergency core cooling systems in LWRs to prevent severe fuel damage in loss-of-coolant accidents. Subsequent to the report's release, the AEC was faced with a major dilemma. How could the agency proceed with the licensing of reactors already under construction with limited modeling and experimental capability to address uncertainties regarding emergency core cooling system performance over a spectrum of loss-of-coolant accidents? Based on the existing empirical database, a prescriptive analysis approach involving conservative modeling assumptions was adopted in Appendix K to 10 US Code of Federal Regulations (CFR) 50 [2]. Although the application of Appendix K enabled licensing activities to proceed, the use of conservative assumptions was considered to lead to unnecessary expenses by the nuclear industry and the potential for misfocusing of regulatory oversight on issues with low safety significance.

The PIRT process was originally developed in the late 1980s as part of the technical basis for transitioning from a conservative assumption to a best-estimate-plus-uncertainty method for demonstrating that NPPs have a low probability of violating safety criteria [3]. Expert opinion has always been a major part of reactor design and safety adequacy evaluation. The PIRT process is distinguished by the use of expert opinion to focus attention on those phenomena that dominate accident progression behaviors from the broad spectrum of plausible effects. Screening plausible phenomena to determine those that dominate accident consequences and the associated level of knowledge avoids diversion of resources toward less important issues.

In 2002, the NRC issued Regulatory Guide 1.203 [4] to provide guidance on "Transient and Accident Analysis Methods" for the development, validation, and verification of an evaluation model (EM) to be used in safety analysis reports analyzing "the design and performance of structures, systems, and components and their adequacy for the prevention of accidents and mitigation of the consequences of accidents." Regulatory Guide 1.203 describes an evaluation model development and evaluation process 
(EMDAP) within which the PIRT plays a significant role. The objectives of the MSR PIRTs performed to date, including the PIRT described in this document, are more limited than the PIRT process described in Regulatory Guide 1.203.

Within the context of the EMDAP, the PIRT is used to identify and rank key phenomena and processes within the EM against figures of merit (FOMs). Initially, the PIRT relies on expert judgment, but the development of the PIRT is iterative and ultimately within the EMDAP process. As research activities improve the state of knowledge of PIRT phenomena, the PIRT is updated. In the documentation that supports the submission of the topical report describing the EM, the PIRT provides a framework for demonstrating the state of the EM's validation.

\subsection{Application of the PIRT Process as a Guide to Research Prioritization}

The objectives of the MSR PIRTs performed to date are to identify and prioritize the research requirements needed to support a licensing application. A PIRT that would satisfy Regulatory Guide 1.203 can only be performed for a specified reactor design. Three prior research PIRTs which have considered MSRs generically are described in this section, covering a variety of designs. The objectives and scope of the PIRT described in the current report are discussed in Section 2.

\subsubsection{DOE/NEUP PIRT}

With funding provided by the DOE Office of Nuclear Energy University Programs (NEUP) under the leadership of Georgia Institute of Technology, a PIRT was undertaken for the Fluoride High Temperature Reactor design [5]. Because this is a solid-fueled, molten-salt-cooled design, only those aspects of the PIRT associated with the molten salt coolant are relevant to the liquid-fueled MSR designs in the current PIRT. The technical experts elicited were selected from several US universities and DOE laboratories. Four licensing basis events (LBEs) were considered: (1) an uncontrolled rod withdrawal event, (2) a station blackout event, (3) a flow blockage event, and (4) a loss-of-coolant accident. The PIRT was focused on thermal-hydraulic phenomena and did not directly address uncertainties associated with radionuclide release. The FOMs addressed peak temperatures of key components, including the reactor vessel and the environmental heat exchangers. Regarding the thermo-physical properties of the salts, the heat capacity of lithium beryllium fluoride with composition $2 \mathrm{LiF}_{-} \mathrm{BeF}_{2}(\mathrm{FLiBe})$ was assessed to be of high importance but the property was assessed to be known. The thermal conductivity and viscosity of FLiBe were assessed to be of high importance and the state of knowledge was considered to be only partially known. Optical properties of the salt were assessed to be of low importance (but recognized that the system studied has a solid fuel core.)

\subsubsection{NRC PIRT}

This study was undertaken to assist the NRC in preparing for receipt of license applications for MSRs [6]. The lead organization for the PIRT was Brookhaven National Laboratory (BNL). The panel of experts included personnel from the NRC, BNL (author of the report), other DOE laboratories, and universities. The assessment is classified as a pre-PIRT because it was not performed for a specific plant design. The study addressed liquid-fuel thermal spectrum, fluoride salt reactor designs, and fast-spectrum chloride salt designs. It specifically did not address phenomena and uncertainties associated with radioactive material release from molten salts, as it was considered premature to do so. The assessments focused on initial steady-state conditions followed by perturbations from initial power for generic scenarios associated with increasing reactivity or power-cooling mismatch. Separate assessments were made for neutronics phenomena and thermal-fluid phenomena. Several FOMs were identified for the neutronics and thermalfluid assessments which were then quantified for the generic scenarios. Within the thermal-fluid area, the needs associated with thermophysical properties for salts were identified, particularly for those containing fission product contaminants. The study concluded that "There remain several areas that need further 
investigation and confirmation...new flow loops and integral test facilities utilizing molten salts will likely be necessary to develop models and correlations, and to assess code performance."

\subsubsection{Canadian Nuclear Laboratory PIRT}

The Canadian Nuclear Laboratory undertook a PIRT for a small MSR with either flowing or fixed salt [7]. The molten salt could be either a fluoride or another halide operating at a temperature in excess of $600^{\circ} \mathrm{C}$. The FOM used was radioactive material release to the environment. The assumed accident scenario was a large earthquake accompanied by flooding, which presumed to be a maximum credible event. Failed piping in the scenario would enable air ingress, thus producing oxidizing conditions.

The high-importance, low-knowledge phenomena identified were chemical speciation, reaction of salts with oxygen (flowing salt), volatilization of radionuclides, radionuclide transport within the salt, natural convection heat transfer, steam generation, and natural convection mass transport.

A unique approach was taken in this PIRT: members of the evaluation team were assigned to review and report on specific physical processes. As a result, this study provides a good reference for the state-of-theart of research on MSR accident phenomena. 


\section{PIRT OBJECTIVES, PROCESS, AND SCOPE}

\subsection{Objectives}

The objectives of this PIRT were to identify and rank the phenomena that can cause a release of radioactive material, inhibit heat removal, or create an unwanted criticality accident in a liquid-fueled MSR. The results are intended to be applicable to any liquid salt-fueled reactor within the scope of this effort, including those with different:

- neutron spectra,

- fuel cycles,

- core configurations,

- moderator,

- and heat transfer configurations.

Because of the breadth of different design concepts included within this PIRT evaluation, many accident scenarios could have been identified that are specific to each different design. To perform the PIRT within the context of such many scenarios would have required an unacceptable time commitment on the part of the panel members. For this reason, a set of generic scenarios with commonality for a variety of designs was developed that formed the basis for consideration by the panel members. The MSR designer can determine whether a particular scenario category is applicable to a particular design's LBEs.

The technical experts elicited were selected from several developers of liquid salt-fueled MSR design, US universities, and DOE laboratories. Six scenarios that could lead to the phenomena of interest were considered: salt spill accident, dynamic system thermal/hydraulic/power response, water-molten salt interactions, accidental criticality external to the core region, emergency response system failures, and radwaste management system failures. The FOMs addressed the potential for release of fission products and/or barrier integrity failure, the potential for unbalanced heat removal, and the potential for an uncontrolled nuclear reaction.

To determine the knowledge and importance of each scenario, research efforts were identified regarding salt spill experiments; analysis of thermophysical properties (and databases) of molten salt; qualification of fuel salts, and modeling and analysis for separate effects and integral effects of molten salt flow, nuclide generation, and travel. This effort identified where more research was needed and where sufficient knowledge exists, and a corresponding importance ranking was assigned.

\subsection{PIRT Process Description}

The objective for developing a broad scope PIRT for liquid-fueled MSRs was to identify the information necessary for evaluating the three fundamental safety functions (FSFs) based on the non- LWR licensing framework developed under a DOE cost-shared, owner/operator-led initiative (Table 1) [8, 9]:

Table 1. Three fundamental safety functions (FSFs) for a liquid-fueled MSR

1. Limiting the release of radioactive materials

2. Removing heat from the reactor and waste stores

3. Controlling reactivity 
A structured and systematic process was used to formally elicit expert judgement. This section describes the systematic expert elicitation process that consists of nine steps across four phases (Figure 1) with a tenth step, not shown in Fig. 1, spanning all four phases in which a participatory peer reviewer provides an independent technical review throughout each step. The level of effort in implementing the steps varies with the nature of the technical issues and available resources. An NRC white paper [10] provides an overview of the expert elicitation process.
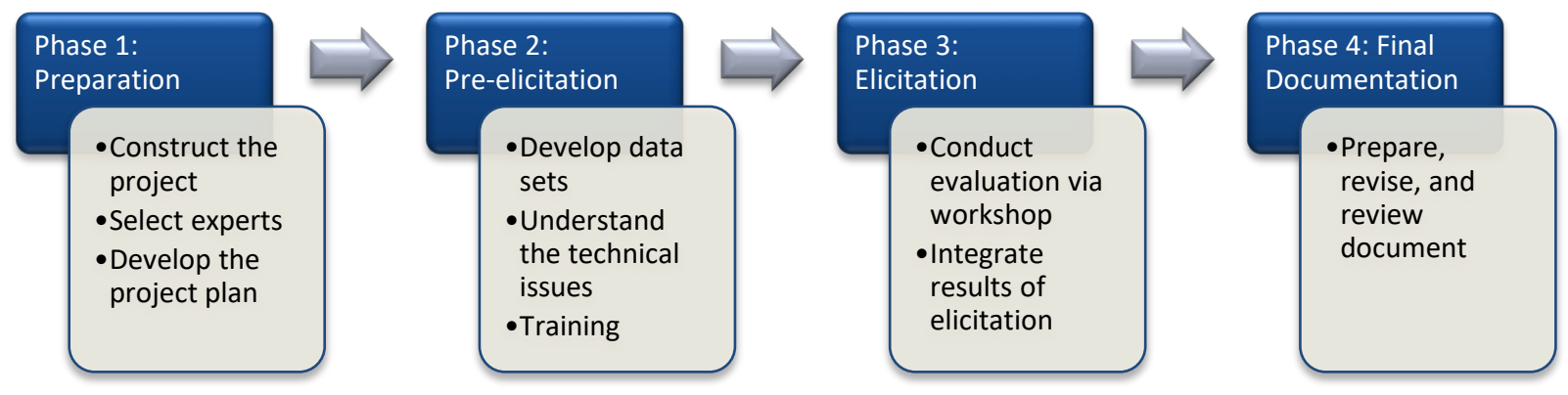

Figure 1. PIRT process.

\subsubsection{Phase 1: Preparation}

\subsubsection{Construct the project}

Expert elicitation is key to identifying the potential phenomena and processes leading to the FSFs identified above. Expert elicitation is employed to increase the probability of addressing all relevant phenomena for the diverse set of MSR designs being pursued. The direct relationship of FOMs to FSFs is consistent with the NRC's performance-based, risk-informed approach to the licensing of non-LWRs. In comparison with PIRTs performed for LWRs, MSRs have less information regarding safety performance or an equivalent set of validated modeling tools than are available for LWRs. Technical judgment is required to assess whether bounding assumptions are reasonable and appropriate and what information would be needed to develop a reasonable suite of accident analysis tools.

The project organization structure is defined below:

- The lead technical integrator (LTI) for this PIRT is Dr. David Holcomb. His role as is to lead the entire process and serve as the key decision-maker in resolving controversial problems or conflicts.

- The co-LTIs for this PIRT are Drs. Alex Huning, Michael Muhlheim, and Rich Denning. Their roles are to assist the LTI, formulate the scenarios to be evaluated, collect the information put forth during the evaluation process, and provide an agenda and record of the process.

- Proponent experts (team members) are those individuals that were selected for this PIRT because they are at the forefront of liquid-fueled MSR technology and are recognized by their peers as authorities because of their sustained and significant expertise on the topic. The proponent experts serve as the primary subject matter experts who evaluate the data and make judgments. The responsibility of a proponent is to make judgments about the technical issues of interest. 
- The participatory peer reviewer is Dr. George Flanagan. His first role is to provide a technical review of the process over all four phases to ensure that the range of data, models, and methods have been duly considered in the assessment, and that all technical decisions are adequately justified and documented. Dr. Flanagan's second role is to ensure that the project conforms to the basic principles and formal process for eliciting expert judgment.

\subsubsection{Select the experts}

A broad-based selection of experts with knowledge in liquid-fueled MSRs and/or PIRT process were chosen to participate in the PIRT. These experts are from industry, DOE national labs, NRC, consultants, and to a limited extent, academia. The team has a strong industry component to represent the diversity of designs being pursued and to ensure that recommended future activities adequately address MSR design options.

\subsubsection{Develop the project plan}

Because the meetings were virtual, access and availability to an MSR PIRT Dropbox was provided to all team members, as well as connectivity via Microsoft Teams. These tools were vital to the completion of this PIRT. References, plans, presentations, meeting agendas and notes were made available throughout the process.

\subsubsection{Phase 2: Pre-elicitation}

\subsubsection{Develop data sets and references}

A preliminary collection of experimental data and references that were expected to be used during the development of this PIRT were made available to all participants via the MSR PIRT Dropbox at the beginning of the process. References included previous PIRTs on MSRs, tristructural isotropic (TRISO) fuel, next-generation nuclear plants, low power and shutdown events, initiating event analysis for MSRs, and descriptions and examples of the PIRT process.

These resources were made available to all participants. References were updated as needed to include presentations by PIRT members during the training process, as well as information that would be helpful to all team members, including references to materials that would assist in the evaluation of phenomena or to document their own evaluations to the LTI.

When experimental datasets became publicly available, they were provided to team members, or contact information and expected release dates were given.

\subsubsection{Understand the technical issues}

At the kickoff meeting that was held prior to the first workshop, all participants were informed of the workshop objectives, purpose, the expected output from the workshops, and the intended use of the results. This was intended to help the expert panel understand the objectives of the PIRT, how the PIRT would proceed, the expected results, and to clarify that they represent the overall technical MSR community instead of their associated organizations.

In this stage of the process, more technical issues are usually identified than can be handled with the limited resources and expert availability. It was recognized that the project team would likely have to prioritize which issues were of highest importance for consideration.

In contrast with LWR accidents, MSR accidents do not involve a threshold for a major release of radioactive material from fuel associated with severe core damage. The fuel is already molten. If the 
primary system is breached, then the consequences depend on the location of the breach, the size of the breach, mitigation measures, and how much of the fuel salt or fission gases leak into a confined space. Even a small breach could result in a large release of fuel salt, and because of the high temperature of the salt (compared to the temperature within containment), an increase in the pressure within the confined space can also result. Thus, the approach to post-accident confinement of radioactive material for an MSR is expected to be different than that for LWRs. Significant quantities of fission products could also be stored in different locations in the plant that could also have associated accidental releases. In addition, the typical accident scenarios potentially associated with plant operation, such as a flow coastdown accident, loss of offsite power, reactivity insertion accident, and external events (including earthquakes and tornado-driven missiles), must be analyzed to determine the magnitude of potential release of radioactive material.

Among the activities performed by the panel members are the review and supplementing of potential accident scenarios that can lead to an offsite release of radioactive material, the identification of phenomena that act as accident initiators (such as corrosion), the identification of phenomena that affect the release of radioactive material from the reactor normal and accident cooling systems, phenomena that affect the potential failure of barriers to the release of radioactive material to the environment and ultimately quantification of the importance of these phenomena and the state of knowledge of the ability to model these phenomena.

A list of potential specific technical issue(s) was developed by Oak Ridge National Laboratory (ORNL) staff to begin the PIRT process. The list was provided to team members by the ORNL LTI and was made available on the MSR PIRT Dropbox. The list was discussed during the PIRT kickoff meeting to promote discussion of the phenomena of interest.

\subsubsection{Training}

Before the first workshop, team members were informed of the DOE and NRC efforts to develop and license MSRs. Team members associated with the different MSR designs provided overviews of their designs, as did researchers associated with fundamental experiments and modeling at the micro and macro levels (see Section 2.3, "Scope of PIRT review"). This provided team members with some understanding of the differences in the various designs. This facilitates understanding of the overall technical issues and identifies possible gaps in research and regulatory needs. These overviews are necessary to ensure that the PIRT is broad based rather than design specific.

Before elicitations began, designers were asked to review and identify additional scenario categories that would be required to address their design or to confirm that the six scenario categories encompassed the potential accident scenarios for their design. The panel was also asked to review the descriptions of associated phenomena and recommend modifications. Therefore, each phenomenon was discussed to identify the key underlying properties. This also served to ensure complete understanding of the definition of each phenomenon.

The last step of the training prior to beginning the elicitation process was to provide a correlation between the three FSFs (Table 1) and the three FOMs (Table 2) against which the scenarios would be evaluated. As applicable, the three FOMs were ranked for each identified phenomenon based on their importance and the state of knowledge. The ranking guidelines are presented in Table 3. 
Table 2. Figures of merit

\begin{tabular}{|l|l|}
\hline FOM-1 & Potential for release of fission products and/or barrier integrity failure \\
\hline FOM-2 & Potential for unbalanced heat removal \\
\hline FOM-3 & Potential for uncontrolled nuclear reaction \\
\hline
\end{tabular}

Table 3. Phenomenon ranking guidelines

\begin{tabular}{|c|l|c|l|}
\hline \multicolumn{2}{|c|}{ Importance } & \multicolumn{2}{c|}{ State of knowledge } \\
\hline $\mathbf{H}$ & $\begin{array}{l}\text { High: the phenomenon has a } \\
\text { controlling impact on the FOM }\end{array}$ & $\mathbf{3}$ & $\begin{array}{l}\text { Models exist and are supported by validation experiments. Data } \\
\text { exist for the underlying properties over the range of applications } \\
\text { (e.g., thermophysical properties). }\end{array}$ \\
\hline $\mathbf{M}$ & $\begin{array}{l}\text { Medium: the phenomenon has a } \\
\text { moderate impact on the FOM }\end{array}$ & $\mathbf{2}$ & $\begin{array}{l}\text { Models exist that can be extended to the required application, but } \\
\text { additional data, theoretical development, or validation are } \\
\text { required. }\end{array}$ \\
\hline $\mathbf{L}$ & $\begin{array}{l}\text { Low: the phenomenon has a } \\
\text { minimal impact on the FOM }\end{array}$ & $\mathbf{1}$ & Models either do not exist, are simplistic, or have insufficient data. \\
\hline $\mathbf{I}$ & $\begin{array}{l}\text { Insignificant: the phenomenon } \\
\text { has insignificant or no impact } \\
\text { on the FOM }\end{array}$ & \multicolumn{2}{|l}{} \\
\hline
\end{tabular}

Before the PIRT elicitation phase, team members were provided with a description of how the six scenarios were selected. Appendix A provides details of the six scenarios.

The scenario categories with an initial list of critical phenomena for consideration during the elicitation phase are shown in Section 3. Phenomena are identified and categorized based on whether they affect the initial state of the scenario or whether they vary over the scenario (i.e., exhibit transient behavior). Some critical parameters that may affect the magnitude or rate of a particular phenomenon are also provided. It is assumed that the parameter salt properties are critical for many or most phenomena and therefore are not listed. Similarly, system design is also assumed to affect many or most phenomena and therefore is not listed. However, a unique system characteristic or material has an especially important impact on a phenomenon, then it may be identified.

The PIRT elicitation team reviewed and contributed to these lists to develop a comprehensive starting point for the elicitation phase. Additionally, as new or unique phenomena were identified, they were added at to the lists and discussed when appropriate.

Before the elicitation phase, PIRT team members were provided with a discussion on the phenomenon assessment worksheets (Table 4) that would be used to identify the key parameters associated with each phenomenon and to assess the state of knowledge and importance against each FOM (Table 2). This discussion identifies the phenomenon of interest, describes the phenomena, identifies key parameters and properties associated with that phenomenon, and for identifies the importance and state of knowledge for each FOM. The worksheet also captures additional clarifying rationales and identifies relevant references for the specific phenomenon. The completed worksheets are provided in Appendix B. 
Table 4. Phenomena summary table

\begin{tabular}{|c|c|c|c|c|}
\hline \multicolumn{5}{|c|}{ Phenomena list and ranking summary } \\
\hline ID & $\begin{array}{c}\text { Phenomena } \\
\text { title }\end{array}$ & $\begin{array}{c}\text { Event leading to } \\
\text { release }\end{array}$ & Importance rank & Knowledge assessment \\
\hline & & $\begin{array}{l}\text { - Fission product } \\
\text { - Actinides } \\
\text { - Graphite } \\
\text { - Salt } \\
\text { - Metal } \\
\text { components } \\
\text { - Metallic } \\
\text { structures } \\
\text { - Core } \\
\text { - Energetic }\end{array}$ & $\begin{array}{l}\text { - High (H): has a controlling } \\
\text { impact on the FOM; a highly } \\
\text { accurate prediction of the } \\
\text { phenomenon is critical } \\
\text { - Medium (M): has a moderate } \\
\text { impact on the FOM; a } \\
\text { moderately accurate prediction } \\
\text { of the phenomenon is required } \\
\text { - Low (L): has minimal impact } \\
\text { on the FOM } \\
\text { - Insignificant (I): has } \\
\text { insignificant or no impact on } \\
\text { the FOM }\end{array}$ & 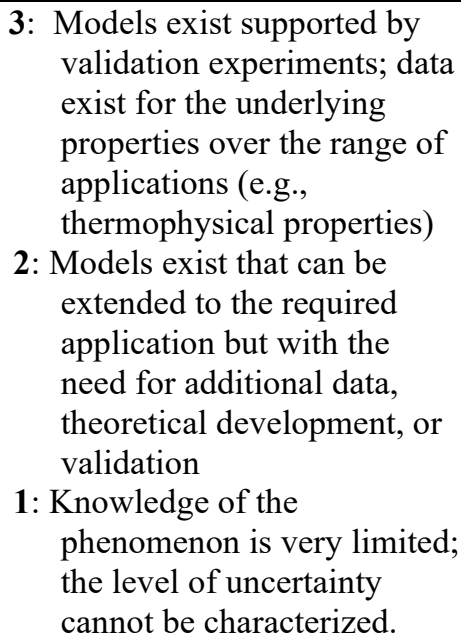 \\
\hline
\end{tabular}

The summary tables are supported by the phenomena assessment work sheets (Table 5) developed by the working group. The LTI led the discussion, and the co-LTI recorded the efforts of the working group. All summary tables are available to working group members for review.

Table 5. Phenomena assessment worksheet

\begin{tabular}{|c|l|}
\hline \multicolumn{2}{|c|}{ Phenomena assessment work sheet } \\
\hline ID & \multicolumn{1}{|c|}{ Phenomenon Title } \\
\hline ID number & Title of phenomenon \\
\hline
\end{tabular}

\section{Phenomenon definition}

Definition of phenomenon

\begin{tabular}{|c|c|c|}
\hline Importance ranking worksheet & Importance rank rationale \\
\hline Event leading to release & Importance rank & \\
\hline
\end{tabular}

\begin{tabular}{|c|c|c|}
\hline Knowledge ranking worksheet \\
\hline Event leading to release & Knowledge rank & Knowledge rank rationale \\
\hline & $1-3$ & \\
\hline
\end{tabular}

\begin{tabular}{|l|}
\hline Detailed description and rationale \\
\hline $\begin{array}{l}\text { Worksheets include a detailed description, importance and knowledge level rankings, and rationales for the } \\
\text { rankings. }\end{array}$ \\
\hline References \\
\hline $\begin{array}{l}\text { Useful references for phenomena that can occur shall be provided, including any references to experiments, } \\
\text { codes, models, other studies, etc. }\end{array}$ \\
\hline
\end{tabular}




\subsubsection{Definitions}

MSRs have a wide variety of potential configurations. The same safety function may be performed by different structures in different design variants, and the same material may perform multiple safety functions. To provide clarity, a glossary of liquid-fueled reactor terminology developed for the final interim staff guidance on aqueous homogeneous reactors [11] was used for guidance. Also, a recommendation for which portions of an MSR constitute its fuel salt system is provided [12]. The definitions provided below are based on these references.

Cover gas system boundary - the portion of an MSR's innermost radionuclide containment layer that is not wetted by the fuel salt.

Fuel salt - the material containing fissionable isotopes that sustains reactor criticality, including materials that have left the salt but could reasonably be anticipated to be reincorporated into it.

Primary reactor containment - the outermost low-leakage pressure-retaining structure credited to retain radionuclides in the event of an accident.

Reactor coolant - the material (aka fuel salt) used to transfer energy away from the reactor core.

Reactor coolant boundary or reactor coolant pressure boundary - the innermost physical barrier surrounding the reactor coolant (aka fuel salt).

Reactor core - the region where nuclear criticality occurs during normal operation.

Reactor vessel - the structure that contains the core during normal operation.

Several additional definitions were necessary for developing the PIRT in addition to the definitions for FOM, knowledge, and importance. These definitions were provided to PIRT members so that all members understood the subtle differences in terminology.

\section{Phenomenon vs. properties vs. parameters}

Phenomenon: a fact, occurrence, or circumstance observed or observable (e.g., condensation). Within the context of this PIRT, a phenomenon may be a broad category with multiple subphenomena. For example, "Radionuclide transport and interactions within the cell atmosphere" comprises several sub-phenomena, such as diffusive and convective transport.

Properties: characteristic features of a system that can specify the system's state (e.g., temperature, pressure)

Parameters: any characteristic that can help in defining or classifying a particular system (e.g., operating cycle history)

\section{Absolute vs. relative ranking goals}

- The goal is to rank phenomena on an absolute scale if possible.

- There is no distribution goal for the number of highs obtained for importance/knowledge.

- Initial inventory/mass/energy may scale the rankings for certain designs.

\subsubsection{Phase 3: Elicitation}

Elicitations were undertaken within the context of the six scenario categories (Section 3.2).

\subsubsection{Conduct evaluation}

Presentation topics presented at the actual start of the workshop included:

- Reminder on the layout and availability of the data in the Dropbox folder (addressed in the kickoff meeting) 
- Reminder that no proprietary, export-controlled, or classified information should be discussed

- Update on the status of safety analysis modeling for MSR accidents (if appropriate)

- PIRT process and recap of previous efforts

- Preliminary list of technical issues (phenomena) to be discussed at this point in the process:

- Accident analyses (e.g., salt spill)

- IE identification

- Phenomena involved in fulfilling each FSF

The evaluation process is outlined below.

Through consensus, the panel identifies the phenomena, physical processes, and parameters that impact a selected FOM in a postulated event, ranks each phenomenon's relative importance to the FOM, and determines how well the phenomenon is understood and/or can be predicted. Phenomena ranked as highly important $(\mathrm{H})$ to the FOM but with low knowledge $(\leq 2)$ (Table 3 ) are prioritized.

The FOM is the primary evaluation criterion used to judge the relative importance of the phenomena. A FOM should be (1) directly related to the issue(s) being addressed, (2) directly related to the phenomena expected during the scenario, (3) easily understood, (4) explicit, and (5) measurable. The FOMs include radionuclide release to the environment, chemical separation, chemical reactions, and corrosion, for example.

Plausible phenomena are those phenomena expected during the postulated scenario. Each one should be precisely defined so that all members of the PIRT panel, who come from varied fields of expertise, have a common understanding of what is being evaluated. The final list of phenomena to be considered in subsequent steps is reached by consensus of the panel members.

A preliminary set of phenomena will be developed with a list to be further considered agreed upon as relevant to the postulated accident scenario. This list considers previous PIRTs, advanced reactor design criteria for non-LWRs [13], accident analyses, and those potential IEs identified for MSRs.

During the evaluation process, the experts rank the importance of each phenomenon identified for each scenario. The importance is ranked relative to the FOM and may be regarded as the relative sensitivity of the FOM with respect to changes in the parameters associated with the phenomenon being considered. A rationale for the ranking will be provided in the phenomena worksheets that are used to record the output of the panel. A four-point scale for estimating the importance of the phenomena is used for this PIRT as follows: high (H), medium (M), low (L), and inactive/insignificant (I).

During the evaluation process, the experts rank the knowledge level of each phenomenon identified for each scenario. The knowledge level can be regarded as either the level of uncertainty or the confidence level with which a phenomenon can be predicted in the postulated scenario. For this PIRT, a three-point scale was used to identify the knowledge of the phenomena ranging from 3 (well-known or low uncertainty) down to 1 (poorly known or high uncertainty). N/A was used when in the worksheets when the phenomena was not assessed because the importance was inactive/insignificant.

\subsubsection{Perform integration}

Expert elicitation does not necessarily create knowledge; rather, it is the evaluation and integration of existing knowledge, to the extent that the knowledge base exists.

To represent the knowledge and interpretations of the technical community, the panel of experts was previously familiar with the datasets provided, or they became familiar with them as the elicitation process proceeded. A PIRT allows team members to interact with each other as they accumulate and evaluate existing knowledge and make interpretations. The expert panel was able to make their interpretations based on the integration of their own knowledge and inputs from other experts. 


\subsubsection{Phase 4: Final Documentation}

\subsubsection{Documentation}

The purpose of this phase is to develop final documentation of the process and results and have the technical staff review the documentation for regulatory assurance. The participatory peer reviewer who oversaw the entire PIRT process is also an expert on PIRTs, MSRs, and licensing of power reactors. This reviewer provided technical, process, and regulatory assurance reviews.

Disparate views or outliers are clearly documented, and their resolutions are provided. This includes documentation of rationales for the specific aggregation techniques employed, impact of disparate views on the final consolidated judgments, and the potential effect of disparate views on the intended use of the final judgments. For example, the knowledge may be ranked as 1 or 2, or the importance may be ranked as $\mathrm{M}$ or $\mathrm{H}$, or something similar, to reflect these differences.

The final report represents the final documentation that indicates what was done, why, and by whom. The final report includes but is not limited to the following:

1. The elicitation process used

2. The dataset used

3. A statement of the key assumptions used in the elicitation

4. The technical issues and the resulting judgments, along with the reasoning supporting these judgments (participatory peer reviewers' comments and responses to those comments are preserved as part of the elicitation process documentation)

5. Any calculations that the experts considered important in determining judgments or models used

6. A discussion of assumptions regarding how the results will be used for decision-making and how the process used provides confidence that the objectives of the elicitation were met

Throughout the discussion, any factors that might have introduced some biases to the results or impose some limitations of the use of the results are addressed. The discussion also includes the expert panel's insights (if any) on how long the results will be valid and the conditions under which the results should be updated. These details are recorded in the Worksheets provided in Appendix B.

Finally, each team member who contributed to the PIRT process provides an independent review and approval of the final documentation.

\subsubsection{Results}

Simply knowing the importance and state of knowledge of phenomena (as opposed to properties or parameters) by itself is insufficient for determining where effort should be focused. It may be easy to assess that if a phenomenon has an insignificant or no impact on a FOM, then further research efforts do not provide additional benefit. However, a low- or moderate-impact phenomenon may require further research because of its low knowledge base. In the panel discussion of phenomena, key properties and parameters that underly the phenomena were identified. A phenomenon may have an inadequate state of knowledge because the underlying knowledge of specific properties is limited. In this case, the limitations in the state of knowledge of these properties were identified as the reason under Rationale.

Once the phenomena assessment worksheets were completed, a results matrix was populated with the phenomena for each FOM (see Section 4). The results matrix prioritizes the data or knowledge level needs based on the importance and the current state of knowledge for each phenomenon. The results matrix shown in Figure 2 was used to prioritize where additional research is necessary based on the state of knowledge and the importance of the phenomena to the scenario being reviewed. 


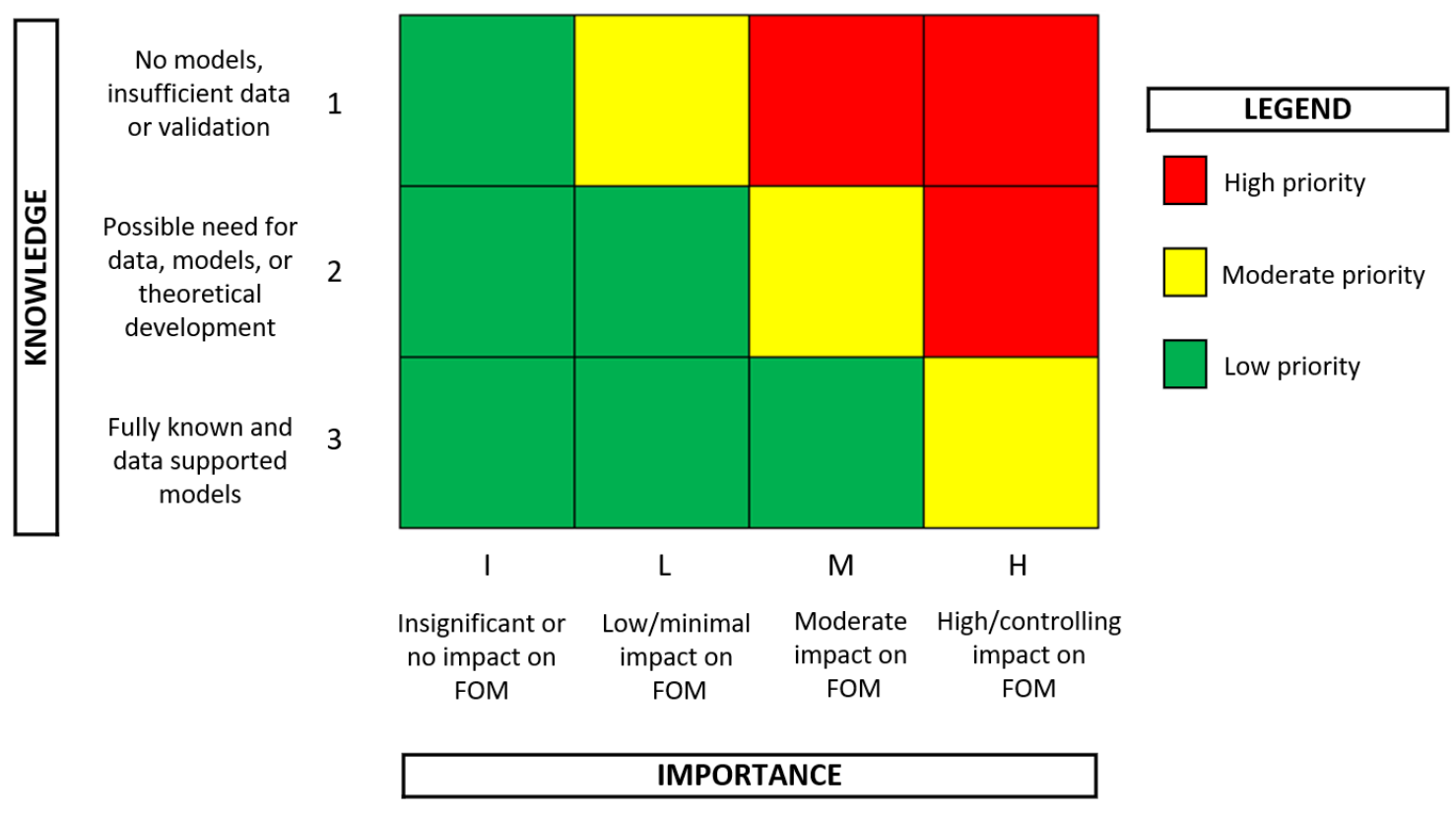

Figure 2. Results matrix for research prioritization.

Research needs could include additional separate effects tests, integral effects tests, model development, model verification, and model validation sufficient to obtain an appropriate level of confidence in the analysis of important phenomena based on the assessment of the three FOMs. In Figure 2, a low priority implies that no further knowledge is necessary to understand the phenomenon's impact on the FSFs. A moderate priority implies that, based on the importance of the phenomenon and the existing state of knowledge, additional experimentation or model development could be necessary to achieve a high level of confidence in the results but is not given high priority. A high priority implies that additional knowledge is essential to achieve a high level of confidence in modeling results to assess FSFs. Although this PIRT provided an assessment of the needs for research to address a specific phenomenon based on a generic assessment of the importance to a FOM and a generic assessment of the state of knowledge, ultimately, these assessments are design specific and must be assessed by the designer/owner-operator for each specific design.

\subsection{Scope of the PIRT Review}

The expert panel members recognized that they represent the overall technical MSR community rather than the organizations with which they are associated. The scenarios and phenomena are applicable to all the designs - some more than others. That is, issues such as reactivity control, off gas control, possible introduction of water, cover gases, addition/deletion of fuel salt, and type of fuel salt are all generic issues to MSRs in general. For this PIRT, the key areas of concern are the FSFs and FOMs that are common issues for all liquid-fueled MSRs, regardless of specific design applications.

For example, the PIRT considered normal operation, including startup and shutdown and how the control elements and additions and subtractions of the fueled salt will affect the system. A specific design may or may not use control rods, although reactivity must be controlled by some means.

The scenarios also addressed unwanted increases in reactivity that could result from adding too much fissile material, changes in the neutron spectrum from inadvertent moderator insertion or withdrawal, or 
inadvertent removal of absorber elements or addition of reflector elements. These events would cause the power to increase, and simultaneously, the temperature of the reactor core would also increase. It was assumed that a critical configuration could also exist outside the reactor core, as was the case with MSRE in abnormal circumstances. Ex-core criticality would be more likely for fast spectrum systems where loss of moderation would be less significant.

\subsubsection{MSR Technologies Reviewed}

Because of the large number of MSR technologies [14], it was necessary to limit the PIRT to liquid saltfueled MSRs. PIRT team members associated with eight different MSR designs each provided an overview of their designs to other team members, thereby providing a general understanding of the differences in the designs. This was necessary to ensure that the PIRT would be broad based by focusing the efforts of the team members on the overall technical issues and identifying possible gaps in research and regulatory needs rather than focusing on a specific design.

Six of the eight designs represent MSRs that produce electricity. These six designs range in size from 200-800 Mwe. One design plans a total plant load of 50 to 1,200 MWe max for a modular set of six saltto-salt heat exchangers, with each module having its own superheater. Some of the six electricityproducing designs could be used for other applications (e.g., desalination, isotopes, heat, electricity). The other two MSRs would produce heat instead of electricity, with thermal outputs of 1 and $100 \mathrm{MWt}$. It should be noted that the presented designs represent their reference cases in terms of electrical vs. thermal output, and many of these designs may be modified to meet different energy applications, such as desalination or isotope production.

The current PIRT effort departs from earlier efforts that were more narrowly focused and that evaluated a single fully developed design in depth. This broad effort is necessary to channel resources efficiently because of the diversity of liquid-fueled MSR designs is as diverse as all solid fuel designs. Moreover, this FSF-based adequacy evaluation is completely based on performance, so it represents a significant departure from the existing prescriptive practice used for current operating plants.

The purpose of this PIRT is to ensure that the issues that will most likely be important in the development of MSRs and the information required for achieving the FSFs for liquid-fueled MSRs have been identified. Definition of the issues and gaps in supporting information can be used to target the necessary remaining experiments, modeling, and analyses to support the safety cases.

Internally and externally generated events are within the scope of this review; however, acts of terrorism and internal sabotage are outside the scope. In addition, events such as waste and removal of spent fuel are outside the scope of this review.

This PIRT process was conducted using only publicly available information. No business sensitive, proprietary, export controlled, or otherwise classified information was provided or used.

Table 6 provides a summary of the characteristics of the eight concepts. 
Table 6. Summary of the design features of eight MSR concepts

\begin{tabular}{|c|c|c|c|c|c|c|c|c|c|c|c|}
\hline $\begin{array}{c}\text { MSR } \\
\text { Company }\end{array}$ & Power & $\begin{array}{l}\text { Spec- } \\
\text { trum }\end{array}$ & Salt type & Fuel type & $\begin{array}{c}\text { Off gas } \\
\text { management }\end{array}$ & $\begin{array}{c}\text { Chemical } \\
\text { processing }\end{array}$ & Containment & $\begin{array}{l}\text { Fuel loading/ } \\
\text { unloading }\end{array}$ & $\begin{array}{c}\text { Double } \\
\text { wall / } \\
\text { Tank in } \\
\text { tank }\end{array}$ & $\begin{array}{l}\text { Moder- } \\
\text { ation }\end{array}$ & Lifetime \\
\hline $\begin{array}{l}\text { Lithium } \\
\text { fluoride } \\
\text { thorium } \\
\text { reactor } \\
\text { (LFTR) } \\
\text { Flibe Energy }\end{array}$ & $\begin{array}{l}250 \\
\text { MWe } \\
\text { (Ref } \\
\text { design) }\end{array}$ & Thermal & $\begin{array}{l}\text { Fuel salt - } \\
\mathrm{LiF}-B e F_{2-} \\
\mathrm{UF}_{4} \text { (FliBeU) } \\
\text { Blanket salt - } \\
{\mathrm{LiF}-T h F_{4}}_{\text {(FLiTh) }} \\
\text { Coolant salt - } \\
\text { LiF-BeF }_{2} \\
\text { (FLiBe) }\end{array}$ & $\begin{array}{l}\text { Th feed to } \\
\text { blanket } \\
\text { salt } \\
{ }^{233} \mathrm{U} \text { bred } \\
\text { onsite } \\
\text { after } \\
\text { startup }\end{array}$ & $\begin{array}{l}\text { Continuously } \\
\text { removes } \\
\text { gaseous fission } \\
\text { products } \\
\\
\text { Metal organic } \\
\text { frameworks } \\
\text { (MOFs) }\end{array}$ & $\begin{array}{l}\text { Online } \\
\text { chemical } \\
\text { process to } \\
\text { remove Pa from } \\
\text { the blanket salt } \\
\text { and allow it to } \\
\text { decay } \\
\text { Online removal } \\
\text { of FPs from } \\
\text { fuel salt }\end{array}$ & $\begin{array}{l}\text { 1. Vessels } \\
\text { 2. Multiple } \\
\text { system cells } \\
\text { (e.g., reactor } \\
\text { cell, coolant } \\
\text { cell, drain tank } \\
\text { cell, chemical } \\
\text { processing cell, } \\
\text { off-gas cell) } \\
\text { 3. Building }\end{array}$ & $\begin{array}{l}\text { Online and } \\
\text { continuous (or } \\
\text { batch) salt } \\
\text { processing } \\
\text { - Seeks an } \\
\text { actinide-free } \\
\text { waste stream of } \\
\text { only some of } \\
\text { the fission } \\
\text { products } \\
\text { - Reuses both } \\
\text { fuel and blanket } \\
\text { salts after plant } \\
\text { end of life in } \\
\text { subsequent } \\
\text { reactor } \\
\text { generations }\end{array}$ & $\begin{array}{l}\text { Freeze } \\
\text { valve and } \\
\text { salt drain } \\
\text { tank likely }\end{array}$ & Graphite & $\begin{array}{l}\text { Replace } \\
\text { graphite at } \\
\text { turnaround } \\
\sim 4 \mathrm{yr} \\
\text { Oxidation } \\
\text { process used } \\
\text { to reduce } \\
\text { waste volume } \\
\text { Plant lifetime } \\
\text { is decades } \\
\text { (TBD) }\end{array}$ \\
\hline $\begin{array}{l}\text { Stable salt } \\
\text { reactor } \\
\text { (SSR) } \\
\text { Moltex } \\
\text { Energy }\end{array}$ & $\begin{array}{l}300- \\
500 \\
\text { MWe } \\
\text { /unit }\end{array}$ & Fast & $\begin{array}{l}\text { Cl-type } \\
\text { Salt in } \\
\text { traditional } \\
\text { fuel pins } \\
\text { (Fixed fuel) } \\
\text { Coolant salt: } \\
\text { sodium/ } \\
\text { magnesium } \\
\text { chloride }\end{array}$ & $\begin{array}{l}45 \% \mathrm{KCl} \text { : } \\
55 \% \mathrm{Pu} \\
\text { and mixed } \\
\text { lanthanide } \\
\text { /actinide } \\
\text { tri- } \\
\text { chlorides } \\
\\
271 \text { pins } \\
\text { per } \\
\text { assembly }\end{array}$ & $\begin{array}{l}\text { Passive control } \\
\text { of xenon off } \\
\text { gassing from } \\
\text { fuel pins to } \\
\text { argon cover } \\
\text { gas }\end{array}$ & $\begin{array}{l}\text { N/A (spent fuel } \\
\text { management } \\
\text { options as for } \\
\text { solid-fueled } \\
\text { reactor) }\end{array}$ & $\begin{array}{l}\text { Inert (argon) in } \\
\text { containment } \\
\text { dome }\end{array}$ & $\begin{array}{l}\text { Fuel assembly } \\
\text { charge / } \\
\text { discharge } \\
\text { undertaken on } \\
\text { load } \\
\text { (comparable to } \\
\text { CANDU and } \\
\text { UK AGR) }\end{array}$ & & $\mathrm{N} / \mathrm{A}$ & $\begin{array}{l}60 \text { yr design } \\
\text { life }\end{array}$ \\
\hline
\end{tabular}




\begin{tabular}{|c|c|c|c|c|c|c|c|c|c|c|c|}
\hline $\begin{array}{c}\text { MSR } \\
\text { Company }\end{array}$ & Power & $\begin{array}{l}\text { Spec- } \\
\text { trum }\end{array}$ & Salt type & Fuel type & $\begin{array}{c}\text { Off gas } \\
\text { management }\end{array}$ & $\begin{array}{c}\text { Chemical } \\
\text { processing }\end{array}$ & Containment & $\begin{array}{l}\text { Fuel loading/ } \\
\text { unloading }\end{array}$ & $\begin{array}{l}\text { Double } \\
\text { wall / } \\
\text { Tank in } \\
\text { tank }\end{array}$ & $\begin{array}{l}\text { Moder- } \\
\text { ation }\end{array}$ & Lifetime \\
\hline $\begin{array}{l}\text { Heavy } \\
\text { water- } \\
\text { moderated } \\
\text { MSR } \\
\text { Copenhagen } \\
\text { Atomic }\end{array}$ & $\begin{array}{l}100 \\
\mathrm{MW}(\mathrm{t})\end{array}$ & Thermal & $\begin{array}{l}\text { Starting fuel, } \\
\mathrm{LiF} \\
\mathrm{ThF}_{4} \mathrm{PuF}_{3}\end{array}$ & $\begin{array}{l}\mathrm{Pu},{ }^{233} \mathrm{U} \\
\mathrm{Rad} \text { waste }\end{array}$ & $\begin{array}{l}\text { Xe removal, } \\
\text { vacuum spray } \\
\text { gas stripping }\end{array}$ & On-line & $\begin{array}{l}\text { Shipping } \\
\text { container size - } \\
\text { buried in } \\
\text { ground }\end{array}$ & & $\begin{array}{l}\text { No freeze } \\
\text { valves, } \\
\text { pumping } \\
\text { through } \\
\text { dump tank }\end{array}$ & $\begin{array}{l}\text { Heavy } \\
\text { water }\end{array}$ & $\begin{array}{l}3-5 \text { yr design } \\
\text { life }\end{array}$ \\
\hline $\begin{array}{l}\text { Thermal } \\
\text { molten salt } \\
\text { ThorCon } \\
\text { US, Inc. }\end{array}$ & $\begin{array}{l}500 \\
\text { MWe } \\
(2 \\
\text { cans })\end{array}$ & Thermal & $\begin{array}{l}{\mathrm{NaF}-\mathrm{BeF}_{2}-} \\
\mathrm{ThF}_{4}-\mathrm{UF}_{4}\end{array}$ & $\begin{array}{l}\text {Th}^{233} \mathrm{U} \\
{ }^{235} \mathrm{U} \\
\mathrm{U}-239 \mathrm{Pu}\end{array}$ & $\begin{array}{l}\text { Radioactive } \\
\text { off gases cool } \\
\text { in can, decay } \\
\text { in header tank, } \\
\text { off gas } \\
\text { recovery and } \\
\text { hold up tanks, } \\
\text { Xe and } \mathrm{Kr} \\
\text { bottled, } \mathrm{He} \\
\text { reused }\end{array}$ & $\begin{array}{l}\text { None. Just } \\
\text { additions for } \\
\text { redox control }\end{array}$ & $\begin{array}{l}\text { 1. Can + fuel } \\
\text { salt drain tank } \\
\text { 2. Silo cavity } \\
\text { 3. Third barrier } \\
\text { is the silo } \\
\text { hall/hull } \\
\text { Cold wall } \\
\text { cooled by } \\
\text { natural circ } \\
\text { water surrounds } \\
\text { can }\end{array}$ & $\begin{array}{l}\text { Makeup fuel in } \\
\text { can added as a } \\
\text { liquid } \\
\text { Spent fuel } \\
\text { stored in } \\
\text { building with } \\
\text { air cooling }\end{array}$ & $\begin{array}{l}\text { Pot (reactor } \\
\text { vessel), } \\
\text { pump, } \\
\text { PHX, and } \\
\text { off-gas } \\
\text { cooling } \\
\text { contained } \\
\text { in a can } \\
4 \text { freeze } \\
\text { valves to } \\
\text { drain tank }\end{array}$ & Graphite & $\begin{array}{l}4 \text { yr for } \\
\text { graphite, } 80 \\
\text { yr for power } \\
\text { plant }\end{array}$ \\
\hline $\begin{array}{l}\text { Molten salt } \\
\text { research } \\
\text { reactor } \\
\text { (MSRR) } \\
\text { ACU }\end{array}$ & $1 \mathrm{MWt}$ & Thermal & $\begin{array}{l}{\mathrm{LiF}-\mathrm{BeF}_{2}-} \\
\mathrm{UF}_{4} \\
\text { Lithium } \\
\text { enriched }\end{array}$ & $\begin{array}{l}\text { HALEU } \\
(19.5 \%)\end{array}$ & $\begin{array}{l}\text { Off gas } \\
\text { managed with } \\
\text { a cover gas } \\
\text { system } \\
\text { integrated with } \\
\text { a fuel } \\
\text { polishing } \\
\text { system. }\end{array}$ & $\begin{array}{l}\text { On-line } \\
\text { insoluable } \\
\text { fission } \\
\text { products, noble } \\
\text { gas fission } \\
\text { products and } \\
\text { volatile chloride } \\
\text { fission products } \\
\text { are removed in } \\
\text { Fuel Polishing } \\
\text { system. }\end{array}$ & $\begin{array}{l}\text { 1. Reactor } \\
\text { vessel } \\
\text { 2. Reactor cell } \\
\text { 3. Containment } \\
\text { Fuel handling } \\
\text { system has its } \\
\text { own } \\
\text { containment }\end{array}$ & $\begin{array}{l}\text { Fuel handling } \\
\text { system is } \\
\text { connected to the } \\
\text { reactor } \\
\text { subsystem } \\
\text { through the } \\
\text { drain tank }\end{array}$ & $\begin{array}{l}\text { No freeze } \\
\text { valves }\end{array}$ & & \\
\hline
\end{tabular}




\begin{tabular}{|c|c|c|c|c|c|c|c|c|c|c|c|}
\hline $\begin{array}{c}\text { MSR } \\
\text { Company }\end{array}$ & Power & $\begin{array}{l}\text { Spec- } \\
\text { trum }\end{array}$ & Salt type & Fuel type & $\begin{array}{c}\text { Off gas } \\
\text { management }\end{array}$ & $\begin{array}{l}\text { Chemical } \\
\text { processing }\end{array}$ & Containment & $\begin{array}{l}\text { Fuel loading/ } \\
\text { unloading }\end{array}$ & $\begin{array}{c}\text { Double } \\
\text { wall / } \\
\text { Tank in } \\
\text { tank }\end{array}$ & $\begin{array}{l}\text { Moder- } \\
\text { ation }\end{array}$ & Lifetime \\
\hline $\begin{array}{l}\text { Molten } \\
\text { chloride fast } \\
\text { reactor } \\
\text { (MCFR) } \\
\text { TerraPower }\end{array}$ & $\begin{array}{l}800 \\
\mathrm{MWe}\end{array}$ & Fast & $\begin{array}{l}\mathrm{NaCl}-\mathrm{UCl}_{3} \\
\text { Primary } \\
\text { cooling fluid: } \\
\mathrm{NaCl}^{-} \mathrm{MgCl}_{2} \\
\text { Secondary } \\
\text { cooling fluid: } \\
\text { Solar / nitrate } \\
\text { salt }\end{array}$ & $\begin{array}{l}\text { Initial } \\
\text { charge: } \\
\text { HALEU } \\
\text { •Feed: } \\
\text { depleted } \\
\mathrm{UCl}_{3} \\
\cdot \mathrm{PuCl}_{3} \text { is } \\
\text { bred up }\end{array}$ & & & $\begin{array}{l}\text { Reactor vessel, } \\
\text { containment, } \\
\text { building } \\
\text { Fuel polishing } \\
\text { vessel, } \\
\text { containment, } \\
\text { building }\end{array}$ & & & & \\
\hline $\begin{array}{l}\text { Integral } \\
\text { MSR } \\
\text { Terrestrial } \\
\text { Energy }\end{array}$ & $\begin{array}{l}200 \\
\text { MWe }\end{array}$ & Thermal & $\begin{array}{l}\text { Fluoride } \\
\text { chemistry } \\
{ }^{7} \text { Li use } \\
\text { avoided due } \\
\text { to current } \\
\text { unavailability } \\
\text { and excess } \\
\text { tritium } \\
\text { production }\end{array}$ & $\begin{array}{l}\sim 2 \% \text { LEU } \\
\text { startup } \\
\text { and }<5 \% \\
\text { LEU } \\
\text { makeup }\end{array}$ & $\begin{array}{l}\text { Larger upper } \\
\text { gas plenum } \\
\left(>10 \mathrm{~m}^{3}\right) \\
\text { provides } \\
\text { internal holdup } \\
\text { volume for } \\
\text { fission gases } \\
\text { and has a } \\
\text { residency time } \\
\text { of many } \\
\text { months } \\
\text { Upper plenum } \\
\text { has double- } \\
\text { walled } \\
\text { connecting } \\
\text { pipe to nearby } \\
\text { off gas } \\
\text { collection }\end{array}$ & $\begin{array}{l}\text { None other than } \\
\text { minor } \\
\text { chemistry } \\
\text { control such as } \\
\text { redox potential } \\
\text { Used fuel salt is } \\
\text { partially reused } \\
\text { in subsequent } \\
\text { operational core } \\
\text { units }\end{array}$ & $\begin{array}{l}\text { All primary } \\
\text { systems in a } \\
\text { sealed reactor } \\
\text { vessel } \\
\text { Reactor vessel } \\
\text { is within tight- } \\
\text { fitting steel } \\
\text { containment, as } \\
\text { are pipe } \\
\text { connections and } \\
\text { used fuel salt } \\
\text { storage tanks } \\
\text { Reactor } \\
\text { building with } \\
\text { filtered release } \\
\text { provides further } \\
\text { confinement }\end{array}$ & $\begin{array}{l}6 \text { storage silos } \\
\text { for used core } \\
\text { units outside } \\
\text { primary } \\
\text { containment } \\
\text { and a spent fuel } \\
\text { vault within a } \\
\text { steel } \\
\text { containment }\end{array}$ & $\begin{array}{l}\text { No freeze } \\
\text { valves or } \\
\text { dump tank } \\
\text { IRVACS - } \\
\text { passive } \\
\text { decay heat } \\
\text { removal }\end{array}$ & Graphite & $\begin{array}{l}7 \text { yr core unit } \\
\text { seal-and- } \\
\text { swap" } \\
\text { approach to } \\
\text { graphite } \\
\text { lifetime } \\
56 \text { yr+ } \\
\text { facility } \\
\text { lifetime with } \\
\text { both used } \\
\text { core units and } \\
\text { fuel salt } \\
\text { remaining } \\
\text { within reactor } \\
\text { building }\end{array}$ \\
\hline
\end{tabular}




\begin{tabular}{|c|c|c|c|c|c|c|c|c|c|c|c|}
\hline $\begin{array}{c}\text { MSR } \\
\text { Company }\end{array}$ & Power & $\begin{array}{l}\text { Spec- } \\
\text { trum }\end{array}$ & Salt type & Fuel type & $\begin{array}{c}\text { Off gas } \\
\text { management }\end{array}$ & $\begin{array}{l}\text { Chemical } \\
\text { processing }\end{array}$ & Containment & $\begin{array}{l}\text { Fuel loading/ } \\
\text { unloading }\end{array}$ & $\begin{array}{c}\text { Double } \\
\text { wall / } \\
\text { Tank in } \\
\text { tank }\end{array}$ & $\begin{array}{l}\text { Moder- } \\
\text { ation }\end{array}$ & Lifetime \\
\hline $\begin{array}{l}\text { Molten } \\
\text { chloride salt } \\
\text { fast reactor } \\
\text { (MCSFR) } \\
\text { Elysium }\end{array}$ & $\begin{array}{l}50 \text { or } \\
200 \\
\text { MWe / } \\
\text { mod- } \\
\text { ule } \\
\\
\text { Up to } \\
6 \text { mod- } \\
\text { ules }\end{array}$ & Fast & $\begin{array}{l}\text { Chloride- } \\
\text { based fuel } \\
\text { salt }\end{array}$ & $\begin{array}{l}\text { Liquid: } \\
\text { DU, LEU, } \\
\text { SNF, } \\
\text { RGPu, } \\
\text { WGPu, } \\
\text { Th, Unat, } \\
\text { DU }\end{array}$ & $\begin{array}{l}\text { ON LINE } \\
\text { • Gases/ } \\
\text { volatiles } \\
\text { • Insolubles/ } \\
\text { particulates } \\
\text { OFF } \\
\text { LINE/Batch } \\
\text { • Two } \\
\text { chemistry } \\
\text { steps }\end{array}$ & $\begin{array}{l}\text { REDOX } \\
\text { All actinides } \\
\text { and chlorine are } \\
\text { recycled at } 40- \\
60 \text { yr intervals, } \\
\text { depending on } \\
\text { startup fuel type }\end{array}$ & $\begin{array}{l}\text { Reactor/HX/ } \\
\text { superheater } \\
\text { contained in } \\
\text { secondary } \\
\text { surrounding } \\
\text { clean salt tank } \\
\text { contained in } \\
\text { sealed } \\
\text { cylindrical } \\
\text { underground } \\
\text { cylinder } \\
\text { Passive decay } \\
\text { heat removal } \\
\text { from } \\
\text { surrounding } \\
\text { clean salt tank } \\
\text { to atmosphere }\end{array}$ & $\begin{array}{l}\text { Beginning of } \\
\text { life } \\
\text { fissile/fertile } \\
\text { load. Tiny daily } \\
\text { fertile feeding } \\
\text { Fuel } \\
\text { purification 40- } \\
60 \mathrm{yr}\end{array}$ & $\begin{array}{l}\begin{array}{l}\text { Always } \\
\text { online } \\
\text { drain tank }\end{array} \\
\text { No freeze } \\
\text { valves }\end{array}$ & None & $\begin{array}{l}\text { Indefinitely } \\
\text { refurbishable } \\
\text { components. } \\
\text { Fuel lasts } \\
\text { indefinitely } \\
\text { with periodic } \\
\text { partial fission } \\
\text { product } \\
\text { removal }\end{array}$ \\
\hline
\end{tabular}


Representatives for each of the eight liquid-fueled MSR technologies provided a seminar on their plant designs to help the PIRT team understand their functionality and to assess the importance of the phenomena and the knowledge base on a generic level. A summary of each of the presentations is provided below.

\subsubsection{Lithium Fluoride Thorium Reactor (LFTR) (Flibe Energy)}

Kurt Harris of Flibe Energy, Inc., provided an overview of the Lithium Fluoride Thorium Reactor (LFTR) (Figure 3 [15]). The public reference design of LFTR is a $250 \mathrm{MWe}$ low-pressure, high-temperature, twofluid, molten salt thermal breeder reactor for power and isotope production [16]. LFTR incorporates inherent safety features whenever possible to maintain system simplicity. The primary system vessel, piping, and heat exchangers are composed of Hastelloy N metal. Graphite makes up the bulk of the vessel volume and provides both neutron moderation and structural flow channels for the two in-core salts. The graphite would be replaced after approximately 4 years. The fuel salt is $\mathrm{LiF}_{-} \mathrm{BeF}_{2}-\mathrm{UF}_{4}(\mathrm{FLiBeU})$, the blanket salt is likely to be $\mathrm{LiF}_{-\mathrm{ThF}_{4}}(\mathrm{FLiTh})$, and the coolant salt is likely to be $\mathrm{LiF}^{-\mathrm{BeF}_{2}}(\mathrm{FLiBe})$. The LFTR would consume a thorium feed while continuously recycling the bred ${ }^{233} \mathrm{U}$ on site, thus retaining all fissile materials on site at all times during operation. Online chemical processing of small salt sidestreams would remove neutron-absorbing protactinium $(\mathrm{Pa})$ from the blanket salt, allowing it to decay outside the core, and would also remove fission products from the fuel salt in preparation for disposal (or commercialization). This would be accomplished without significant long-lived actinide contamination. Off-gas management would also remove volatile fission products continuously. The coolant salt would extract thermal energy from both fuel and blanket salts, transferring it to a supercritical $\mathrm{CO}_{2}\left(\mathrm{sCO}_{2}\right)$ power conversion system. The LFTR has a drain tank with a freeze valve to drain salt from the reactor. About $0.5 \mathrm{~kg}$ /day of fission products would be generated in fuel salt. Ideally, processing would be continuous, but batches may be necessary. Fluorination would remove uranium, as well as some fluoride volatile fission and activation products. Following fluorination, the remaining fission products would be extracted from the fuel salt through reductive extraction onto a cathode. Off-gas management will include the use of metal organic frameworks (MOFs) an emerging technology for gas capture from a variety of process streams. The LFTR reference design represents a class of reactors that could be constructed in various configurations for use in numerous applications ranging from non-electricity microreactors to multimodule gigawatt-scale power plants, each with an economic and sustainable fuel cycle.

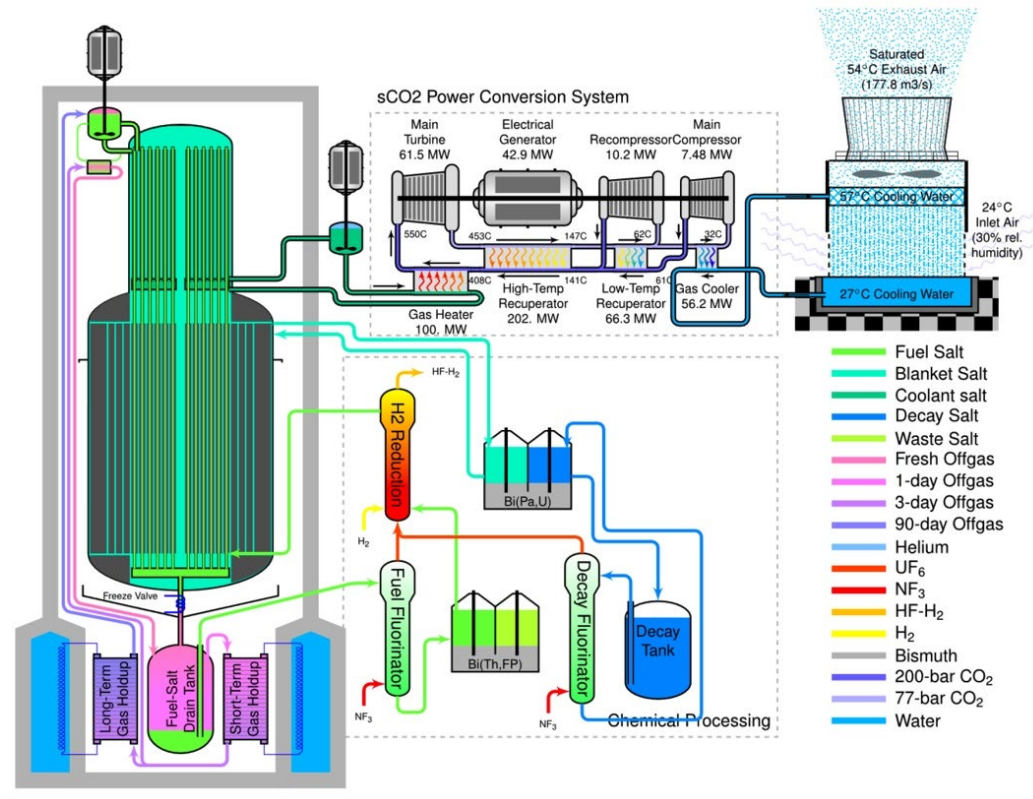

Figure 3. LFTR layout. 


\subsubsection{Stable Salt Reactor-Waste Burner (SSR-W) (Moltex Energy)}

Guy Anderson provided an overview of the Moltex Energy300-MWe stable salt reactor-waste burner (SSR-W) reactor (Figure 4 [17]). The SSR-W is a fast reactor that uses recycled nuclear waste as fuel. The reactor fuel salt is an actinide chloride/potassium chloride eutectic in a liquid state at atmospheric pressure. The molten salt nuclear fuel is contained within static fuel tubes. In the SSR design, the liquid salt fuel mixture is contained within fuel assemblies that are very similar to those used in traditional liquid metal fast reactor technology. The fuel assemblies are then submerged in a pool of pure liquid salt coolant. Each assembly contains 271 fuel tubes filled with fuel salt. The tubes have diving bell gas vents at the top to control the release of fission gases. The fuel in the SSR is composed of potassium chloride salt, plutonium, and mixed lanthanide/actinide trichlorides. Fuel for the initial reactors is planned to come from converted conventional spent oxide nuclear fuel. The coolant salt is circulated through the reactor core by three pumps, each of which is associated with an individual heat removal loops. In the event of a reactor shutdown and failure of all active heat-removal systems in the SSR, decay heat from the core dissipates into air cooling ducts around the perimeter of the tank that operate continually. The heat transfer is sufficient for passive decay heat removal at higher accident temperatures.

At power, the SSR is self-controlling through negative reactivity feedback from the temperature coefficient and the ability to continually extract heat from the fuel tubes. The ability to shut down is ensured through the provision of shutdown rod assemblies, with boron-containing rods in some positions in the core. These rods are used to control the reactor through the initial criticality and the early stages of power ascension, and they can be released on demand to shut down the reactor, thus rendering the system subcritical. A separate system that releases a liquid neutron absorber into dedicated channels in the core provides an option for shutting down the reactor.

The core is cylindrical in shape, and the fuel assemblies are charged and discharged vertically to and from the area above the core. The reactor is refueled at power, and the position to be refueled is selected in order to maintain the desired power and neutron flux profile across the core.

The waste stream from the SSR is the solid salt in the fuel tubes in discharge fuel. The intent is for this fuel to be reprocessed to permit further irradiation of actinides so that the ultimate waste stream is actinide free. This activity is undertaken in the separate fuel manufacturing facility that is used to produce the initial SSR fuel from spent oxide fuel assemblies.

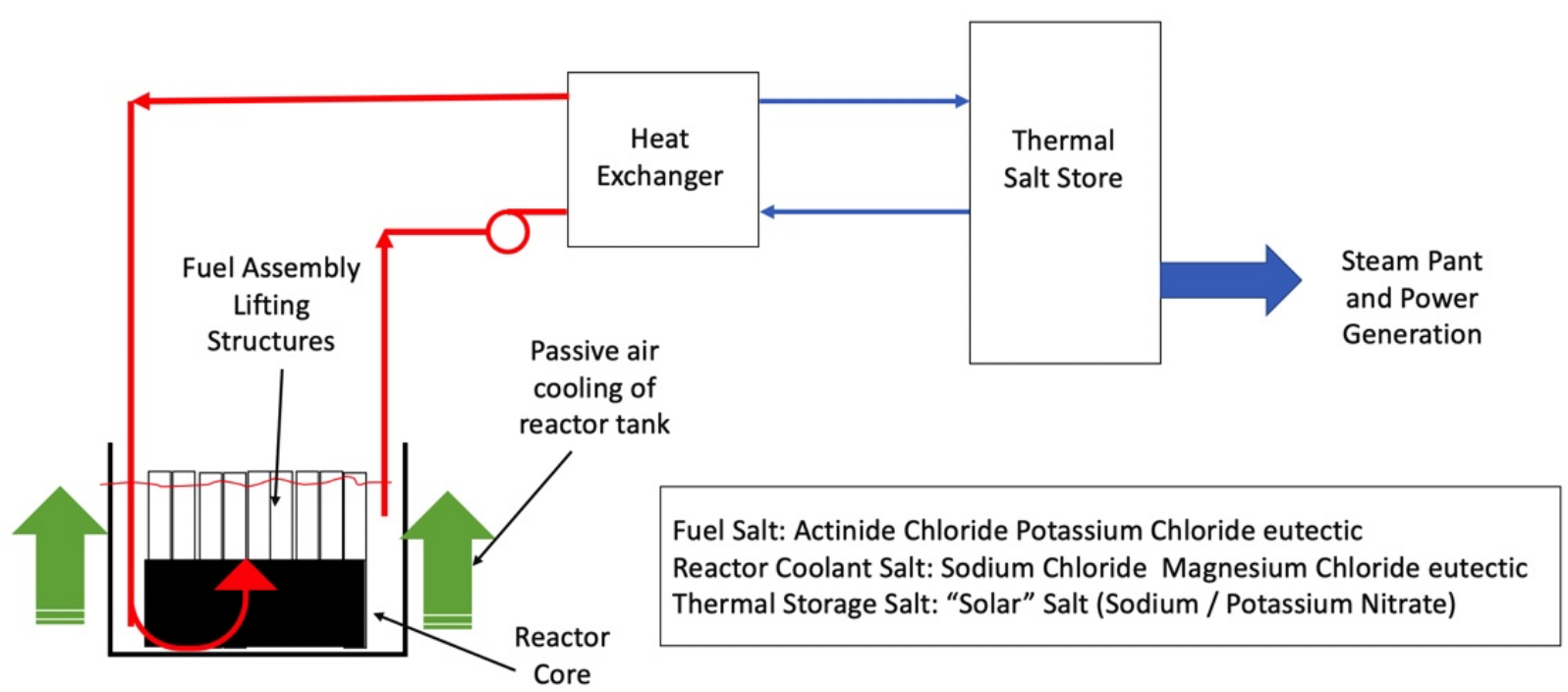

Figure 4. SSR-W layout. 


\subsubsection{100MWt Copenhagen Atomics Wasteburner (Copenhagen Atomics)}

Aslak Stubsgaard of Copenhagen Atomics provided an overview of their 100 MWt heavy watermoderated MSR (Figure 5 [18]). It is housed in a $40 \mathrm{ft}$ shipping container and has closed loop systems. The heavy water operates at room temperature and is unpressurized and thermally insulated from the salt. There are no control rods, but reactivity can be controlled by adjusting the fuel salt / coolant salt flow rate or adjusting the level of the heavy water. The main market for the MSR is for heat production; it does not generate electricity, but a customer can choose to generate electricity from the heat. Both the fuel salt and the heavy water moderator can be separately and passively drained from the core. Following reactor shutdown, the primary heat removal pathway is to remove decay heat passively to the ground. Vacuum spraying in a closed argon gas loop recirculates the gas through filters and the scrubber. The noble gases are kept in circulation, whereas most of the tritium collects in the filters and scrubber. A nonfission prototype will be built and tested in 2022. A 1 MWth demonstration reactor with an operating lifetime of 1-5 weeks is expected to be available in 2025, with the full-size MSR coming online in 2028. The MSR has a design lifetime of approximately 5 years.

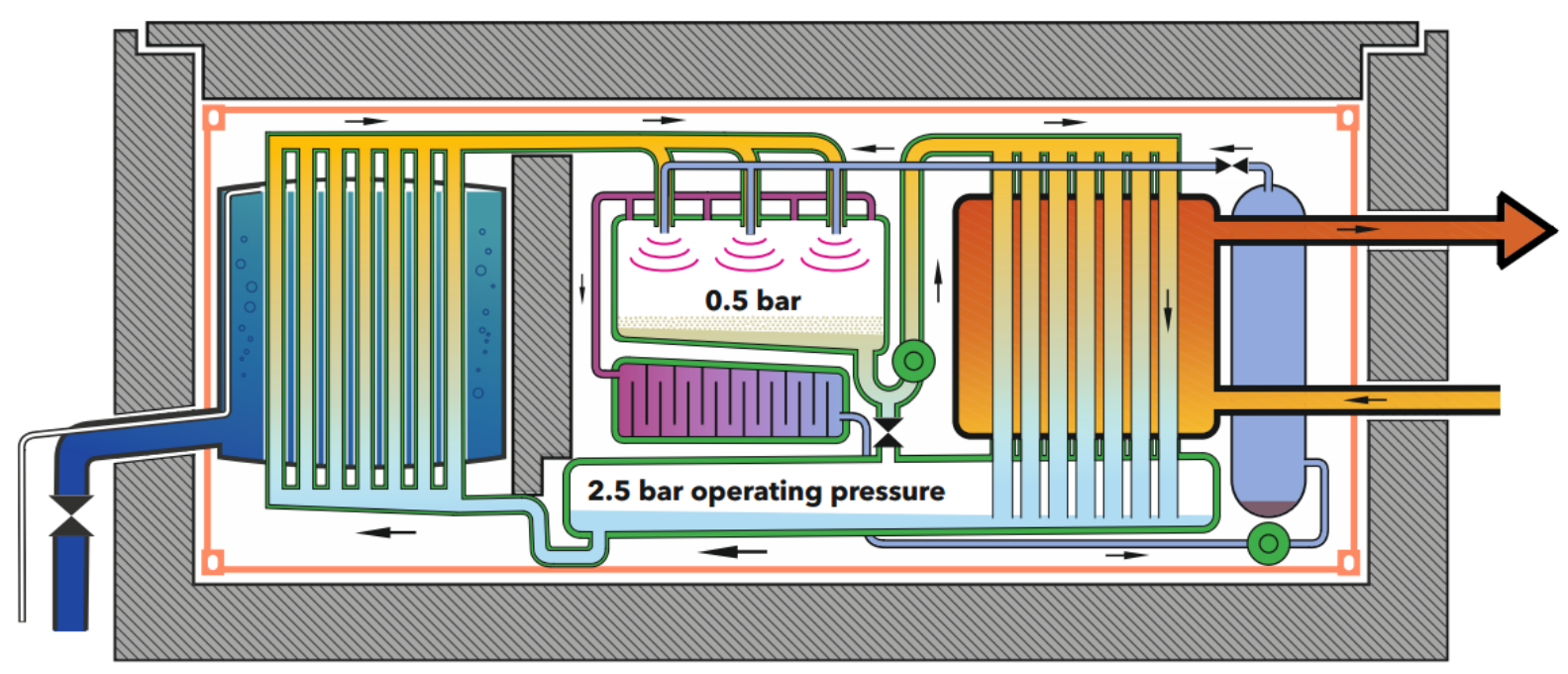

Figure 5. 100MW Copenhagen Atomics Wasteburner.

\subsubsection{ThorCon Molten Salt Reactor (ThorCon)}

Dane Wilson of ThorCon US, Inc. provided an overview of their 500 MWe facility, with each unit comprising two 250 MWe modules. ThorCon is a scale-up of the Molten Salt Reactor Experiment (MSRE). ThorCon is a hybrid thorium/uranium liquid fuel molten salt reactor. Each module is made up of two cans housed in silos. Each can contains a reactor, a primary loop pump (PLP), and primary heat exchanger (PHX). The cans are duplexed. To accommodate 4-year moderator lifetime, a can operates for four years, cools down for four years, and then is changed out. The molten fluoride salt reactors operate in the thermal spectrum. There are three salt loops. There are three control rods, any one of which will shut down the reactor. Draining of the fuel salt from the can to the drain tank will also shut down the reactor. Thus, if the can overheats for whatever reason, a fuse-valve melts, and the primary loop drains to a fuelsalt drain tank. The barriers to prevent a release of fission products include (1) The can/fuel salt drain tank, which includes the pot (vessel) surrounded by a cold wall, (2) the inerted silo cavity, and (3) the silo hall/hull. The can contains the primary loop piping, primary pump, PHX, and the first week of off-gas holdup. Attached to the can is the fuel-salt drain tank. Decay heat removal is achieved by heat radiated from the drain tank across an inert gas gap to the cold wall. Natural circulation of water inside the cold 
wall brings the steam/water mixture to a condenser in a cooling pond. Evaporation of cooling pond water provides many months of decay heat removal. Radioactive off-gases cool in the can to remove short-lived isotopes and in the basement holdup tanks to remove long-lived isotopes except $\mathrm{Kr}^{85}$. $\mathrm{Xe}$ and $\mathrm{Kr}$ isotopes are bottled, and $\mathrm{He}$ is reused.

The PLP circulates the primary salt $\mathrm{NaF}-\mathrm{BeF}_{2}-\mathrm{ThF}_{4}-\mathrm{UF}_{4}$ between the can and the PHX (Fig. 6 [19]). The secondary loop pump (SLP) circulates the $\mathrm{NaF}_{-} \mathrm{BeF}_{2}$ coolant between the PHX and the secondary heat exchanger (SHX). The tertiary loop pump (TLP) circulates the solar salt from the SHX to the steam generator and to the steam reheater $(\mathrm{SRH})$. The balance of plant converts the heat produced in a power module (PMOD) to electricity through the generator and can dump excess heat to the condenser. The steam water pump (SWP) provides water to the condenser. From the condenser, the boiler feedwater pump (BFP) circulates steam through the low-pressure and high-pressure heaters.

The silo cavity is a $25 \mathrm{~mm}$ stainless-steel container at $140^{\circ} \mathrm{C}$ with a few bar pressure. The silo hall/hull is a layered $25 \mathrm{~mm}$ steel, $3 \mathrm{~m}$ concrete or sand, and $25 \mathrm{~mm}$ steel container that surrounds the silo. The ThorCon MSR has built-in spent fuel storage capability that is air-cooled and has the capacity to store 80 years' worth of salt from two active cans.

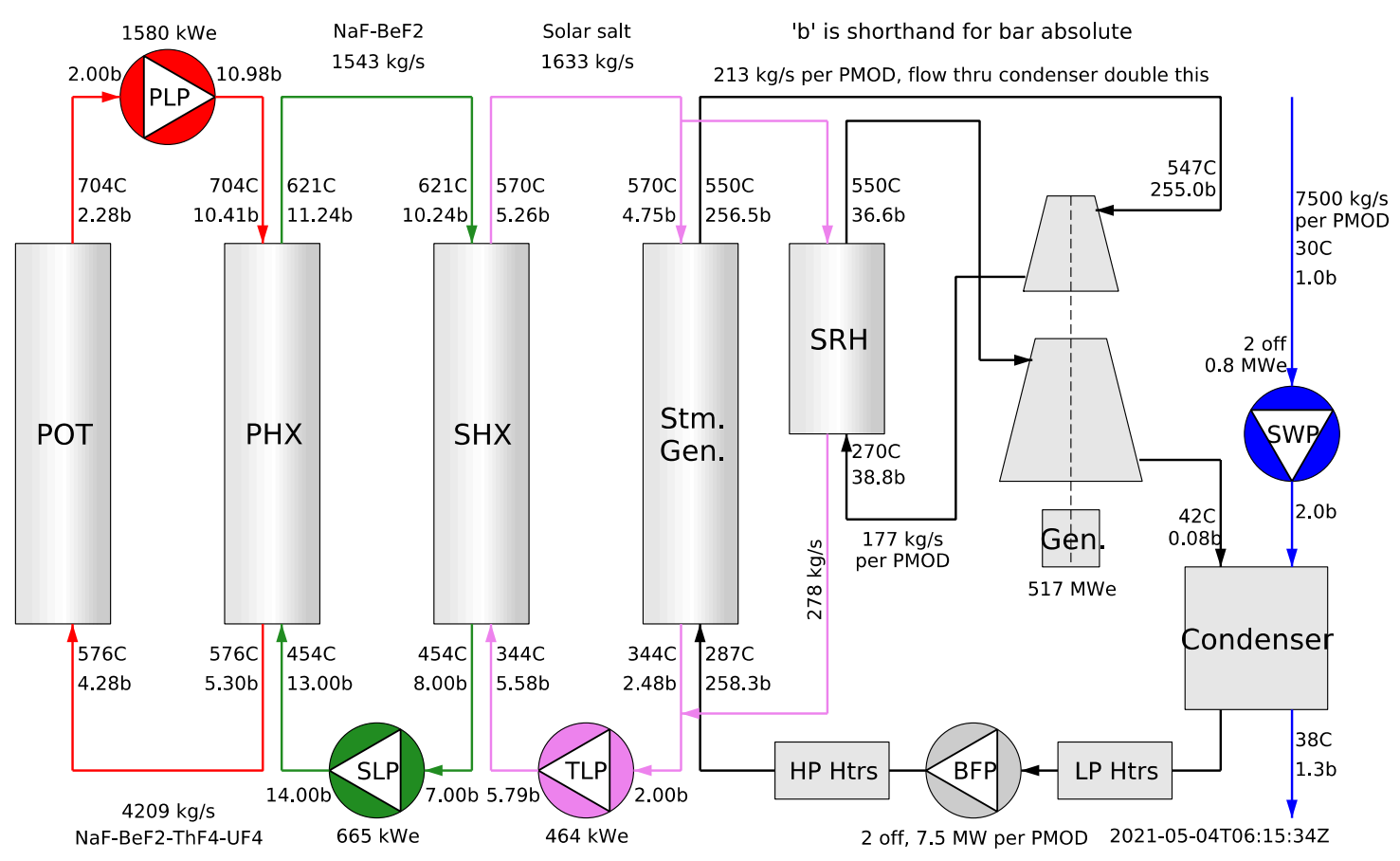

Figure 6. ThorCon.

\subsubsection{Molten Salt Research Reactor (MSRR) (Natura Energy)}

Tony Hill of Natura Energy discussed their 1 MWt molten salt research reactor (MSRR) (Figure 7 [20]). The reactor vessel is $6 \mathrm{ft}$ tall and $4.5 \mathrm{ft}$ in diameter. This is a simplified variation of the MSRE that went critical in 1965 and operated until 1969. The MSRR will operate on a $\mathrm{LiF}-\mathrm{BeF}_{2}-\mathrm{ZrF}_{4}-\mathrm{UF}_{4}$ fuel salt. Its 1 MWth power level is approximately an order of magnitude smaller in thermal output than the 7.5 MWth of the MSRE. There are three major differences between the MSRE and the MSRR: (1) the MSRR is to be fueled with high-assay low-enriched uranium (HALEU) with an enrichment of $\sim 19.5 \%$ instead of highly enriched uranium (HEU), (2) the MSRR has a lower power level and lower power density, and (3) the MSRR does not require external cooling water. Other safety features include a large thermal capacity, 
the maximum fuel salt temperature is less than $700^{\circ} \mathrm{C}$, and there are no strong pressure differentials. The MSRR has a leak-tight, low operating pressure, high design-pressure secondary containment vessel. The MSRR will have forced primary flow for full power operations. A secondary loop will be used to remove the reactor thermal power. The ultimate heat sink will be air. Reactor power will be rejected through a heat exchanger to a secondary salt loop. The outer wall of the containment vessel is actively cooled with air. Cooling during an accident or power outage will be completely passive. Rather than using a freeze valve, the MSRR uses hydraulic pressure to suspend the fuel salt in the primary reactor loop and enables rapid draining of fuel salt from the primary loop when there is a decrease or loss of pressure in the drain tank. The MSRR design employs a defense-in-depth approach for its fuel handling system (FHS) with the use of multiple physical barriers. The FHS is connected to the reactor subsystem through the drain tank. Because the FHS is a supporting auxiliary system located external to the MSRR containment vessel, the FHS will need its own suitably designed containment.

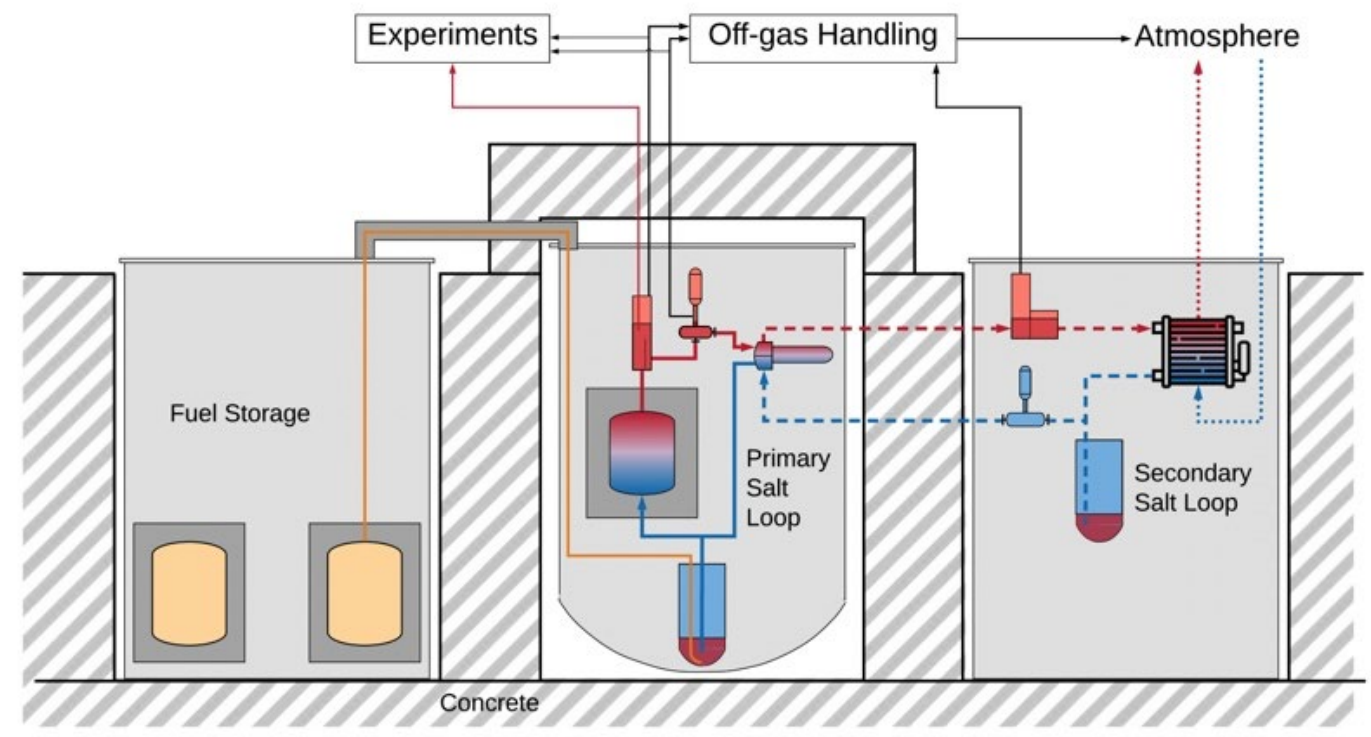

Figure 7 Molten salt research reactor (MSRR).

\subsubsection{Molten Chloride Fast Reactor (MCFR) (TerraPower)}

Tommy Cisneros of TerraPower provided an overview of the molten chloride fast reactor (MCFR), an 800 MWe plant (Figure 8 [21]). This is a pool design with shell-and-tube PHXs. There are 4 primary cooling loops and 4 secondary cooling loops. In-vessel, there are 8 parallel circuits, each with its own pump and heat exchanger. Reactivity control is achieved with an active control rod, negative feedback (fast acting), and structural reactivity temperature coefficient (slow acting). Design features not shared by all liquid-fueled MSRs include fast-spectrum chloride, U-Pu cycle (not Th), and the make-up feed is DU or natural uranium. Because the fast spectrum largely mitigates fission product poisoning, the MCFR does not require online reprocessing to reduce the effects of fission product poisoning. Radioactive source terms in the MCFR could arise from the fuel in the reactor vessel or the fuel in the fuel polishing system. There are three layers of retention of radioactive material for each source: the reactor/fuel polishing vessel, the reactor/fuel polishing containment, and the reactor/fuel polishing buildings. In 2016, the MCFR team performed a preliminary PIRT (MCFRG-INNOV-RPT-0002, Rev-0). TerraPower is performing separate and integrated effects testing with plans to build a molten chloride reactor experiment (MCRE), an MCFR demonstration reactor (10-300 MWe), culminating in the MCFR grid scale reactor (500-1,200 MWe). 


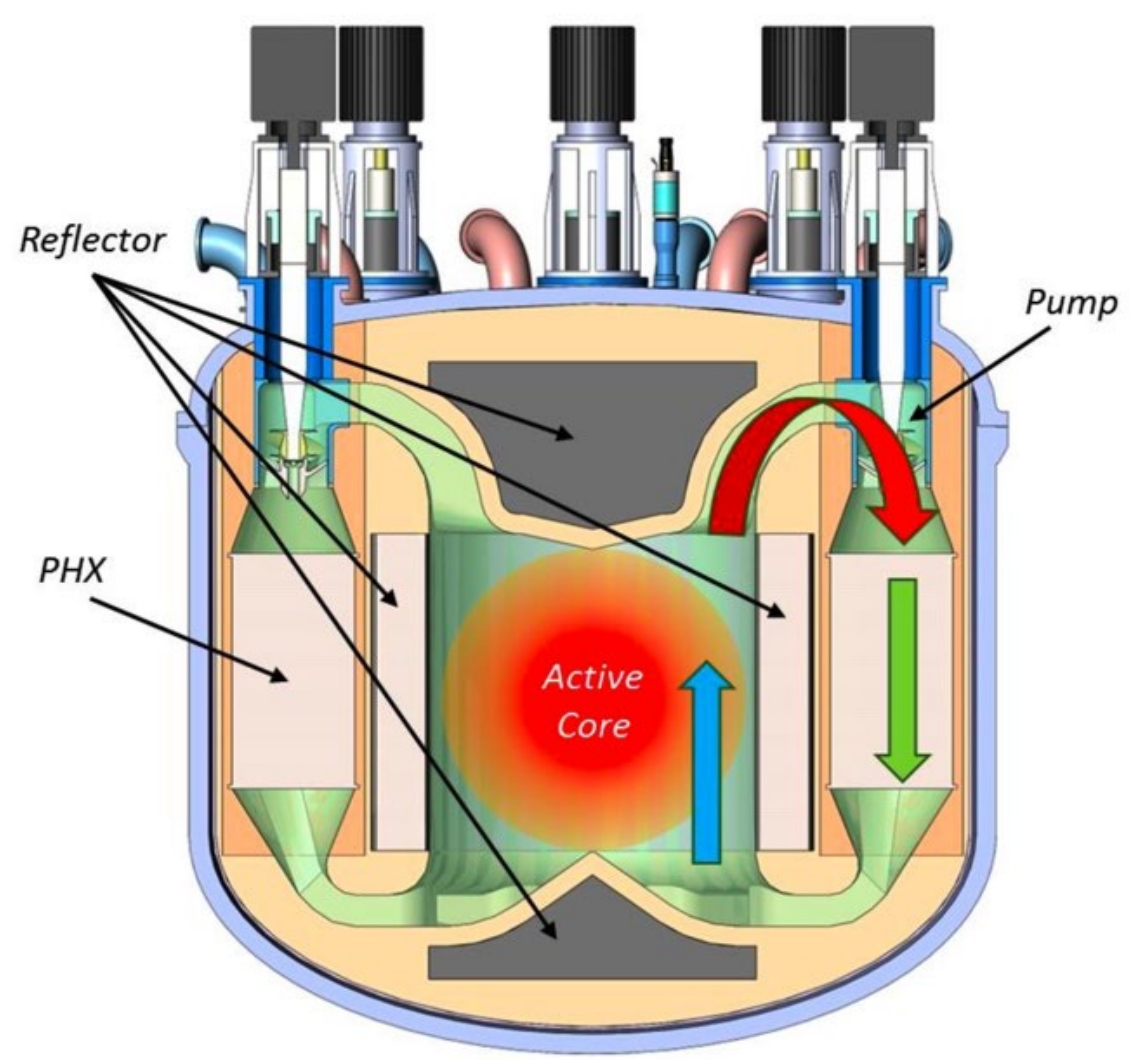

Figure 8. Molten chloride fast reactor.

\subsubsection{Integral MSR (IMSR) (Terrestrial Energy)}

David LeBlanc of Terrestrial Energy provided an overview of their Integral MSR (IMSR), a 200 MWe plant (Figure 9 [22]). The IMSR is a burner design with $2 \%$ LEU at start-up and $<5 \%$ LEU makeup. The IMSR has a sealed reactor vessel with a 7-year core replacement period. Three silos are used to store drained coolant. In-situ decay heat removal is used rather than freeze valves and dump tanks. The liquidfueled MSR provides stability because of its negative temperature reactivity coefficient, very low reactivity control requirements, and the ability to control the reactor by heat removal. Challenges are material related: radiation damage and graphite replacement. Many attributes of the IMSR result in a naturally low xenon worth, which enables load following and reduces concern about return to criticality after failure to scram, all without helium bubbling. To reduce the complexity and cooling needs of off-gas handling, the IMSR has a larger upper gas plenum coupled with the slow production of fission gases, resulting in a residency time of many months. Simple but proprietary methods to remove off-gas heat are in place and appear well worth the overall system simplification of this approach. 


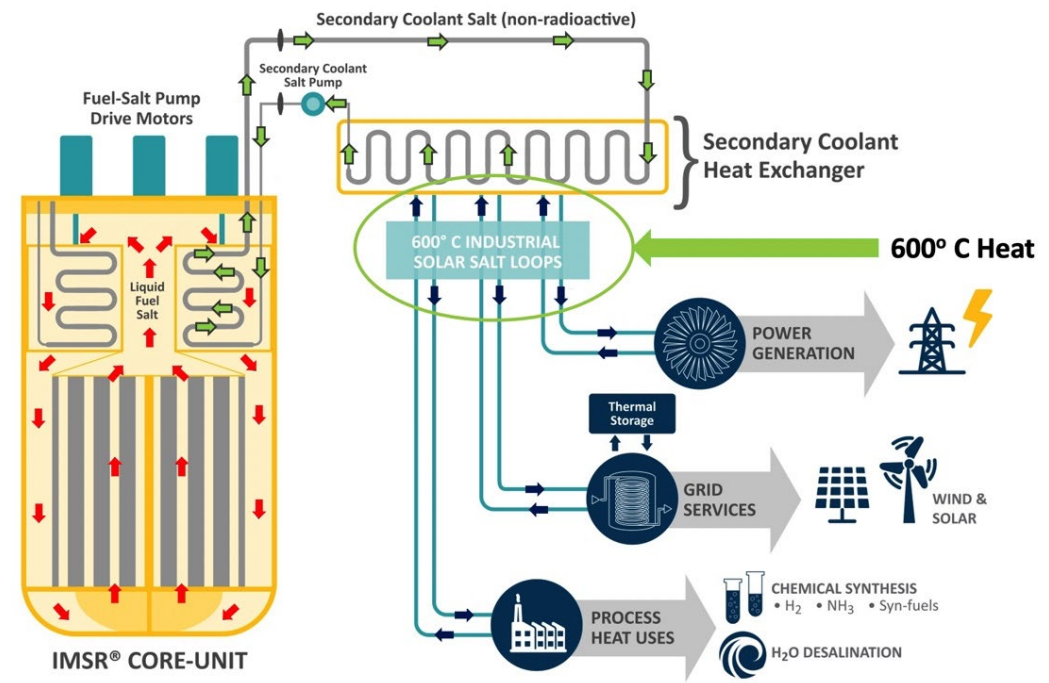

Figure 9. IMSR.

\subsubsection{Molten Chloride Salt Fast Reactor (MCSFR) (Elysium)}

Ed Pheil of Elysium provided an overview of the molten chloride salt fast reactor (MCSFR) (Figure 10 [23]). Electric power output for the fast-spectrum reactor can range from 50 Mwe (for a single small module) to $200 \mathrm{MWe}$ (for a single large module) up to 1,200 MWe for a modular set of 6 large salt-to-salt heat exchangers with each module having its own superheater. One module (200 MWe) up to six modules $(1,200 \mathrm{MWe})$ are contained within a secondary clean salt tank that provides passive cooling through a pool reactor auxiliary cooling system (PRACS) configuration. The modular components are limited to 4 $\mathrm{m}$ in one direction each to allow for overland shipping. The MCSFR uses chloride fuel salts and operates in the fast neutron spectrum. SNF with added plutonium for startup, and SNF is the preferred ongoing feed in fertile, but the flexibility exists to use other fissile and fertile fuels. The design does not include control rods. During normal operation, a portion of the molten salt fuel drains into the drain tank, which serves as a continuously open/tested drain capability. Fuel salt is pumped continuously from the drain tank back into the reactor vessel and salt-to-salt heat exchangers. Upon loss of power, the return flow stops, and all the fuel salt drains into the passively cooled, criticality safe drain tank. The reactor vessel is completely filled, and each salt-to-salt heat exchanger includes a gas-filled expansion volume above the salt impeller. Heat is rejected from the PRACS pool to air via heat pump heat exchangers. Fuel salt expansion from temperature increases results in decreased fuel in the critical region of the vessel, thereby reducing reactor power. Noble gas / noble material is removed online via systems in the drain tank with degassing going to a series of off-gas MOF systems. A $10 \mathrm{MWth}$ prototype reactor is planned of the same size as a $125 \mathrm{MWth}$ demonstration reactor to enable progressive power uprates as safety data are obtained. 


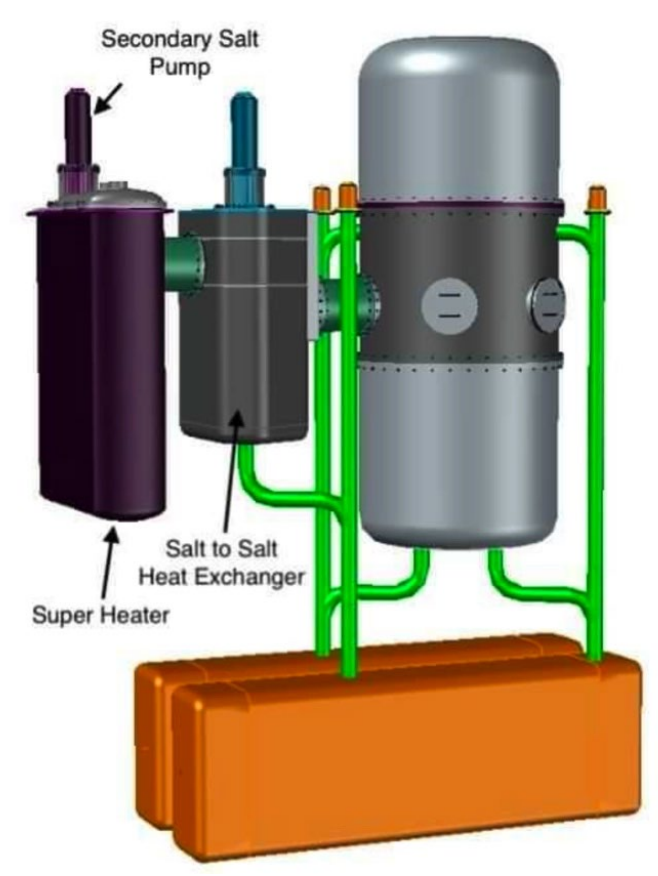

Figure 10. Molten chloride salt fast reactor.

\subsubsection{MSR Experiments and Databases}

The purpose of this PIRT is to ensure that the most likely issues important to the development of MSRs and to the achievement of the FSFs at liquid-fueled MSRs have been identified. The issues and required information can be used to identify needed remaining experiments, modeling, and analyses to support the safety case.

To support the PIRT, experts from industry and the national laboratories discussed current experiments and modeling, and NRC provided an overview of the PIRT process.

\subsubsection{Salt Spill Experiments at Argonne}

Sara Thomas of Argonne National Laboratory (Argonne) discussed DOE's salt spill experiments [24]. The development of an understanding of the phenomena of salt spill accidents is essential to the licensing of an MSR because of the potential for the environmental release of radioactive material from the salt and ultimately to the environment. Fundamentally, there is a need for the measurement of the thermochemical and thermophysical properties of salt in order to accurately model salt spill accidents. Furthermore, to develop and validate models that address the various phenomena associated with salt spill accidents, it is necessary to perform prototypic salt spill experiments. The initial experiments are performed at a benchtop scale and in an argon gas environment to remove the effects of oxidation and hydrolysis. Three aspects of a salt spill are being investigated:

1. Molten salt spreading and heat transfer: The MELTSPREAD code (ANL/NE-17/20) [25] that was developed to model molten core flow in a flooded core catcher for LWR accidents requires validation measurements to model bulk salt spreading and heat transfer. Small volumes of molten salt are poured onto a sloped stainless-steel sheet, and the temperatures of the sheet underside, salt surface, and atmosphere are measured. The extent of the molten salt's spreading is quantified by measuring the leading edge and covered area as a function of time. 
2. Salt-substrate interactions: This is investigated by conducting tests on substrate deformation, salt freezing as salt flows through stainless-steel tubing, and the corrosion of stainless steel in molten salt.

3. Aerosolized droplet formation and splashing: Small volumes of salt containing surrogate fission products (Cs and I) are poured into a stainless-steel box, and the generated splatter and mist that form over the cooling salt pool are collected to determine particle composition and size.

The knowledge on separate effects gained from these studies can be applied to subsequent integral tests at an engineering scale that quantify the above-mentioned phenomena simultaneously. Results from the tests will be publicly available.

\subsubsection{Molten Salt Chemistry and Off-Gas Monitoring}

Joanna McFarlane of ORNL discussed molten salt chemistry and off-gas monitoring [26]. The goal of DOE's national advanced reactor campaign on MSR technology is to develop an understanding and identification of the technology needed to design and license an MSR and to have a workable path for licensing commercial prototypes in the near term. This objective requires an understanding of the salts' properties, including chemical behavior, and transport properties. Thermophysical properties, neutronic properties, and thermochemical properties are required to design an MSR and to analyze accident behavior to support facility licensing. Thermochemical properties, which are the principal focus of the referenced study, include the chemical state, vapor pressures, and radionuclide mass transport, leading to the radioactive source term during operation and as a result of accidents. Off-gas can be a key source of a radioactive material release for MSRs because the system transports radioactive material released from the salt external to the reactor vessel $[27,28]$. Thermochemistry determines the partitioning of radioactive material between the salts and cover gas. Transport modeling predicts deposition on surfaces, retention in porous volumes, and flow through the off-gas systems. Most of the efforts so far are laboratory scale. The functional testing requirements of an MSR off-gas system include component testing, online sensing, systems modeling, and coupling with chemical measurements. Salt behavior is critical to reactor design and licensing. The program is building a community through benchmark testing at multiple institutions using FLiNaK and $\mathrm{NaCl}-\mathrm{KCl}$ eutectic to refine the testing procedures. Efforts include building benchmark testing capabilities at multiple institutions and coordinating with DOE programs, academia, and industry. The program is also developing on-line monitoring techniques [29]. For example, laser-induced breakdown spectroscopy (LIBS) provides quantitative elemental analysis of the off-gas. Molecular spectroscopies (Raman/Infrared) are also being investigated as online sensors. The experimental data are being integrated with dynamic simulations. The simulation platform is the Transient Simulation Framework of Reconfigurable Modules (TRANSFORM), as discussed in Subsection 2.3.2.7. TRANSFORM is used to model mass transfer at gas-liquid interfaces. The reactor, off-gas system, and mass transport models are integrated into a dynamic system performance code. The models provide an understanding of the time-dependent behavior of MSR off-gas system behavior.

\subsubsection{Current Status of Fuel Salt Qualification Guidance Development}

David Holcomb of ORNL summarized the status of a fuel salt qualification guidance development document $[30,31]$, which will be provided in a NUREG/CR. The initial draft was completed in July 2021, with an expected release date of September 2021 for stakeholder review. Fuel qualification is a process which provides high confidence that the physical and chemical behavior of fuel is sufficiently understood so that it can be adequately modeled for both normal and accident conditions, reflecting the role of the fuel design in the overall facility safety. Uncertainties are defined so that calculated fission product releases include the appropriate margins to ensure conservative calculation of radiological dose consequences [32]. The scope of the NRC guidance document for fuel salt qualification is broad because it is not possible to predict which of the diverse set of MSRs under development will proceed into 
licensing. Guidance for fuel salt qualification is needed because existing regulations are based on the characteristics and safety functions of LWR fuels, and liquid fuel has substantially different characteristics and safety functions. The fuel salt qualification process builds from fuel salt properties and the role of the fuel salt in supporting achievement of the FSFs. The methodology can be applied using best-estimate-plus-uncertainty or conservative-parameter assumptions. Fuel salt does not come in discrete elements (rods or assemblies), and it moves independently of its container during normal operations. Fuel salt includes all the material containing fissionable elements or radionuclides that remains in hydraulic communication, but it does not include the surrounding systems, structures, or components. Thus, salt vapors and aerosols remain part of the fuel salt system until they become adequately trapped. Container corrosion products become part of the fuel salt and remain part of the fuel salt system. The principle of functional containment is also important because fuel salt properties will have a substantial impact on containment performance. Fuel salt properties that stress barriers cause them to be more likely to release radionuclides. The fuel salt properties must be known to adequately model accident progression and interaction characteristics with materials in containment. A liquid salt property database is under development and relates salt composition to physical and chemical properties as a function of temperature. At present, the Molten Salt Thermal Properties Database (MSTDB) is sparsely populated, but additional data will be added over time [33] (see Subsection 2.3.2.8).

\subsubsection{MELCOR for non-LWR Analysis}

Dave Luxat of Sandia National Laboratories (SNL) provided an overview of MELCOR, MELCOR MSR systems modeling, and MELCOR MSR fission product transport modeling [34]. MELCOR is a fully integrated, engineering-level computer code developed, maintained, tested, and managed by SNL for the US NRC to model the progression of accidents in NPPs. A broad spectrum of accident phenomena in a broad range of nuclear energy systems is treated in MELCOR in a unified framework. MELCOR applications include estimation of accident source terms, as well as their sensitivities and uncertainties in a variety of applications. MELCOR was originally developed with a focus on LWRs, and it has evolved over the last several years to be able to examine a broader range of reactor types, including fast reactors and MSRs, with respect to modeling accident progression and fission product transport. The SCALE system developed by ORNL [35] provides input to MELCOR for neutronics modeling - criticality, depletion analysis, and burnup credit. MELCOR then performs integrated accident and source term modeling - hydrodynamics of a range of working fluids, accident response of plant structures, systems and components, and generalized fission product transport modeling inside facilities. Output from MELCOR is provided to the MELCOR Accident Consequence Code System (MACCS) to estimate consequences from a release of radioactive material to the environment. This includes near- and far-field atmospheric transport and deposition, as well as the assessment of the health and economic impacts of radiological accidents. User manuals and validation reports are provided in the literature [36, 37, and 38]. The MELCOR Assessment Problems in Vol. III provides an expansive validation basis for the application of MELCOR to assess both LWR and non-LWR systems. An upcoming update of Vol. III will expand the range of validation studies to include additional non-LWR-specific assessments. For non-LWR systems, recent development of MELCOR has introduced modeling capabilities to represent liquid-phase fission product transport and release. In the case of an MSR, this modeling enables the time-resolved characterization of the mass of radionuclides released into the molten salt, the evaluation of the thermochemical equilibrium of fission products in the salt, associated solubility and vapor pressure of fission products in the molten salt, and finally, the release of fission products to overlying gas spaces. MELCOR computes what remains in the salt as soluble or colloidal forms, as well as the release of vapors and aerosols from the salt. MELCOR also calculates the deposition within compartments of the reactor building and release to the environment. An interface between MELCOR and the MSR salt database allows the database to drive a Gibbs Energy analysis used to establish the thermochemical equilibrium state of fission products in the molten salt. The analytical capabilities integrated into MELCOR have supported a number of recent non-LWR demonstration calculations. These analytical capabilities are 
generalized; they can flexibly adapt through user input to evolution of the state-of-knowledge in accident progression and fission product release/transport in non-LWR systems.

\subsubsection{Quality Aspects of Molten Salt Property Measurements}

Melissa Rose of Argonne discussed quality assurance (QA) requirements for allowed variances in salt properties required to maintain the FSFs [39]. Argonne is identifying the acceptable uncertainty bands in fuel salt thermophysical and thermochemical parameters and is examining how well current measurements satisfy those criteria. Efforts must include understanding what can affect the quality of the data and how to ensure quality. For example, density measurements prior to 1980 did not include a surface tension term, but it has been shown that this is an important term and must be measured and considered. Interlaboratory salt studies will provide a comparison of different measurement techniques on the same salt batches. Although Argonne is developing a consensus standard for practices and uses for salt properties, vendors/developers must make their own safety cases. To do this, developers can use national laboratories for data/testing, or they can do their own testing.

\subsubsection{SAM Overview for MSR Analyses}

Rui Hu of Argonne provided an overview of the Systems Analysis Module (SAM) that is under development as a modern system-level modeling and simulation tool for advanced non-LWR safety analyses [40]. SAM uses the object-oriented application framework of MOOSE to leverage the modern software environment and advanced numerical methods. The capabilities of SAM are being extended to enable the transient modeling, analysis, and design of various advanced nuclear reactor systems [41]. SAM supports safety analyses for licensing. The finite element method (FEM) model of single-phase fluid flow and heat transfer has been developed and verified. Flexible coupling capability between fluid and solid components is also provided. The point-kinetics module has been implemented in SAM and verified against numerical solutions and can be used to calculate the fission power during a transient. SAM provides flexible coupling with external codes and has reactor-specific modeling features. At present, the output from SAM cannot be automatically read into MELCOR, but it can be easily formatted and read into MELCOR. Because tritium disassociation in metals is important when considering potential environmental release, Argonne is working on the transport of tritium and the interface between structures and fluids. The SAM modeling capabilities for MSR analyses have also been demonstrated and validated with MSRE test data [42].

\subsubsection{TRANSFORM: Description and Applications}

Scott Greenwood of ORNL discussed the capabilities of TRANSFORM as a dynamic system modeling tool and the development of a TRANSFORM model of an MSR [43]. TRANSFORM is an ORNLdeveloped component library created using the Modelica programming language for the investigation of dynamic thermal-hydraulic systems and other multiphysics systems [44]. The TRANSFORM library allows for rapid development of energy systems with a focus on enabling the modeler to customize the components for any application, including instrumentation and control design. TRANSFORM is a scoping tool: it is not a licensing tool. TRANSFORM models thermal-hydraulic fluid and heat and mass transfer with lumped and 1D models and can model simple power systems. Nuclear results use point kinetics (fixed fuel and non-fixed fuel). Isotopes are tracked on an atomic basis, including fission product decay and tritium diffusion though solids. TRANSFORM uses the nuclear data from SCALE to perform calculations equivalent to those of ORIGEN for the generation and decay of radionuclides.

TRANSFORM provides users with the ability to construct and incorporate mechanical systems into the models. TRANSFORM models can be exported to advanced tools such as the Risk Analysis and Virtual Environment (RAVEN) and Dakota through executables or python functional mockup (FMU) interfacing. TRANSFORM is being actively used to explore a wide range of multi-physics systems such as MSRs 
[45]. Note that TRANSFORM is not a high-performance code; nor is it a highly structured legacy Nuclear Quality Assurance (NQA) code for licensing. The results from TRANSFORM could be validated with experiments. The flexibility of TRANSFORM limits its verifiability. Unlike MELCOR and SAM, TRANSFORM does not mechanistically model the phenomena associated with accident progression and radionuclide transport, but it is more suited to assessing overall system behavior.

\subsubsection{Molten salt thermal properties database}

Jake McMurray of ORNL (now at Kairos Power) discussed the molten salt thermal properties database (MSTDB) [46]. There is broad interest in the database, and its benefit to the MSR community has been recognized. Although it was originally developed to provide a reference set of thermal properties, the database has been extended via thermochemical modeling to enable the prediction of phase diagrams and equilibrium vapor pressures of radionuclide species, which is an essential element of source term analysis $[47,48,49]$. The thermochemical and thermophysical properties of the salts are captured in a fundamental/multicomponent database. The MSTDB is intended to include both fueled and un-fueled molten salt systems, consequential fission product and transuranic elements, contaminants such as air and moisture, and likely corrosion product elements such as nickel and chromium. Phases include the ideal gas, liquids (e.g., molten salts, noble metals), and solid compounds. Mixtures include the liquid fluorideand chloride-based molten salts, as well as several solid solutions. The models and values within the MSTDB are obtained through a combination of literature-reported information, first principles calculations, and experimental measurements for performing pseudo-binary, pseudo-ternary, and higher order system assessments. A system is sufficiently assessed ${ }^{1}$ when models and values allow for accurate computing of the phase equilibria (e.g., phase diagrams) and attendant values such as heat capacity and vapor pressures. The MSTDB consists of Gibbs energy models for fluoride- and chloride-based systems of interest for MSR technology and related heat transfer applications. Complete descriptions of the contents of the databases can be found in the report by Ard et al. [50]. The initial release of the MSTDB contains nearly half of publicly available assessed fluoride- and chloride-based salt systems, as well as systems newly assessed in the current work. Future updates to the MSTDB will be released as more data are acquired.

\subsubsection{NRC Perspective on the Use of PIRTs}

The NRC's Wendy Reed provided a summary of their perspective on the use of PIRTs [51]. There are two roles: (1) industry's role is to make its safety case, and (2) the NRC's role is to ensure regulatory compliance. The NRC staff, licensees, and applicants have used expert judgment to support many important regulatory activities. Expert judgments can be a direct input to decision-making, or they can serve as indirect input for cases in which the elicited judgment feeds into an analysis that is used for decision-making. Application of the PIRT process is an example of the direct use of expert judgment to support decision-making [52]. The NRC has used PIRTs in activities involving systematic identification of technical issues and qualitative determination of their significance. PIRT can be implemented to ensure safety by identifying the areas where more experiments, modeling, and analysis are needed. PIRTs can be used to help identify areas where the NRC reviewer must focus to make sure that all applicable accident sequences are identified and reviewed. PIRTs are also used to identify areas requiring more regulatory tools. The value of PIRTs is shown in the accident-tolerant fuel (ATF) project plan [53]. In addition to the ATF plan, other source documents of interest include (1) a literature review of severe accidents for MSRs [54]; (2) an evaluation of a new design, confirmatory safety analyses to understand the validity and

\footnotetext{
${ }^{1}$ A system is said to be assessed when sufficient experimental and theoretical data are available to optimize adjustable thermochemical values and parameters for each phase in the system.
} 
accuracy of computational methods being used by licensees, the sensitivity of results to uncertainties, and the safety margin under varying conditions from normal operation to design-basis and beyond-designbasis accidents [55]; and (3) NRC lessons learned from recent PIRTs [56].

A question was posed on the use of NRCs MELCOR code.

Chris Van Wert stated that MELCOR is used by the NRC staff as a confirmatory tool, and to date, it has not been submitted for review and approval. Therefore, an applicant who wishes to use it as a licensing tool would need to address verification and validation (V\&V), QA, biases, uncertainties, and other concerns as part of the licensing efforts.

\subsubsection{Overview of MSR Capabilities in SCALE}

Will Wieselquist of ORNL provided an overview of SCALE and its added capabilities for evaluating MSR simulations [57]. The SCALE Code System is a widely used modeling and simulation suite for nuclear safety analysis and design that is developed, maintained, tested, and managed by ORNL. SCALE provides a comprehensive, verified and validated tool set for criticality safety, reactor and lattice physics, radiation shielding, spent fuel and radioactive source term characterization, and sensitivity and uncertainty analysis [58]. SCALE includes current nuclear data libraries and problem-dependent processing tools for continuous-energy and multigroup neutronics and coupled neutron-gamma calculations, as well as activation, depletion, and decay calculations. New capabilities and significant improvements of existing features in SCALE include the addition of two approaches for MSR simulations. TRITON-MSR is new in SCALE 6.3, which is undergoing beta testing. This addition provides the ability to account for flowing fuel materials in a liquid-fueled system [59]. The second approach uses ORIGEN (available in SCALE 6.2) to investigate inventory throughout the system following "slugs" of fuel. This leverages standard SCALE/ORIGEN simulations and helps users understand inventory and gamma emissions at various points in the salt loop. Because investigation of inventory solely using slug flow would require too many ORIGEN calculations, a hybrid approach is used that generates a reasonable operational scenario using TRITON-MSR, saves the ORIGEN one-group library (i.e., reaction rate coefficients), and then uses ORIGEN slug flow to determine the distribution of isotopes in the loop and the sources at accident conditions.

\subsubsection{GOTHIC Thermal Hydraulic Analysis Package}

GOTHIC [60] is a multiphysics software package for the engineering design and analysis of LWR and non-LWR technologies. GOTHIC integrates coarse-grid multi-phase computational fluid dynamics (CFD) and traditional system level thermal hydraulics modeling capabilities. GOTHIC uses a multi-volume domain decomposition approach that makes it easy to model system and loop behavior with a small number of computational nodes. The ability to vary the nodalization throughout the model from $0 \mathrm{D}$ (lumped parameter) to full 3D enables multi-scale simulation and focuses the computational resources in regions of interest while still capturing system response and feedback effects. Most applications can be run on a standard desktop or laptop computer. GOTHIC's integrated analysis environment, which consists of (1) a graphical user interface, (2) a transient compressible multi-phase, multi-component numerical solver, and (3) post-processing capabilities, allows for fast model creation and visualization of results. GOTHIC has been developed and maintained within an NQA program compliant with 10CFR50, Appendix B [61], and applicable parts of ASME NQA-1 [62], particularly Subpart 2.7.

GOTHIC uses a porous media approach, with volume and area porosities used to model complex and arbitrary geometries. In the multi-dimensional volumes, it includes a full treatment of the momentum transport terms, with optional models for turbulent shear and turbulent mass and energy diffusion, where a two-equation turbulence model is used to calculate the turbulent diffusion coefficients. GOTHIC also considers molecular diffusion and second-order accurate advection schemes to minimize numerical diffusion. These elements allow GOTHIC to accurately simulate mixing, stratification, and buoyancy- 
driven natural circulation of liquid or vapor in large open regions (e.g., open cores, pools, containments, rooms). GOTHIC includes the same types of features and capabilities provided by traditional system level codes, such as point reactor kinetics, control systems, trips and models for plant equipment such as pumps/fans, valves/doors, heat exchangers, fan coolers, vacuum breakers, pressure relief valves, spray nozzles, and heaters/coolers.

GOTHIC solves the fluid conservation equations for mass, momentum, and energy for liquid, steam, any number of non-condensing gases, and any number of interacting aerosol fields. Optional secondary fields are also available to represent ice, mist/fog, and any number of solid particle components, dissolved gases, and tracers (including radioactive decay and progeny) that can be tracked in the liquid vapor and aerosol fields.

GOTHIC includes a generic fluid property framework. Thermophysical properties, including options for modelling the changing salt composition over time resulting from fission and transmutation products either using multiple fluid property tables or liquid components, depending on the available fluid property data. GOTHIC includes fluid property tables for several commonly used molten salts, including: NaCl$\mathrm{MgCl}_{2}, \mathrm{LiF}-\mathrm{BeF}_{2}, \mathrm{LiF}-\mathrm{NaF}-\mathrm{KF}, \mathrm{NaF}-\mathrm{ZrF}, \mathrm{KF}_{-} \mathrm{ZrF}_{4}$, and $\mathrm{NaBF}_{4}-\mathrm{NaF}$. GOTHIC includes a generalized tracer or species tracking capability that has been used for delayed neutron precursor concentration, fission product transport, and concentration or $\mathrm{pH}$ of non-reacting chemical species. GOTHIC has been benchmarked to steady-state and transient conditions from the MSRE [63]. This provides evidence of GOTHIC's applicability for modelling the circulating fuel in MSRs. Further enhancements will be included in the next software release, which is planned for March 2022.

*Acknowledgment: GOTHIC incorporates technology developed under the sponsorship of the Electric Power Research Institute. 


\section{IDENTIFICATION OF INITATING EVENTS}

The expert panel was responsible for assessing the most appropriate means for representing accident risk for liquid-fueled MSRs. Probabilistic risk assessments (PRAs) for LWRs assess the risk of severe core damage based on accident sequences derived from component failures using event tree/fault tree methodology in response to initiating events (e.g., internal events, external flooding, seismic). For MSR designs, achievement of the FSFs in response to initiating events depends to a much greater extent on passive safety features and functional containment than component or engineered safety feature performance. Liquid-fueled systems also lack a clear equivalent to core damage frequency, which is typically considered a representation of accident severity in solid-fueled reactors. Also, MSR accidents are likely to lead to lower levels of pressurization than that caused by depressurization of an LWR or high-temperature gas-cooled reactor (HTGR). Mitigating the risk associated with the environmental release of radioactive material from MSR accident scenarios could rely more on a combination of leaktight and no-leak-tight barriers rather than a high strength containment.

\subsection{LICENSING BASIS EVENTS (LBEs)}

In 2019, ORNL held a workshop for MSR design and research organizations to identify the potential licensing basis events: anticipated operational occurrences (AOOs), design basis events (DBEs), and beyond design basis events (BDBEs) [64]. In many cases, the issues identified in the workshop can be resolved by the design teams using state-of-the-art, adequately validated calculational tools. Because the objective of the PIRT is to identify critical areas requiring research to address MSR issues, many of the events identified were screened from further consideration. Nevertheless, the first level of screening, which considered several plant systems - reactor primary system, secondary heat removal system, drain tank and decay heat removal system, confinement system, salt management system, off-gas system, reactor control and protection system, and radioactive waste management system - resulted in too many scenarios to address, practically recognizing the time commitment required by the PIRT assessment team. For this reason, initiating events were further aggregated into generic scenario categories to address they key accident phenomena that impact importance measures.

\subsection{AGGREGATION OF INITIATING EVENTS INTO GENERIC SCENARIO CATEGORIES}

In this stage of the PIRT process, more technical issues are typically identified than can be handled given the limited resources and expert availability. Recognizing this, the project team prioritized the phenomena to be considered for elicitation.

In contrast with LWRs, MSR accidents do not involve a threshold for a major release of radioactive material from fuel associated with severe core damage. The fuel is already molten. If the primary system is breached, then the consequences depend on the location of the breach, the size of the breach, mitigation measures, and how much of the fuel salt or fission gases leak into a confined space. Even a small breach could result in a large release of fuel salt, and the high temperature of the salt could result in an increase in the pressure within the confined space. Therefore, the approach to post-accident confinement of radioactive material for an MSR is expected to be different than that for LWRs. Significant quantities of fission products could also be stored in different locations in the plant, each of which could each have associated accidental releases. In addition, the typical accident scenarios that could be associated with operation of the plant, such as a flow coastdown accident, loss of offsite power, reactivity insertion accident, external events (including earthquakes and tornado-driven missiles) must be analyzed to determine whether an environmental release of radioactive material would occur and to discern the magnitude of the release.

Another complicating element of the PIRT is the diversity of design features associated with the MSR technologies under development (as discussed in Section 2.2.3). To make the elicitation process 
manageable, six generic accident scenarios were identified that would likely need to be addressed in a safety analysis report. The initiating events from the workshop that were retained following screening were associated with a generic scenario category with a designator IEx. For example, IE1 is "System Breach with a Salt Spill," and it is associated with Generic Scenario I. IE3 is "High Primary Flow" and is associated with Generic Scenario II. It should be noted, however, that the presented design in the 2019 workshop was not firmly followed or assumed as the "reference design" for this PIRT. However, the list of elicited phenomena was generated assuming applicability to this and any MSR concepts that were presented during Phase 2 of the PIRT. It is possible that a particular accident sequence could involve more than one generic scenario. For example, if a reactor transient analyzed in Scenario Category II results in primary system failure, then there is potential for a release of radioactive material to a region external to the primary system, as analyzed in Scenario Category I. Because FOM1 is the most important of the three FOMs, the phenomena associated with the release and transport of fission products, Scenario I phenomena, are likely to have high importance, regardless of the specific plant design. If an event does not result in a potential environmental release of radioactive material, even for cases in which FOM 2 or FOM3 is high, then the associated phenomena would not be of high enough significance to the safety case for the plant. Six generic scenarios were identified, and taken together, these provide the framework for the PIRT.

\subsubsection{Scenario Category I: Salt Spill Accident}

\subsubsection{General description}

There are two types of scenarios associated with this category. In one type, there is a breach in the primary system boundary in a vapor region, such that the liquid fuel salt is not spilled from the primary system, but instead, radioactive material evolves from the salt and flows in a gas/vapor phase out of the primary system into an external region or cell. A cell can have substantial design-dependent differences. For example, a cell could be a guard vessel or a room. The other type of scenario is one in which fuel salt actually spills from the primary system (or off-gas system as an extension of the primary system boundary) into a cell. In this scenario, there could also be a phase of the accident in which the liquid salt level is below the breach, and radioactive material continues to evolve and be released, as in the first scenario.

As liquid salt leaves the primary system, there is a potential for a spray to form at the exit point from the primary system or for splash droplets to form as the salt contacts the floor of the cell (see Section 2.2.4.1). Depending on the surface contacted, there could be an interaction such as the spallation of concrete and the incorporation of concrete decomposition products into the molten salt pool; or for a steel-lined surface, distortion of the steel or chemical interaction with the steel. The horizontal spread of the salt pool will depend on the cell geometry and the physical properties of the salt, such as viscosity, thermal conductivity, and freezing point. Radioactive material within the salt pool could vaporize from the pool surface into the cell atmosphere, depending on the chemical forms of the radioactive materials, pool temperature, and the thermal-hydraulic behavior of the cell atmosphere. Within DOE's research program, equilibrium vapor pressures for important radionuclide species in fuel salts are being experimentally measured as a function of temperature and are being made available in the MSTDB [65] for combinations of fuel salts and radionuclide chemical species. However, in mid-2021, there are no integral data that account for non-equilibrium processes affecting the transport of radionuclide species into the atmosphere of a cell and the return flux of radioactive material to the pool. Experiments performed by Langmuir and others for evaporating gases indicate that empirical correction factors are needed to predict release fractions and return fractions [66]. As non-condensable gases (either fission products or sparging gases) form bubbles in the molten salt and these bubbles break the surface of the pool, they will release salt droplets into the cell atmosphere, in addition to radioactive gases in the bubbles. In experiments performed in the MSRE program [67], an additional source of salt aerosols was identified which has not 
been fully interpreted but has been attributed to beta recoil. Thus, the prediction of the net flux of radioactive material into the cell atmosphere is complex.

Within the cooler cell atmosphere, radioactive vapors released from the pool could condense to form or grow aerosols, depending on their temperatures and chemical forms. Thus, aerosol transport and growth mechanisms can impact the transport and removal mechanisms for radioactive material in the cell atmosphere. Any subsequent leakage of radioactive material from the cell to another level of confinement would depend on the form of the radioactive material and the driving forces for transporting the material.

Internal to the pool, radioactive material will relocate as a result of convection and diffusion, effectively bringing radioactive material to the surface, from which it will evaporate. Any contaminants that form a layer (dross layer) on the surface of the molten pool will affect the transport of radioactive material and heat transfer from the pool to the atmosphere of the cell.

Within the cell atmosphere, a sharp temperature gradient will initially exist between the molten salt pool and the cell structures. A classic unstable condition, Rayleigh-Bénard instability, associated with a fluid (the atmosphere of the cell) heated from below, is expected to develop, leading to strong mixing within the cell atmosphere and enhanced heat flux from the pool surface. Typically, under Rayleigh-Bénard conditions, nearly all of the temperature gradient occurs in a small boundary layer above the pool and in a second boundary layer at the structure such as the ceiling of the cell $[68,69]$. Heat transfer by thermal radiation will also occur between the pool and the structures below the surface of the pool, in addition to the walls and ceiling of the cell [70]. A mist of condensed salt vapor could affect radiation transport within the cell atmosphere. Freezing of the salt at the upper surface of the pool would effectively prevent further release of radioactive material to the cell atmosphere.

In the safety analysis report for the MSRE [71], it was assumed that in addition to a salt spill, a substantial source of water would also flood the cell in which the salt is released. The likelihood of such a combination of events is clearly design specific. An event in which molten salt falls into a pool of water could have the potential for an energetic steam explosion like those experienced in foundry accidents. The conditions leading to energetic steam explosions have received intense study in the nuclear industry related to core meltdown accidents. The likelihood of steam explosions occurring as a result of MSR accidents would require very specific configurations that appear unlikely. The more likely design-specific conditions leading to molten salt/water flooding would result in steam generation, cell pressurization, salt hydrolysis, and production of reactive gases.

\subsubsection{Principal properties, phenomena and modeling activities}

The principal properties affecting Scenario I phenomena are heat capacity, density, viscosity, thermal conductivity, surface tension, coefficient of thermal expansion, spectral dependence of optical absorption, volatility of key radionuclide species, and fuel salt phase diagram. In the case of water incursion into the cell, the principal properties of concern are the rates of hydrolysis of salts and the production of reactive gases. However, given a specific configuration, the production rate of steam and the pressurization of a cell are predictable.

Elicitations were performed for 20 phenomena affecting the assessment of salt spill accidents as identified in Section 4.1.

Modifications are being made to the MELCOR code [72] as a predictive tool for these types of MSR accident scenarios. 


\subsubsection{Scenario Category II: Dynamic System Thermal/Hydraulic/Power Response}

\subsubsection{General description}

The analysis of dynamic system thermal/hydraulic/power response transient accident sequences has historically been a focus of regulatory oversight of LWRs, as well as the analysis of loss-of-coolant accidents. The transient accident scenarios involve component failures or operator errors that initiate a transient response of the system, such as primary pump overspeed, primary pump failure, control rod withdrawal accidents, and reduction in secondary cooling. The initial condition for the transient response is typically full-power operation, but it could also be associated with power startup or shutdown. The transient analysis code must be capable of predicting the subsequent power level, fluid flow rates, fluid temperatures, radionuclide quantities and distributions, and system conditions that could result in a release of radioactive material to the environment. Based on history, each reactor vendor will have its own proprietary transient analysis computer code which has been validated against a range of experiments, verified, and described in a topical report that has been reviewed and approved by the NRC. A "frozen" approved version of the code is used in the performance of safety analyses.

Although the typical automated safety response of a nuclear plant to a thermal-hydraulic transient that challenges safety limits is to perform a controlled shutdown of the reactor or to trip the reactor (insert control rods), temperature coefficients of reactivity will impact the neutronic power level. Because delayed neutron precursors flow with the molten salt around a salt loop in loop-type designs, reactor kinetics for these systems are more complex. Activities undertaken in the SCALE development program were described in a presentation to the PIRT team [57]. This program is developing the capability to perform reactor kinetics analysis of MSR systems, including the potential for an energetic reactivity excursion.

Although several transient events could be addressed in the PIRT assessment, elicitations were only performed for scenarios with the potential for challenging primary system integrity and releasing radioactive material. The phenomena associated with two events were elicited, as described in Section 4.2 .

\subsubsection{Principal properties, phenomena and modeling activities}

The principal properties affecting Scenario Category II phenomena are largely the same as those described for Scenario I phenomena. DOE laboratories are currently developing three computer codes that could provide the basis for NRC codes or vendor codes (or a suite of vendor codes): MELCOR, an extension of the code initially developed for LWR severe accident analysis [72], SAM, developed within the DOE the Nuclear Energy Advanced Modeling and Simulation (NEAMS) program using the MOOSE partial differential equation solver [73], and TRANSFORM, which uses the object-oriented Modelica program language, incorporating plug-and-play component models [45]. The experimental programs undertaken by DOE for validation of these computer codes should have direct applicability to the validation of a vendor code. Some integrated analyses of salt spill accidents have been documented in the literature, such as an article by Kalilainen et al. [75]. This work is based on the use of a thermochemical database developed at the Paul Scherrer Institute (PSI) in conjunction with their Gibbs Energy Minimization Software (GEMS). MELCOR has recently introduced a Gibbs Energy Minimization capability for molten salt thermochemistry using the software package Thermochimica. MELCOR can flexibly use a range of databases, such as the Joint Research Centre's (JRCs) database of molten salt reactor fuel systems [74] as well as the Molten Salt Thermal Database (MSTDB) being developed by the DOE $[46,49,50]$. Data from the DOE programs will be valuable to confirm and validate models, responses, and assumptions used in the codes. Given the flexible capabilities in MELCOR, it will be able to better assess the impact of evolving databases on our understanding of molten salt thermochemistry of relevance to fission product release. 
Accidental criticality in an area external to the core region resulting from a transient event could also result in radionuclide release. This scenario is considered under Category IV.

\subsubsection{Scenario Category III: Water-Molten Salt Interactions}

\subsubsection{General Description}

The effect of water flooding a compartment containing components of the primary system envelope would not lead to a release of radioactive material unless the water contacted and interacted with the molten fuel salt.

Although some MSR designs would produce electricity using a Rankine cycle involving steam production, current designs have the primary fuel salt separated from the steam cycle by an intermediate loop containing a non-fuel salt.

One event, although it is beyond unlikely, would be a salt spill accident followed by flooding of the compartment containing the spilled fuel salt. This would likely be externally produced since there are no potential internal flood sources. This would imply that a breach of the compartment has occurred which led to water ingress. However, any breach of the compartment containing spilled primary fuel salt would likely lead to a release of radioactive material, with or without the presence of water. Water-molten salt interaction may further enhance the event consequences.

\subsubsection{Scenario Category IV: Accidental Criticality External to the Core Region or in Other Plant Systems}

Any plant system which would be expected to contain fuel salt at some point in the fuel cycle, such as fresh fuel storage and handling, would be designed to be criticality safe based on geometry, moderation, reflection, and potentially neutron poisons. These more obvious cases were not considered in the elicitation process. Nevertheless, it is possible that physical processes could occur that were not recognized by the design organization.

Two phenomena were considered in the elicitation process that could result in criticality external to the core region within the reactor primary system: (1) a cooler region in the vicinity of the primary heat exchanger, or (2) precipitation leading to high concentration of fissile isotopes in an external vessel such as a fuel drain tank. The elicitations are discussed in Section 4.4.

\subsubsection{Scenario Category V: Emergency Response System Failures}

In the licensing event workshop held at ORNL, some potential failures of emergency response systems were identified, such as failure of the melt plug to function, or for the drain rate to the drain tank to be too slow to address a safety-related event. These types of events were considered to be too design-specific to be productively addressed in the PIRT.

\subsubsection{Scenario Category VI: Radwaste Management System}

It was concluded that a safety review of the plant's radwaste management system is of high importance, but such a review would require a detailed system design [75]. Nevertheless, a generic elicitation was performed, as discussed in Section 4.6. 


\section{PHENOMENA RANKING AND IDENTIFICATION}

From Figure 1, the PIRT process is composed of four phases. Phase 1, "Preparation," began in late 2020 and concluded with the first PIRT meeting in early 2021. Appendix C details the PIRT panel composition. In Phase 2, Pre-elicitation, the MSR design teams provided presentations describing their plant designs. Presentations were also made by researchers (primarily associated with DOE laboratories) on their research programs and findings, as well as details identifying phenomenological or data limitations. These technology summaries are found in Sections 2.3.1 and 2.3.2. After each presentation, a general discussion of related design features and technical issues was held among the PIRT panel members.

At the conclusion of Phase 2, the PIRT technical integration team constructed a set of scenario categories (see Sections 2.4.1. through 2.4.6) for the purposes of identifying relevant phenomena to discuss and rank in terms of importance and knowledge level during the elicitation phase, Phase 3 . The intent was not to generate a list that exhaustively spans the set of plausible accident scenarios, but to identify a list of highlevel, common, liquid-fueled MSR accidents that sufficiently spans the range of possible phenomena for the purposes of assessing the achievement of FSFs. A schematic of example radionuclide transport and release paths for liquid-fueled MSRs [76] was presented to the PIRT panel to use in identifying phenomena, as shown below in Figure 11.

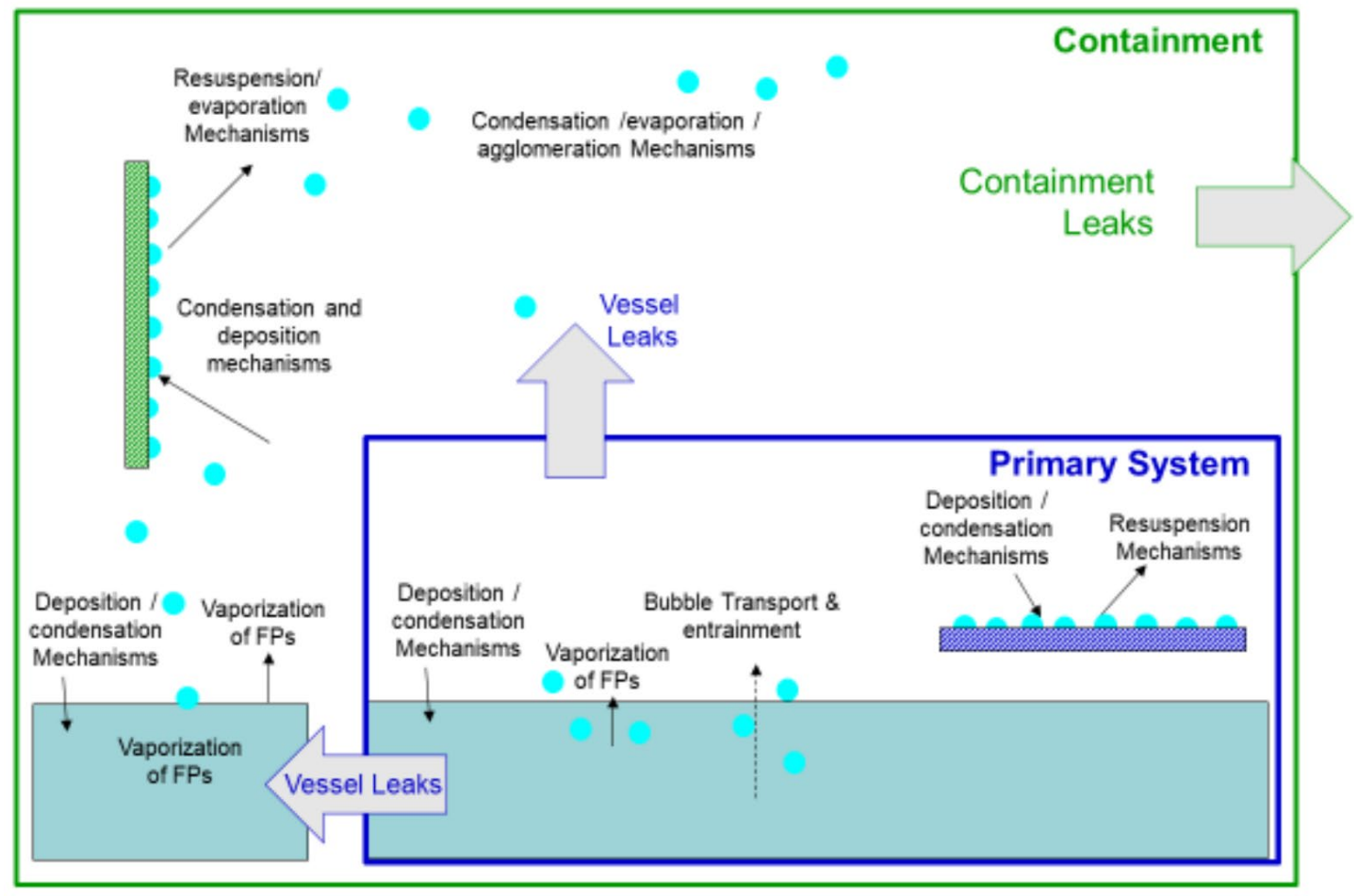

Figure 11. Schematic diagram of example radionuclide transport and release paths for liquid-fueled MSRs.

The elicitation phase was then divided into two sub-phases:

Sub-phase 1. Identify MSR phenomena which may impact FSFs.

Sub-phase 2. Rank the phenomena in terms of importance and knowledge level. 
The basic process of each sub-phase is illustrated in Figure 12.

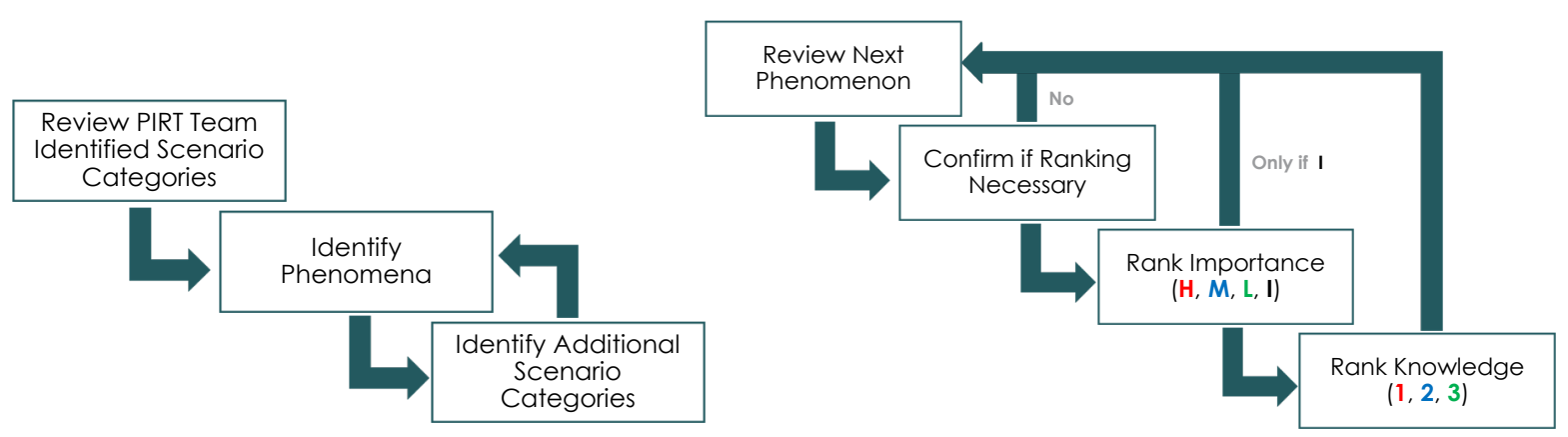

(Sub-phase 1) Identify MSR phenomena

(Sub-phase 2) Rank phenomena

Figure 12. PIRT elicitation phase process.

During the identification sub-phase, the PIRT panel first reviewed the scenario categories and provided feedback. Although no additional scenario categories were added, some were renamed slightly according to the panel's feedback. One scenario category was eliminated in favor of listing it as a single phenomenon. These cases are discussed in more detail in the next sections.

Phenomena were identified within each scenario category and were labeled according to their order of identification and to their associated scenario category. However, it should not be inferred that an identified phenomenon may only belong to or pertain to the scenario category for which it was first identified. For example, although I18, "Radionuclide transport and interactions within the cell atmosphere," is identified with Scenario Category I, "Salt spill accident," this phenomenon will also be present for breaks/leaks/ruptures of the radwaste and/or other non-fuel salt radionuclide sources in the plant. Worksheets developed during the elicitation Sub-phase 1 are provided in APPENDIX A.

Between the elicitation Sub-phase 1, "Identify MSR phenomena," and Sub-phase 2, "Rank phenomena," the list and descriptions of the phenomena were updated to be consistent and to ensure that duplicates were eliminated. During the phenomena ranking stage, importance and knowledge were also ranked for each FOM.

Elicitation worksheets developed during the ranking sub-phase are provided in APPENDIX B. The following sections contain some insights and notes recorded during the elicitation meetings. Since most of the elicitation was focused on the salt spill accident, the next section for Scenario I contains more observations than the others, with many also being applicable to the other scenario categories.

\subsection{SCENARIO CATEGORY I: SALT SPILL ACCIDENT}

The key phenomena for which elicitations were performed for Scenario I are listed in Table 7. 
Table 7. Scenario Category I: Salt spill accident, identified phenomena

\begin{tabular}{|c|c|c|c|c|c|}
\hline Phenomena & & Importance & Knowledge & Priority & Rationale \\
\hline \multirow{4}{*}{$\begin{array}{l}\text { I01. Base/floor } \\
\text { material } \\
\text { thermochemical } \\
\text { interaction with } \\
\text { molten salt (e.g., } \\
\text { concrete, steel) }\end{array}$} & FOM-1 & $\begin{array}{c}\mathrm{M}-\mathrm{H} \\
\text { (concrete) }\end{array}$ & $1-2$ & & \multirow{4}{*}{$\begin{array}{l}\text { The base/floor of the cell into which salt spills is } \\
\text { likely to be steel or steel over thermal insulation } \\
\text { over concrete. For those conditions, there is } \\
\text { likely to be little thermochemical interaction. If } \\
\text { the salt spills onto concrete, then there is likely } \\
\text { to be spallation, or the mixture of concrete } \\
\text { decomposition products with the salt, including a } \\
\text { release of bound water and the production of } \\
\text { hydrogen. Contamination byproducts of the } \\
\text { decomposition of concrete could affect the } \\
\text { chemical form and release of radioactive } \\
\text { material. The effects on heat balance and } \\
\text { criticality potential are not likely to be } \\
\text { substantial. No research has been identified that } \\
\text { directly relates to radioactive material release or } \\
\text { thermal conditions of the salt. Neutronic } \\
\text { modeling with available tools (SCALE) is } \\
\text { feasible. } \\
\text { The assessment indicated a potential high } \\
\text { priority for research associated with molten salt } \\
\text { thermochemical interaction with concrete, but } \\
\text { only if designs are identified involving this } \\
\text { potential. }\end{array}$} \\
\hline & FOM-1 & $\begin{array}{c}\mathrm{L}-\mathrm{M} \\
\text { (steel) }\end{array}$ & $1-2$ & & \\
\hline & FOM-2 & M & $1-2$ & $\square$ & \\
\hline & FOM-3 & $\mathrm{L}-\mathrm{M}$ & $2-3$ & $\square$ & \\
\hline \multirow{3}{*}{$\begin{array}{l}\text { I02. Radionuclide } \\
\text { inventory (mass) or } \\
\text { radioactivity level, } \\
\text { speciation, and } \\
\text { distribution (at the } \\
\text { start of the accident) }\end{array}$} & FOM-1 & $\mathrm{H}$ & 2 & & \multirow{3}{*}{$\begin{array}{l}\text { These processes relate to conditions while the } \\
\text { salt is still in-vessel at the time of the breach. } \\
\text { They have a substantial impact on the } \\
\text { characteristics of the molten pool that forms in } \\
\text { the cell. There has been relevant research that } \\
\text { impacts all three FOMs, but additional research } \\
\text { is required to achieve a level consistent with the } \\
\text { importance of the three FOMs. Thus, this } \\
\text { phenomenon has high priority for research. }\end{array}$} \\
\hline & FOM-2 & $\mathrm{H}$ & 2 & & \\
\hline & FOM-3 & $\mathrm{H}$ & 2 & & \\
\hline \multirow{3}{*}{$\begin{array}{l}\text { I03. Mass/volume and } \\
\text { energy of molten salt } \\
\text { (fueled salt) pool }\end{array}$} & FOM-1 & $\mathrm{H}$ & 2 & & \multirow{3}{*}{$\begin{array}{l}\text { These characteristics of the molten salt pool } \\
\text { formed in the cell external to the primary system } \\
\text { directly impact all three FOMs. Relevant } \\
\text { research has been performed that relates to all } \\
\text { three FOMs, but because of the high importance } \\
\text { of the phenomenon, high priority is assigned for } \\
\text { additional research. }\end{array}$} \\
\hline & FOM-2 & $\mathrm{H}$ & 2 & & \\
\hline & FOM-3 & $\mathrm{H}$ & 2 & & \\
\hline
\end{tabular}




\begin{tabular}{|c|c|c|c|c|c|}
\hline \multirow{3}{*}{$\begin{array}{l}\text { I04. Initial } \\
\text { temperature of molten } \\
\text { salt pool and } \\
\text { structures within the } \\
\text { volume }\end{array}$} & FOM-1 & $\mathrm{H}$ & 3 & $\square$ & \multirow{3}{*}{$\begin{array}{l}\text { The evolution of radioactive material from the } \\
\text { pool is highly dependent on the pool } \\
\text { temperature, but given the initial conditions of } \\
\text { the salt within the vessel and the ambient } \\
\text { temperature of structures in the cell, the initial } \\
\text { temperatures are well defined. The priority } \\
\text { associated with the thermal response of the } \\
\text { system was assessed to be a greater driver for } \\
\text { research than the impact on radionuclide release. } \\
\text { The impact on the potential for a reactivity } \\
\text { excursion is small. }\end{array}$} \\
\hline & FOM-2 & $\mathrm{H}$ & 2 & & \\
\hline & FOM-3 & $\mathrm{L}$ & 3 & & \\
\hline \multirow{3}{*}{$\begin{array}{l}\text { I05. Molten salt } \\
\text { spreading }\end{array}$} & FOM-1 & $\mathrm{M}$ & $1-2$ & & \multirow{3}{*}{$\begin{array}{l}\text { The importance of spreading depends on the } \\
\text { mass released and the geometry of the cell. } \\
\text { Although both radioactive material release and } \\
\text { thermal response are of only moderate } \\
\text { importance, there has been very little research } \\
\text { that directly relates to the spreading of molten } \\
\text { salts. Thus, there is some priority for additional } \\
\text { research. Spreading phenomena have little } \\
\text { impact on reactivity control. }\end{array}$} \\
\hline & FOM-2 & $\mathrm{M}$ & $1-2$ & & \\
\hline & FOM-3 & $\mathrm{L}$ & 2 & & \\
\hline \multirow{3}{*}{$\begin{array}{l}\text { I06. Salt } \\
\text { fragmentation }\end{array}$} & FOM-1 & M & 1 & & \multirow{3}{*}{$\begin{array}{l}\text { The importance of salt fragmentation on } \\
\text { radioactive material release is dependent on size } \\
\text { distribution. Mechanical interactions are likely to } \\
\text { produce droplets larger than the respirable range. } \\
\text { Nevertheless, other than the Argonne } \\
\text { experimental plans described to the panel, the } \\
\text { level of knowledge is low, and additional } \\
\text { research is warranted. FOM-2 and FOM-3 are } \\
\text { largely unaffected. }\end{array}$} \\
\hline & FOM-2 & $\mathrm{L}$ & 1 & & \\
\hline & FOM-3 & $\mathrm{L}$ & 3 & & \\
\hline \multirow{3}{*}{$\begin{array}{l}\text { I07. Generation of } \\
\text { dross/crust layer on } \\
\text { surface of salt pool }\end{array}$} & FOM-1 & $\mathrm{M}-\mathrm{H}$ & 1 & & \multirow{3}{*}{$\begin{array}{l}\text { This is an area of very high uncertainty with } \\
\text { substantial potential impact on FOM-1 and } \\
\text { FOM- } 2 \text {. }\end{array}$} \\
\hline & FOM-2 & $\mathrm{M}$ & 1 & & \\
\hline & FOM-3 & $\mathrm{L}$ & 1 & & \\
\hline \multirow{3}{*}{$\begin{array}{l}\text { I08. Vaporization and } \\
\text { release of salt } \\
\text { components and } \\
\text { radioactive material } \\
\text { from the surface of a } \\
\text { molten salt pool }\end{array}$} & FOM-1 & $\mathrm{H}$ & $1-2$ & & \multirow{3}{*}{$\begin{array}{l}\text { Although there has been considerable research in } \\
\text { this area, it remains the primary area of } \\
\text { uncertainty for FOM-1, particularly associated } \\
\text { with prototypic non-thermodynamic equilibrium } \\
\text { behavior and a full range of radionuclide- } \\
\text { speciation/salt combinations. There is relatively } \\
\text { little impact on FOM-2 and virtually no } \\
\text { relationship to FOM-3. }\end{array}$} \\
\hline & FOM-2 & $\mathrm{M}-\mathrm{H}$ & 2 & $\square \square$ & \\
\hline & FOM-3 & $\mathrm{L}$ & 3 & & \\
\hline
\end{tabular}




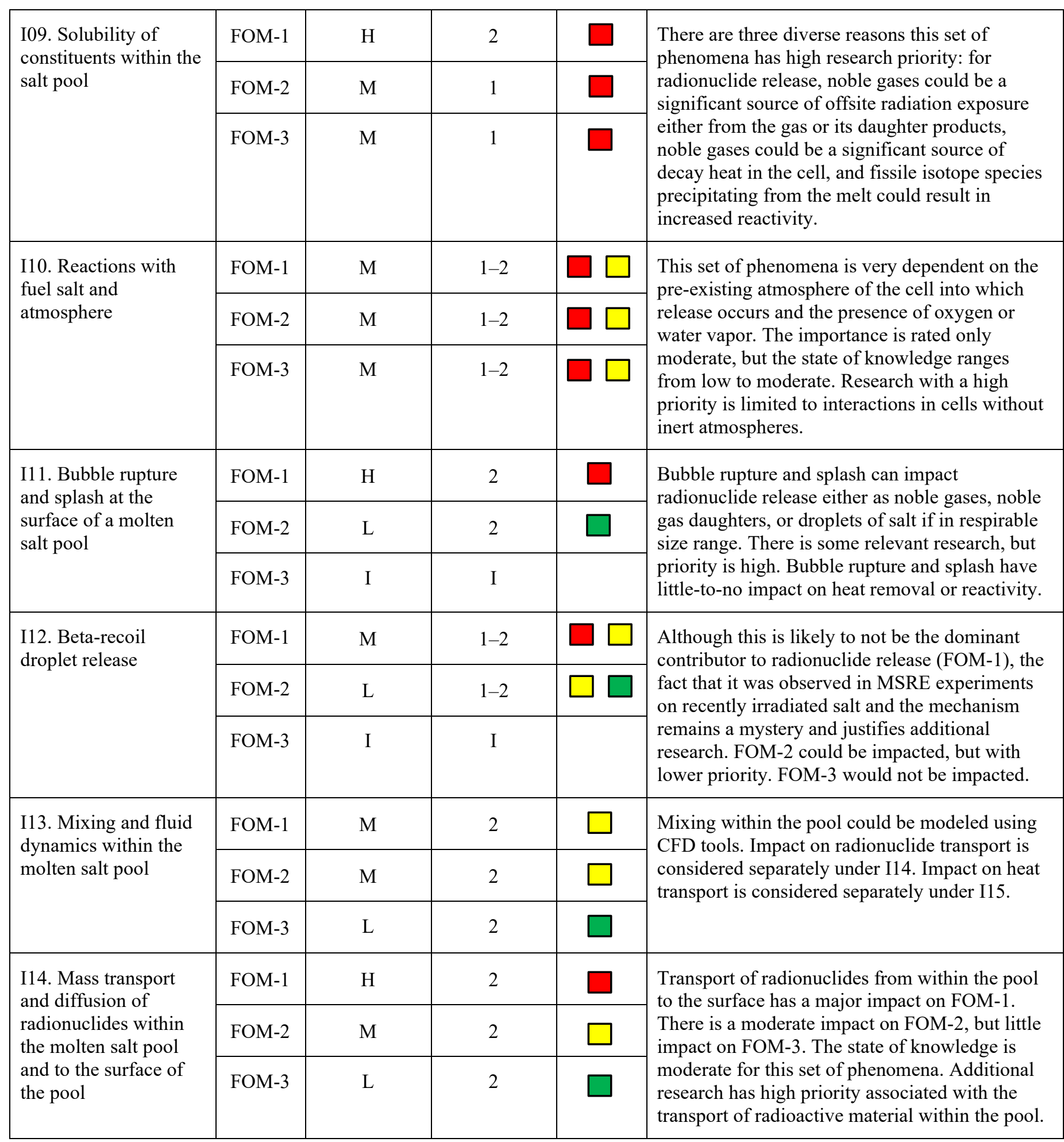




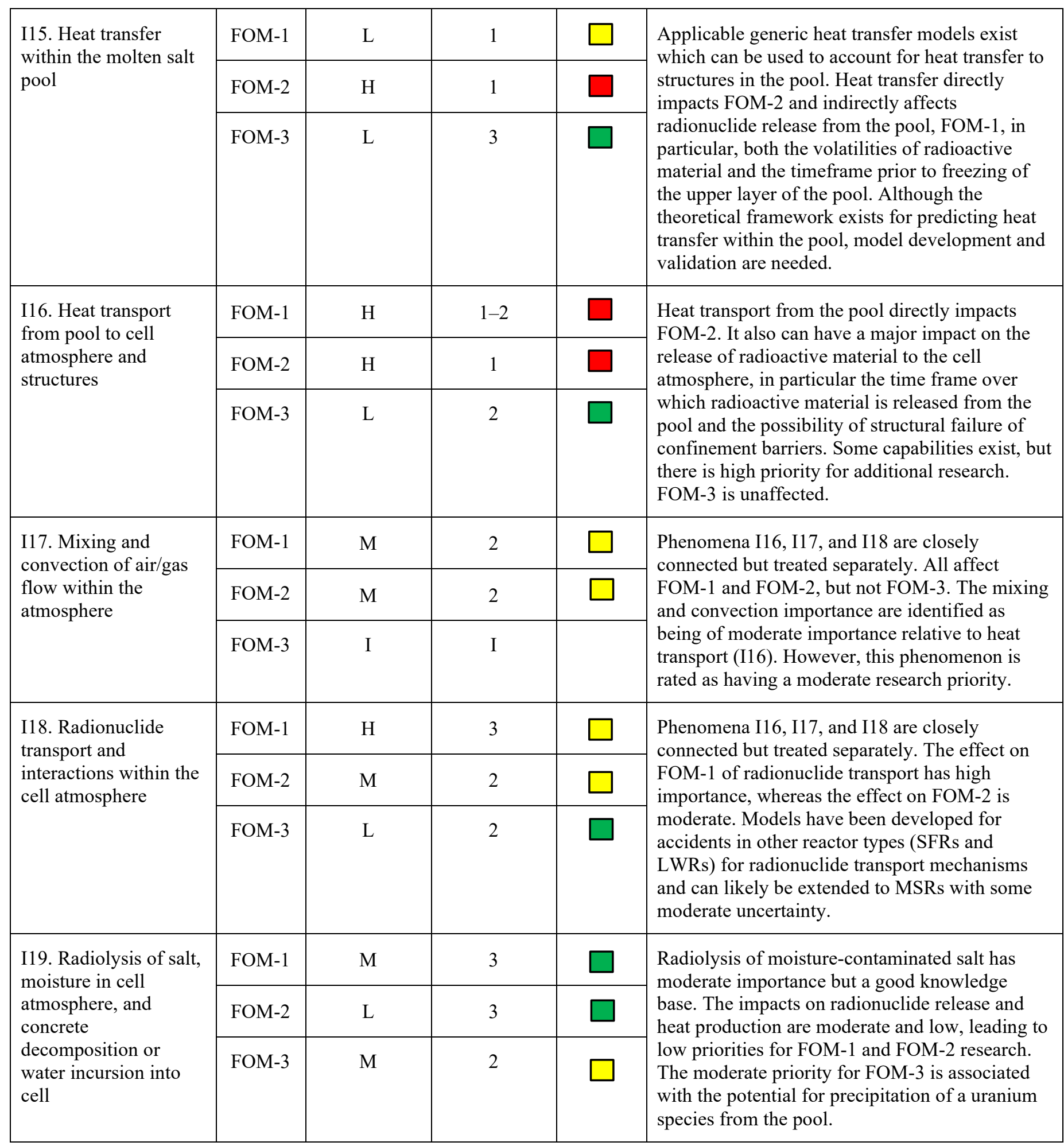




\begin{tabular}{|l|l|l|l|l|l|}
\hline $\begin{array}{l}\text { I20. Water-salt } \\
\text { interactions, including } \\
\text { hydrolysis in salt }\end{array}$ & FOM-1 & M & 2 & $\square$ & $\begin{array}{l}\text { Interactions with small amounts of water, such as } \\
\text { moisture in the cell atmosphere, would have } \\
\text { limited impact. Potential for energetic salt/water } \\
\text { interaction is very unlikely based on the unlikely } \\
\text { presence of water and extensive research on } \\
\text { mechanisms for energetic steam explosions. } \\
\text { Potential for over-pressure failure from steam } \\
\text { produced by water incursion (see MSRE design } \\
\text { basis event) is significant. Water incursion could } \\
\text { increase the potential for reactivity excursion, } \\
\text { but likelihood is low. There is a moderate } \\
\text { priority for additional research associated with } \\
\text { FOM-1 and FOM-3. }\end{array}$ \\
\hline
\end{tabular}

The results of the elicitation of research priorities based on the matrix of importance vs. the state of knowledge for each phenomenon are shown in Table 8. In some cases, a phenomenon was assessed to span two levels of priority because the PIRT panel ranked either the importance, knowledge, or both with a split ranking. For these cases, the phenomenon is listed under two levels of priority but is denoted with an asterisk $(*)$.

Table 8. Scenario Category I:

Salt spill accident ranked research priorities

\begin{tabular}{|c|c|c|c|}
\hline & High priority & Moderate priority & Low priority \\
\hline FOM 1 & $\begin{array}{l}\mathrm{I} 01, \mathrm{I} 02, \mathrm{I} 03, \mathrm{I} 05^{*}, \mathrm{I} 06, \mathrm{I} 07^{*} \\
\mathrm{I} 08, \mathrm{I} 09, \mathrm{I} 10^{*}, \mathrm{I} 11, \mathrm{I} 12^{*}, \mathrm{I} 14 \\
\mathrm{I} 16,\end{array}$ & $\begin{array}{c}\mathrm{I} 04, \mathrm{I} 05^{*}, \mathrm{I} 07^{*}, \mathrm{I} 10^{*}, \mathrm{I} 12^{*}, \mathrm{I} 13 \\
\mathrm{I} 15, \mathrm{I} 17, \mathrm{I} 18, \mathrm{I} 20\end{array}$ & I19 \\
\hline FOM 2 & $\begin{array}{c}\mathrm{I} 01^{*}, \mathrm{I} 02, \mathrm{I} 03, \mathrm{I} 04, \mathrm{I} 05^{*}, \mathrm{I} 07 \\
\mathrm{I} 08^{*}, \mathrm{I} 09, \mathrm{I} 10^{*}, \mathrm{I} 15, \mathrm{I} 16\end{array}$ & $\begin{array}{c}\mathrm{I} 01^{*}, \mathrm{I} 05^{*}, \mathrm{I} 06, \mathrm{I} 08^{*}, \mathrm{I} 10^{*}, \mathrm{I} 12^{*}, \\
\mathrm{I} 13, \mathrm{I} 14, \mathrm{I} 17, \mathrm{I} 18\end{array}$ & $\mathrm{I} 11, \mathrm{I} 12^{*}, \mathrm{I} 19, \mathrm{I} 20$ \\
\hline FOM 3 & $\mathrm{I} 02, \mathrm{I} 03, \mathrm{I} 09, \mathrm{I} 10^{*}$ & $\mathrm{I} 01^{*}, \mathrm{I} 07, \mathrm{I} 10^{*}, \mathrm{I} 19, \mathrm{I} 20$ & $\begin{array}{c}\text { I01*, I04, I05, I06, I08, I11, } \\
\text { I12, I13, I14, I15, I16, I17, } \\
\text { I18 }\end{array}$ \\
\hline $\begin{array}{c}\text { Any } \\
\text { FOM }^{\dagger}\end{array}$ & $\begin{array}{c}\mathrm{I} 01, \mathrm{I} 02, \mathrm{I} 03, \mathrm{I} 04, \mathrm{I} 05, \mathrm{I} 06, \mathrm{I} 07, \\
\mathrm{I} 08, \mathrm{I} 09, \mathrm{I} 10, \mathrm{I} 11, \mathrm{I} 12, \mathrm{I} 14, \mathrm{I} 15, \\
\mathrm{I} 16\end{array}$ & I13, I17, I18, I19, I20 & \\
\hline
\end{tabular}

*Phenomenon has a split ranking (e.g., knowledge is a $1-2$, instead of either just a 1 or a 2 value)

'Phenomena with the highest priority of any FOM

Based on the elicitations for Scenario Category I and the results presented in Table 8, several observations are made:

- $\quad 75 \%$ of the identified critical phenomena for a salt spill accident have at least one FOM ranking as a high priority for additional research. The high priority ranking occurs when any FOM has an importance of high with a knowledge level ranking of 1 or 2, or with an importance of moderate with a knowledge level of 1 . The high priority research areas for limiting the release of radioactive material to the environment (FOM1) and assuring adequate heat removal (FOM2) are largely the same. In contrast, the status of understanding of reactivity control (FOM3) is either adequately known or would be addressed by research performed to improve the understanding of FOM1 or FOM2 high research priority phenomena. 
- The remaining $25 \%$ of the identified critical phenomena for a salt spill accident have at least one FOM ranking as a moderate priority, and there are no phenomena that were solely identified as a low priority. This is largely due to the process of identifying phenomena that could be important in affecting the achievement of at least one of the three critical safety functions. As a result, nearly all the phenomena are recognized as having at least moderate importance for at least one FOM. Nearly all of these phenomena have recognized limitations in the state of knowledge of the underlying database. Therefore, it is not surprising that few phenomena are categorized as having a low priority for research.

- Although efforts were made to be as exhaustive as possible given the time available for this phase of the PIRT, it should not be assumed that the list of phenomena identified as part of this PIRT is complete for any specific reactor design.

- Additionally, the moderate priority phenomena are listed at the end of the scenario category IDs (i.e., I13, and I17-I20 out of a total of 20 identified phenomena). Because the ID numbers were assigned as the phenomena were identified, and the PIRT panel progressively identified lower priority phenomena, the most critical high priority phenomena were identified first.

- Only one phenomenon was ranked with a low priority for FOM 1: Phenomenon I19 "Radiolysis of salt, moisture in cell atmosphere, and concrete decomposition or water incursion into cell." During the discussion of this event, radiolysis was generally considered to be well understood relative to other phenomena with greater importance.

- Several of the phenomena were identified because of their potential importance to FOM1 and FOM2, which would have limited impact on reactivity. The exceptions are I02, I03, I09, and I10, which were ranked with a high priority for FOM 3 . These phenomena deal primarily with the initial conditions of the accident (i.e., the initial concentrations of radionuclides, the amount of mass/energy, the solubility, and the material configuration). Phenomenon I10, "Reactions with fuel salt and atmosphere." is the exception, because it is considered highly dependent on design and whether air or moisture is present for the accident. These factors would then affect how much fissile material would precipitate out of the spilled molten salt pool. Phenomena I02, I03, I09, and I10, were also ranked as high priority for both FOM 1 and FOM 2, in addition to FOM 3. The initial conditions and design details surrounding the accident were judged to be highly important with significant uncertainty. Whereas many other phenomena highlighted the need for additional experiments to further understand unique salt behavior during an accident (e.g., crust/dross formation), the collection of these phenomena and their ranking of high priority for all three FOMs place a unique focus on the need for sufficient modeling capabilities to adequately address the range of potential salt spill accident conditions.

In addition to these observations, several consistent remarks were made by the panel members regarding the phenomena:

- The salt spill accident is the most critical scenario from the viewpoint of the potential for a large environmental release of radioactive material, irrespective of MSR design.

- Many of the phenomena identified for the salt spill accident also apply to accidents involving a release from a breach in the cover gas region of the primary system boundary or to transient accident scenarios in which the progression of the accident results in primary system failure from factors such as over-temperature/over-pressure failure of a primary system component or an energetic reactivity excursion.

- The thermophysical and thermochemical behavior of the molten salt affects nearly all of the identified phenomena. Because programs are being undertaken to remove gaps in the state of knowledge of thermophysical and thermochemical salt properties, it was decided to focus the PIRT on phenomena rather than properties. Nevertheless, the assessed state of knowledge of phenomena was impacted by recognized deficiencies in the state of knowledge of the underlying 
salt properties, as illustrated by the assessment of I13, "Mixing and fluid dynamics within the molten salt pool."

- Phenomena that are common to other reactor types, such as aerosol growth and deposition processes, independent of salt thermochemistry, were generally assessed to have a higher knowledge ranking (i.e., I04, I18).

- Although many important observations were made for liquid-fueled MSRs with common design features, design dependence played a significant role in the discussion and the ranking of phenomena that had critical parameters related to cell/confinement geometry, break location, and base/floor material. These phenomena principally included I01, I02, I03, I05, I10, and I13.

- Design dependence and time constraints on the members of the PIRT Panel played a role in determining the level of phenomena refinement. For example, phenomenon I15, "Heat transfer within the molten salt pool" could have been subdivided into conduction, convection, and radiation as distinct phenomena, but the analysis would have been design dependent, requiring considerable additional effort by the panel members, with no change to the conclusion that area has a high research priority.

For cases in which there was clearly more importance or knowledge for a specific design, as compared to the more broad or general case, or for cases in which the panel members did not reach a clear consensus, a split ranking was assigned. For example, for phenomenon I01, FOM 3, a moderate importance was denoted because of the potential for a breeder blanket salt system, and a low importance was assigned for a reflector or no other blanket system.

\subsection{SCENARIO CATEGORY II: DYNAMIC SYSTEM THERMAL/HYDRAULIC/POWER RESPONSE}

Although this scenario category includes a variety of potential initiating events leading to a transient response of the reactor coolant system, the principal safety function - release of radioactive material to the environment (FOM 1)-is only challenged if there is a resulting failure of the reactor coolant system. A salt spill accident was addressed in Scenario Category I. Thus, from a larger list of accident phenomena associated with transient system response, only two were identified for elicitation, as shown in Table 9. 
Table 9. Scenario Category II:

Dynamic system thermal/hydraulic/power response, identified phenomena

\begin{tabular}{|c|c|c|c|c|c|}
\hline \multicolumn{2}{|l|}{ Phenomena } & Importance & Knowledge & Priority & Rationale \\
\hline \multirow{3}{*}{$\begin{array}{l}\text { II01. Over- } \\
\text { temperature, over- } \\
\text { pressure } \\
\text { conditions }\end{array}$} & FOM-1 & M & 2 & & \multirow{3}{*}{$\begin{array}{l}\text { Within the spectrum of accident transient conditions } \\
\text { possible, only those that could result in over- } \\
\text { temperature or over-pressure failure of the primary } \\
\text { system are of concern. Because the MSRs are not } \\
\text { pressurized systems, stresses are likely to be small in } \\
\text { primary system boundary structures. Nevertheless, } \\
\text { these events are design dependent and have } \\
\text { moderate importance for each of the FOMs. Several } \\
\text { references exist regarding the state of knowledge of } \\
\text { transient response, but there is high design } \\
\text { dependence. As a result, the assessed research } \\
\text { priority for each FOM is moderate. }\end{array}$} \\
\hline & FOM-2 & M & 2 & $\square$ & \\
\hline & FOM-3 & M & 2 & $\Gamma$ & \\
\hline \multirow{3}{*}{$\begin{array}{l}\text { II02. Leak/rupture } \\
\text { of primary heat } \\
\text { exchanger tube } \\
\text { and radionuclide } \\
\text { release to } \\
\text { secondary systems }\end{array}$} & FOM-1 & M & 2 & & \multirow{3}{*}{$\begin{array}{l}\text { The interface between the primary and secondary } \\
\text { systems is an area of potential concern for system } \\
\text { failure as an initiating event (e.g., from corrosion) or } \\
\text { in response to a transient. By designing the } \\
\text { secondary system to be at a higher pressure than the } \\
\text { primary system, the issue becomes one of the } \\
\text { compatibilities of the primary salt and the secondary } \\
\text { coolant, but it is unlikely to lead to an event with a } \\
\text { radiological release. Thus, moderate research } \\
\text { priority is associated with FOM-1 and FOM-2. } \\
\text { FOM-3 is unlikely to be impacted and has low } \\
\text { priority. }\end{array}$} \\
\hline & FOM-2 & M & 2 & $\square$ & \\
\hline & FOM-3 & $\mathrm{L}$ & 2 & {[} & \\
\hline
\end{tabular}

In relation to the salt spill accident, this scenario category is even more design dependent. Historically, the analysis of a broad spectrum of off-normal conditions leading to transient system response has been required in the safety analysis reports for the existing fleet of operating reactors. Although a full hazard and operability (HAZOP) or failure modes and effects analysis (FMEA) approach could be applied (e.g., pump speed increases, pump speed decreases), for the purposes of the PIRT, it was judged to be most appropriate in the interest of time to focus on those transients which have a direct impact on FOM 1.

Although a leak or rupture of the primary heat exchanger tube (II02) in a pressurized reactor such as an LWR could result in an off-site release of radioactive material, in an MSR, the primary pressure is likely equal to or slightly less than the secondary pressure. Therefore, instead of fuel salt flowing into the secondary system (salt or another intermediate heat transfer fluid), the secondary coolant is likely to flow into the primary system. Thus, the safety issues relate to whether the reaction between secondary coolant and primary coolant could adversely impact the reactivity or coolability of the primary system. For the case in which the secondary coolant is a salt property similar to those of the fuel salt, it is unlikely that this reaction would prevent shutdown of the reactor and the retention of radioactive material within the system.

Table 10 presents the results of ranking and elicitation assessed against the matrix knowledge needs prioritization. 
Table 10. Scenario Category II:

Dynamic system thermal/hydraulic/power response, ranked research priorities

\begin{tabular}{|c|c|c|c|}
\hline & High priority & Moderate priority & Low priority \\
\hline FOM 1 & & II01, II02 & \\
\hline FOM 2 & & II01, II02 & II02 \\
\hline FOM 3 & & II01 & \\
\hline Any & FOM
\end{tabular}

${ }^{\dagger}$ Phenomena with the highest priority of any FOM

No high priority research needs were identified for this scenario category.

\subsection{SCENARIO CATEGORY III: WATER-MOLTEN SALT INTERACTIONS}

The water-molten salt scenario category was initially presented to the PIRT panel as a separate scenario category. However, none of the system designs includes an interface between a water system and the system containing the fuel salt without some other intervening coolant system. Because flooding of the intact reactor coolant system does not lead directly to salt/water interactions, the PIRT panel recommended that only water-molten salt interaction be considered as a phenomenon under the salt spill accident scenario category, specifically in I20, "Water-salt interactions, including hydrolysis in salt."

\subsection{SCENARIO CATEGORY IV: ACCIDENTAL CRITICALITY}

It was recognized that any system that would contain fuel salt would be designed to assure criticality control, including geometry, poisons, moderation and reflection, which are well within the capability of current neutronic tools such as SCALE. Thus, the focus of the assessment was on salt-related phenomena that could result in unanticipated accumulation of fissile material or increase in reactivity, and the two phenomena in Table 11 were identified for elicitation. 
Table 11. Scenario Category VI:

Accidental criticality, identified phenomena

\begin{tabular}{|c|c|c|c|c|c|}
\hline Phenomena & & Importance & Knowledge & Priority & Rationale \\
\hline \multirow{3}{*}{$\begin{array}{l}\text { IV01. } \\
\text { Unrecognized } \\
\text { accumulation of } \\
\text { fissile material }\end{array}$} & FOM-1 & M & 2 & & \multirow{3}{*}{$\begin{array}{l}\text { Any plant system that will contain fissile material } \\
\text { will be designed with high confidence to avoid } \\
\text { accidental criticality. However, the potential for an } \\
\text { uncontrolled nuclear reaction could result from an } \\
\text { unrecognized buildup of material. Given the } \\
\text { configuration, mass, degree of reflection, and degree } \\
\text { of moderation, the ability to predict criticality is } \\
\text { good [ } 77,78] \text {. Nevertheless, by its nature, this issue } \\
\text { addresses uncertainty regarding mechanisms that } \\
\text { could result in an unexpected accumulation. As a } \\
\text { result, the panel identified the state of knowledge as } \\
\text { low or moderate. }\end{array}$} \\
\hline & FOM-2 & M & 2 & & \\
\hline & FOM-3 & $\mathrm{H}$ & $1-2$ & & \\
\hline \multirow{3}{*}{$\begin{array}{l}\text { IV02. Overcooling } \\
\text { leading to } \\
\text { precipitation and } \\
\text { accumulation }\end{array}$} & FOM-1 & M & 2 & & \multirow{3}{*}{$\begin{array}{l}\text { This scenario is highly dependent on event scenario } \\
\text { characteristics and the design features for limiting } \\
\text { overcooling events. The equations of state, } \\
\text { conditions leading to precipitation of actinide } \\
\text { species, and the characteristics of the precipitates are } \\
\text { not well known [79]. The priority of these events is } \\
\text { moderate because they can likely be addressed } \\
\text { through conservative analysis (i.e., sufficient } \\
\text { margin). }\end{array}$} \\
\hline & FOM-2 & M & 2 & & \\
\hline & FOM-3 & M & 2 & & \\
\hline
\end{tabular}

During the elicitation, there was significant discussion as to how to best describe and categorize the range of possible criticality-oriented or criticality-focused accidents. Because of the (1) flowing nature of the fissile salt within the primary system circuit, (2) the many volumes where fissile salt could accumulate within the primary circuit, (3) the potential for events leading to inadvertent changes in moderation, reflection, or control materials, and (4) the potential for the inadvertent accumulation of fissile material in various systems external to the primary system, it was necessary to identify potential phenomena beyond the standard condition of an anticipated transient without a SCRAM-type of event, which has been the focus of reactivity-initiated accidents for LWRs. The discussion led to phenomena being categorized with a view as broad as possible to identify and understand the range of possible accidents in which accidental criticality could occur.

Table 12 shows the results of the ranking and elicitation assessed against the matrix knowledge needs prioritization.

Table 12. Scenario Category IV:

Accidental criticality, ranked phenomena research priorities

\begin{tabular}{|c|c|c|c|}
\hline & High priority & Moderate priority & Low priority \\
\hline FOM 1 & & IV01, IV02 & \\
\hline FOM 2 & & IV01, IV02 & \\
\hline FOM 3 & IV01 & IV02 & \\
\hline \hline Any FOM & IV01 & IV02 & \\
\hline \hline
\end{tabular}

${ }^{\dagger}$ Phenomena with the highest priority of any FOM

Observations beyond those documented for the other scenario categories include: 
- Unrecognized accumulation is a high concern and should be adequately designed against.

However, some uncertainty persists on joint solubility data and whether sufficient tools exist that can track all possible sources of accumulation over the life of the plant.

- Overcooling is associated with the unique concern of possibly precipitating out fissile salt, which would then form a higher fissile concentration than the bulk liquid that flows back into the core, thus creating a transient power spike. The impression from the PIRT panel is that this is a shortlived effect with adequate negative feedback mechanisms. However, like the observation above about having sufficient tools to predict this behavior, it remains a concern.

\subsection{SCENARIO CATEGORY V: EMERGENCY RESPONSE SYSTEM FAILURES}

No phenomena were elicited related to emergency response system failure. This was because there is a large variety of different system designs, as well as variations in how design concepts drain/transport, store, and remove residual heat from the primary fuel salt. System failures could be associated with drain tanks, freeze plugs, vessel cooling systems, confinement cooling/heating systems, or other passive heat removal systems. Ultimately, an emergency response system failure could lead to an event through some successive failures, which could trigger a salt spill, transient, or other accident that is already captured in other scenario categories. Each concept designer must analyze any unique phenomena associated with these system failures and evaluates if sufficient data exist for their system.

This scenario category is retained as part of the PIRT documentation to illustrate the process and how phenomena were organized.

\subsection{SCENARIO CATEGORY VI: RADWASTE MANAGEMENT SYSTEM}

MSR radwaste management systems are complex. They contain a potentially large source of volatile radionuclides, and they have a variety of designs for different MSR concepts. Phenomena identified as part of this scenario category are sufficiently unique, so they may not be appropriate for appending to any other scenario category. However, it is likely that a significant number of phenomena, some which may be high priority, may be identified for this scenario category, depending on the specific design and operation of the radwaste management system. However, because of the strong emphasis on the design in

this area, it was impractical for the PIRT panel to assess all designs and all associated phenomena. Therefore, this scenario category and its associated phenomena will likely be treated in separate design specific PIRTs in the future, thus only one phenomenon is identified in 
Table 13. 
Table 13. Scenario Category VI:

Radwaste management system failures, identified phenomena

\begin{tabular}{|c|c|c|c|c|c|}
\hline Phenomena & & Importance & Knowledge & Priority & Rationale \\
\hline \multirow{3}{*}{$\begin{array}{l}\text { VI01. Radwaste } \\
\text { and other non-fuel } \\
\text { radioactive } \\
\text { gas/fluid system } \\
\text { failures }\end{array}$} & FOM-1 & $\mathrm{H}$ & 2 & & \multirow{3}{*}{$\begin{array}{l}\text { Radionuclide sources for liquid-fueled MSRs are } \\
\text { expected to span beyond just the core region to } \\
\text { include fission product removal and other radwaste } \\
\text { management systems. The initial state for these } \\
\text { scenarios is highly dependent on the system design } \\
\text { and the location of the failure. Its high importance is } \\
\text { based on the potential consequences of an accident } \\
\text { involving high levels of radioactive material } \\
\text { external to the reactor's primary system. The } \\
\text { phenomena associated with release mechanisms are } \\
\text { not necessarily complex, but they are highly design } \\
\text { dependent. There are known (and different) methods } \\
\text { for handling radwaste and non-fuel radioactive } \\
\text { gas/fluid systems, but the panel's assessment } \\
\text { emphasizes the importance of performing a detailed } \\
\text { safety evaluation of each specific plant's radwaste } \\
\text { system design. }\end{array}$} \\
\hline & FOM-2 & M & 2 & $\square$ & \\
\hline & FOM-3 & $\mathrm{M}$ & 2 & $\square$ & \\
\hline
\end{tabular}

VI01 was ranked as a high priority for FOM 1 and a moderate priority for FOM 2 and FOM 3. However, this is noted as somewhat arbitrary, because it is highly design dependent. It is recommended that a separate PIRT be performed in the future to address a particular radwaste management system. 


\section{SUMMARY AND CONCLUSIONS}

The liquid-fueled MSR FSF PIRT described in this document followed the traditional PIRT process. However, some of the implementation steps differed from previous PIRTs. Most notably, earlier PIRTs were applied to specific reactor designs which had reached a significant level of design maturity. The technical issue evaluated by this PIRT - whether MSRs could continue to achieve the FSFs following postulated accidents - was broader in scope, and less technical detail is available for any particular design. Furthermore, this issue was more performance-based than prior efforts. An alternate implementation process was followed for multiple reasons. First, it was desired to have the outcome of the PIRT be as broadly applicable as possible to the multiple, widely varied MSR designs under development. At the current development stage, it is not yet possible to reasonably assess which designs will proceed into deployment. In addition, all current designs remain in early-phase development, and significant revisions are still possible. Focusing on specific design elements would leave the PIRT vulnerable to rapid obsolescence. Moreover, several of the designs that might be deployed in the United States are being developed internationally. Consequently, the PIRT process must be performed using only public information to remain cognizant of intellectual property protection and export control rules. Finally, the current NRC objective is to base the regulatory process on performance as much as possible to broaden its applicability and maximize its durability.

Information gathering and expert elicitation steps for this PIRT were performed entirely virtually. The PIRT elicitation process has traditionally been performed through a few multi-day meetings attended by a focused range of experts in the subject discipline. Holding the meetings virtually resulted in more numerous (a dozen), shorter (two-hour) meetings with broader participation. One advantage of virtual meetings was the ease of participation by technology/discipline experts without specific knowledge of the PIRT process. For example, the PIRT panel was able to actively interchange with multiple different modeling tool developers, which would have been more difficult with in-person meetings requiring travel. Another advantage of weekly (or bi-weekly) meetings was the reflection enabled during the intervals. For example, the PIRT organizing team refocused elements of the elicitation process based on responses to initial accident scenarios. This would have been more difficult to implement without the time intervals between meetings. In general, not requiring the additional time and dedicated days needed for travel was significantly positive. Holding virtual meetings also provided educational benefits by enabling students and other non-panel members to listen in to the information gathering and panel elicitation processes. Overall, the virtual format drew active participation from the panel and support from a larger, more diverse set of participants.

The results of the PIRT are intended to be of value to three distinct groups. The information provides guidance to DOE to focus its limited MSR research, development, and demonstration resources on the highest value activities. Designers can use the PIRT results to focus on mitigating the events that have the potential to be most significant. The NRC can use the information to ensure that potential accident sequences have been adequately considered and that the likelihood and consequences of their occurrence have been adequately reduced.

The information gathering and elicitation processes did not identify any previously unrecognized vulnerabilities, which provides confidence that the June 2019 initiating event workshop activities can be used to support accident progression evaluation. The elicitation process did identify several areas with low levels of knowledge and significant potential impact on accident progression. These areas either require additional research to improve the state of knowledge or additional conservatism in design to accommodate the remaining unknowns. Although the most important FSF is to adequately prevent the release of radioactive material, many questions relate to the FSF to provide adequate heat rejection. Multiple discussions during the elicitation process focused on the need to consider the extended radionuclide distribution characteristic of MSRs over the course of accidents. In particular, the fission gases and vapors require specific consideration in any accident sequence because an unmitigated 
containment bypass accident could have significant consequences resulting from the large quantity of radionuclides released, their high mobility, and their high radiotoxicity. Adequately robust containment and/or sufficient radionuclide release mitigation methods must be developed to achieve the first FSF. It should be noted that the radiotoxicity of the cover gas decreases rapidly following shutdown. A vapor release that occurs two days after shutdown would have less than $0.1 \%$ of the radionuclide content of a breach at power [80].

For radionuclides to be released from the plant, all leak-tight barriers must be breached or bypassed, or the series of consecutive non-leak tight barriers must be degraded sufficiently to no longer adequately perform their function. A key step in all accident sequences that may result in an environmental release of radionuclides is the breach or bypass of the first containment layer - the primary system boundaryresulting in a spill of fuel salt. Breaches above the liquid vapor line would release only gaseous and vapor phase materials, whereas breaches below the liquid line spill both liquid (down to the level of the breach) and vapor-phase materials. Consequently, much of the PIRT elicitation process was focused on salt spill accidents.

A particular challenge resulting from the diversity of reactor designs is the wide diversity in accident progression details. Three different potential plant configurations are listed below to illustrate the challenge of generalizing a salt spill accident.

1. The reactor vessel is contained within a larger vessel of coolant salt (PRACS type configuration).

2. The salt spill is onto a sloped catch pan designed to channel the salt flow into a passively cooled drain tank.

3. The reactor vessel is surrounded by a closely fitting guard vessel that is not normally in contact with the salt.

The achievement of FSFs is design dependent. Each reactor configuration results in a substantially different fuel salt spill accident progression sequence that requires different simulation capabilities to be effectively modeled. Plants that rely on heat transfer from elevated cooled surfaces require an understanding of mechanisms that could impede convective and radiative heat transfer (e.g., fogs and mists in the atmosphere, crust formation on a spill, and/or insulative deposits forming on heat transfer surfaces). Other plant designs (e.g., those that employ a drain tank or PRACS) do not rely upon the same heat transfer mechanisms, so these mechanisms would be less important when developing their safety case.

A key outcome of the PIRT is the consensus that decay heat removal processes following a major salt spill have substantial remaining unknowns with potentially significant safety implications. The designers participating in the PIRT had recognized these issues during the design phase and had elected to mitigate the risks by implementing alternative mechanisms such as employing a thick reactor vessel constructed with proven materials or segmenting the fuel salt to reduce the potential consequences from a single failure. Nevertheless, the level of uncertainty in the heat transfer performance of spilled fuel salt, including from the vapor phase materials, necessitates substantial design conservatism and consequential expense.

Several potentially important phenomena have been identified that require additional analysis to develop adequate accident progression models.

- Crust forms on the salt spill and inhibits heat transfer from the spilled salt.

- Thermally insulative snow-like deposits form on surfaces within containment and inhibit heat transfer.

- A frozen layer forms when liquid salt contacts a catch pan and inhibits conductive heat transfer.

- Mists and fogs form in the containment atmosphere and inhibit radiative heat transfer.

- Fuel salt interactions with component or structural coolants cause pressure generation or inhibit heat transfer. 
- Hot salt interacts with materials in containment, leading to ignition and smoke formation that inhibits radiative heat transfer.

- Chemical interactions between the salt and the containment materials result in solid material formation (e.g., oxide chunks), thus decreasing convective heat transfer

Adequate reactor safety is based on limiting radioactive material to the environment, which is the primary FSF. The probability of failure of unstressed passive barriers is very low if they are designed, constructed, operated, and maintained under an appropriate QA program. However, plant accidents and external events can cause stress on barriers, and sufficiently high stresses lead to failure. Temperature is the primary barrier stressor for MSR containments if significant quantities of materials, such as water, whose phase change would result in a pressure spike, are not present. Hence, a recommended future research activity focus is acquiring the experimental data necessary to adequately model decay heat removal following a major fuel salt spill.

MSRs have distinctive radionuclide movement characteristics because of the fluid nature of their fuel. A much higher fraction (than in the plenum of solid fuel pins) of the short-lived radionuclides would be in the vapor space above the liquid fuel. All gaseous, vapor phase, and aerosol fission products could be released from an unmitigated early breach or bypass of containment. The consequences of such an accident would be so high that the accident probability must be sufficiently low as to be outside of credible accident space.

Failure of metallic containments is not a cliff-edge phenomenon. Raising the temperature of structural alloys beyond their design limits increases the material creep rate. If the material is maintained at temperatures above the design limits for extended periods (hundreds of degrees for thousands of hours) then the vessel will exceed its creep margin and reach its end of useful life. Release of radioactive material would only be anticipated for extreme temperature excursions. Information on quantities and species of releases would be useful to assess the consequences of these types of low probability events, but this is not be of primary interest in safety adequacy assessment.

Separate-effects testing is in progress to provide information on the equilibrium partial pressures of key radionuclide species for different fuel salts and heat transfer during a spill. However, the ability to model the release and transport of radionuclide species under non-equilibrium conditions is very limited. Furthermore, there have been no integral fuel salt spill experiments performed under the prototypic conditions needed to validate decay heat rejection models.

A key accident progression issue is to establish the initial conditions, such as the location of the radionuclides at the start of an accident. No available reactor modeling toolset includes significant MSR phenomena such as cover gas content and location, plated out radionuclides, or insoluble particle filtering - all of which have potentially significant safety implications. Developing and validating an MSR-focused, normal operations radionuclide tracking tool would be useful. 


\section{REFERENCES}

1. W. K. Ergen (Ed.), Emergency Core Cooling, Report of Task Force Established by the US Atomic Energy Commission to Study Fuel Cooling Systems of Nuclear Power Plants, USAEC Report (undocumented, see ORNL-NSIC-24).

2. US Atomic Energy Commission, 10CFR50, Appendix K 39 FR 1003, Jan. 4, 1974.

3. Gary E. Wilson and Brent E. Boyak, "The Role of the PIRT Process in Experiments, Code Development and Code Application Associated with Reactor Safety Analysis," Nuclear Engineering and Design, 186 (1998) 23-37.

4. US NRC, Transient and Accident Analysis Methods, Regulatory Guide 1.203, December 2005

5. X. Sun, G.L. Yoder, R.N. Christensen, S. Shi, H-C. Lin, and S. Zhang, Thermal Hydraulics Phenomena Identification and Ranking Table (PIRT) for Advanced High Temperature Reactor (AHTR), IRP-14-7829, 2016.

6. David J. Diamond, Nicholas R. Brown, Richard Denning, and Stephen Bajorek, Phenomena Important in Modeling and Simulation of Molten Salt Reactors, BNL-114869-2018-IR, April 23, 2018.

7. Hummel, E.W., Y.S. Chin, M. Yetisir, G.A. Glowa, Phenomena Identification and Ranking Table (PIRT) for a Severe Accident in a Molten Salt Small Modular Reactor, Canadian Nuclear Laboratories, 153-120200-REPTf-033, February 2020. Status of salt properties.

8. Southern Company, Definition of Fundamental Safety Functions for Advanced Non-Light Water Reactors, Draft B, SC-16166-100 Rev A, November 2019. Fundamental Safety Functions.

9. NRC Staff Comments on Technology Inclusive Content of Application Project Definition of Fundamental Safety Functions for Advanced Non-Light Water Reactors - Draft Report Revision B, ML20021A182, January 2020, https://www.nrc.gov/docs/ML2002/ML20021A182.pdf (accessed October 2020).

10. J. Xing and S. Morrow, "NRC White Paper: Practical Insights and Lessons Learned on Implementing Expert Elicitation," October 13, 2016. (NRC ADAMS Accession No. ML16287A734)

11. US Nuclear Regulatory Commission. 2012. Final Interim Staff Guidance Augmenting NUREG-1537, Part 1, Guidelines for Preparing and Reviewing Applications for the Licensing of Non-Power Reactors: Format and Content, for Licensing Radioisotope Production Facilities and Aqueous Homogeneous Reactors, ML12156A069.

12. D. E. Holcomb, W.P. Poore, III, and G. F. Flanagan, MSR Fuel Salt Qualification Methodology, ORNL/TM-2020/1576, July 2020.

13. Regulatory Guide 1.232, "Guidance for Developing Principal Design Criteria for Non-Light-Water Reactors," April 2018. (NRC ADAMS Accession No. ML17325A611)

14. EPRI, "Molten Salt Reactors," Technology Insights, EPRI 3002020066, December 2020.

15. Kurt Harris, Overview of LFTR, Flibe Energy, Inc., MSR PIRT Working Group, Zoom Virtual Meeting, February 3, 2021.

16. EPRI 3002005460, "Program on Technology Innovation: Technology Assessment of a Molten Salt Reactor Design -- The Liquid Fluoride Thorium Reactor (LFTR),” Oct 22, 2015. 
17. Guy Anderson, Overview of SSR-W Reactor Design, Moltex Energy, MSR PIRT Working Group, Zoom Virtual Meeting, February 3, 2021.

18. Aslak Stubsgaard, Copenhagen Atomics Reactor Design Overview, Copenhagen Atomics, MSR PIRT Working Group, Zoom Virtual Meeting, February 16, 2021.

19. Dane Wilson, ThorCon's Implementation of Control, Cool and Contain, ThorCon US, Inc., MSR PIRT Working Group, Zoom Virtual Meeting, February 16, 2021.

20. Rusty Towell, Introductions, Licensing Pathway and Technical Summary, Abilene Christian University, MSR PIRT Working Group, Zoom Virtual Meeting, February 16, 2021.

21. Tommy Cisneros, MCFR System Description, TerraPower, MSR PIRT Working Group, Zoom Virtual Meeting, March 3, 2021.

22. David LeBlanc, Overview of the IMSR ${ }^{\circledR}$, Terrestrial Energy, MSR PIRT Working Group, Zoom Virtual Meeting, March 3, 2021.

23. Ed Pheil, Molten Chloride Salt Fast Reactor PIRT Presentation, Elysium Industries, MSR PIRT Working Group, Zoom Virtual Meeting, March 17, 2021.

24. Sara Thomas, Salt Spill Experiments, Argonne National Laboratory, MSR PIRT Working Group, Zoom Virtual Meeting, March 17, 2021.

25. Farmer, M., The MELTSPREAD Code for Modeling of Ex-Vessel Core Debris Spreading Behavior, ANL/NE-17/20, Code Manual- Version 3-beta, September 2017.

26. Joanna McFarlane, Molten Salt Chemistry and Off-Gas Monitoring, Oak Ridge National Laboratory, MSR PIRT Working Group, Zoom Virtual Meeting, March 17, 2021.

27. Mcfarlane, Joanna; Riley, Brian; Holcomb, David Eugene; Lines, Amanda; Andrews, Hunter; Bryan, Sam; Chapel, Shay; Ezell, N Dianne Bull; Felmy, Heather M.; Greenwood, Michael Scott; Humrickhouse, Paul W.; and Myhre, Kristian. Molten Salt Reactor Engineering Study for Off-Gas Management. United States: N. p., 2020. Web. doi:10.2172/1649021. ORNL/TM-2020/1602

28. Mcfarlane, Joanna; Bull Ezell, N. Dianne; Del Cul, Guillermo D.; Holcomb, David Eugene; Myhre, Kristian; Lines, Amanda; Bryan, Sam; Felmy, Heather M.; Riley, Brian J.; and Chapel, Austin. Fission Product Volatility and Off-Gas Systems for Molten Salt Reactors. United States. https://doi.org/10.2172/1560441. https://www.osti.gov/servlets/purl/1560441. ORNL/TM-2019/1266; PNNL-28974

29. Andrews, Hunter, Mcfarlane, Joanna, Holcomb, David Eugene, Ezell, N Dianne Bull, Myhre, Kristian, Lines, Amanda, Bryan, Sam, and Felmy, Heather M. Tue. "Sensor Technology for Molten Salt Reactor Off-Gas Systems." United States. https://www.osti.gov/servlets/purl/1808191. Conference: 12th Nuclear Plant Instrumentation, Control and Human-Machine Interface Technologies (NPIC\&HMIT) - Providence, Rhode Island, United States of America - 6/13/2021

30. David Holcomb, George Flanagan, and Mike Poore, Current Status of Fuel Salt Qualification Guidance Development, Oak Ridge National Laboratory, MSR PIRT Working Group, Zoom Virtual Meeting, March 17, 2021.

31. Holcomb, D., G. Flanagan and M. Poore, Current Status of Fuel Salt Qualification Guidance Development, MEI-MSR Technical Working Group," March 2021. Fuel salt property status.

32. US NRC, Presentations for August 3, 2017 Public Meeting Regulatory Improvements for Advanced Reactors, August 3, 2017. (NRC Adams Accession No. ML17220A315)

33. J. McMurray et al., Roadmap for Thermal Property Measurements of Molten Salt Reactor Systems, ORNL/SPR-2020/1865, March 2021. 
34. David L. Luxat, MELCOR for non-LWR Analysis, Sandia National Laboratories, MSR PIRT Working Group, Zoom Virtual Meeting, March 31, 2021.

35. W. A. Wieselquist, R. A. Lefebvre, and M. A. Jessee, Eds., SCALE Code System, ORNL/TM2005/39, Version 6.2.4, Oak Ridge National Laboratory, Oak Ridge, TN (2020).

36. MELCOR Computer Code Manuals, Vol. 1: Primer and Users' Guide, Version 2.2.9541, SAND 2017-0455 O, Sandia National Laboratories, January 2017. (ADAMS Accession No. ML17040A429)

37. MELCOR Computer Code Manuals, Vol. 2: Reference Manual, Version 2.2.9541, SAND 2017-0876 O, Sandia National Laboratories, January 2017 (ADAMS Accession No. ML17040A420).

38. MELCOR Computer Code Manuals, Vol. 3: MELCOR Assessment Problems, Version 2.1.7347 2015," SAND 2015-6693 R, Sandia National Laboratories, August 2015. (ADAMS Accession No. ML15300A476)

39. Melissa Rose, Quality Aspects of Molten Salt Property Measurements, Argonne National Laboratory, MSR PIRT Working Group, Zoom Virtual Meeting, March 31, 2021.

40. Rui Hu, SAM Overview for MSR Analyses, Argonne National Laboratory, MSR PIRT Working Group, Zoom Virtual Meeting, April 14, 2021.

41. Rui Hu, et. al., SAM Developments to Support Transient Safety Analysis of Advanced non-LWRs, ANL/NSE-19/31, Argonne National Laboratory, September 2019.

42. T. Fei, T. Hua, B. Feng, F. Heidet and R. Hu, "MSRE Transient Benchmarks Using SAM." EPJ Web of Conferences (Proceedings of PHYSOR'20), Vol. 247, 07008, 2021.

43. M. Scott Greenwood, TRANSFORM: Description and Ap, Oak Ridge National Laboratory, MSR PIRT Working Group, Zoom Virtual Meeting, April 14, 2021.

44. Modelica Association, “A Unified Object-Oriented Language for Systems Modeling, Modelica Language Specification,” Version 3.5, February 18, 2021. https://www.modelica.org

45. Greenwood, M.S., Betzler, B.R., Qualls, A.L., Yoo, J., Rabiti, C.," Demonstration of the Advanced Dynamic System Modeling Tool TRANSFORM in a Molten Salt Reactor Application via a Model of the Molten Salt Demonstration Reactor." Nuclear Technology. 1-27 (2019). https://doi.org/10.1080/00295450.2019.1627124

46. Jake McMurray, MSTDB, Oak Ridge National Laboratory, MSR PIRT Working Group, Zoom Virtual Meeting, February 16, 2021.

47. Besmann, Theodore M., Ard, Johnathan, Utlak, Stephen, McMurray, Jake W., and Lefebvre, Robert Alexander. Status of the Salt Thermochemical Database. ORNL/SPR-2019/1208, 2019, doi:10.2172/1559647.

48. Jerden J., Molten Salt Thermophysical Properties Database Development: 2019 Update, ANL/CFCT19/6, 2019, doi:10.2172/1559846

49. C. Agca, K.E. Johnson, J.W. McMurray, J.A. Yingling, T.M. Besmann, FY21 Status Report on the Molten Salt Thermal Properties Database (MSTDB) development, ORNL/SPR-2021/2102. https://doi.org/10.2172/1814280

50. Ard, Johnathan, Johnson, Kaitlin, Christian, M, Schorne Pinto, J, Yingling, Jacob, Besmann, Theodore M., McMurray, Jake W., and Peng, Jian. FY20 Status Report on the Molten Salt Thermodynamic Database (MSTDB) Development. United States: N. p., 2020. Web. doi:10.2172/1778080. 
51. Chris Van Wert and Wendy Reed, Phenomena Identification and Ranking Tables: US NRC Perspective, US Nuclear Regulatory Commission, MSR PIRT Working Group, Zoom Virtual Meeting, March 3, 2021.

52. J. Xing and S. Morrow, "NRC White Paper: Practical Insights and Lessons Learned on Implementing Expert Elicitation," October 13, 2016. (NRC ADAMS Accession No. ML16287A734) DUPLICATE OF REF 9.

53. Accident Tolerant Fuel Regulatory Activities, https://www.nrc.gov/reactors/atf/related-docs.html.

54. M. Khatib-Rahbar, A. Krall, Z. Yuan, and M. Zavisca, Review of Accident Tolerant Fuel Concepts with Implications to Severe Accident Progression and Radiological Releases, Final Report, ERI/NRC 20-209, Energy Research, Inc., October 2020. (NRC ADAMS Accession No. ML20287A477).

55. D. J. Diamond, N. R. Brown, R. Denning, and S. Bajorek, Phenomena Important in Modeling and Simulation of Molten Salt Reactors, BNL-114869-2018-IR, April 23, 2018. (NRC ADAMS Accession No. ML18124A330).

56. M. Bales, "Phenomena Identification and Ranking Tables, WHY and HOW," February 26, 2018 (NRC ADAMS Accession No. ML18057A212)

57. W. Wieselquist, A. Lo, J. W. Bae, B. Betzler, F. Bostelmann, and S. Skutnik, Overview of MSR Capabilities in SCALE, Oak Ridge National Laboratory, MSR PIRT Working Group, Zoom Virtual Meeting, April 29, 2021.

58. W. A. Wieselquist, R. A. Lefebvre, and M. A. Jessee, Eds., SCALE Code System, ORNL/TM2005/39, Version 6.2.4, Oak Ridge National Laboratory, Oak Ridge, TN (2020).

59. B. R. Betzler, J. J. Powers, and A. Worrall, "Molten Salt Reactor Neutronics and Fuel Cycle Modeling and Simulation with SCALE," Annals of Nuclear Energy, Volume 101 (2017).

60. GOTHIC Thermal Hydraulic Analysis Package, Version 8.3 (QA). EPRI, Palo Alto, CA: (2018).

61. 10 CFR 50, Appendix B, "Quality Assurance Criteria for Nuclear Power Plants and Fuel Reprocessing Plants,” June 14, 2021.

62. ASME NQA-1-2019, "Quality Assurance Program Requirements for Nuclear Facility Applications," December 31, 2019.

63. R. C. Harvill, J. W. Lane, J. M. Link, S. W. Claybrook, T. L. George \& T. Kindred (2021), "SteadyState and Transient Benchmarks of GOTHIC to the Molten Salt Reactor Experiment," Nuclear Technology.

64. Holcomb, D., A. Huning, A.G. Yigitoglu, W.P. Poore and G.F. Flanagan, Molten Salt Reactor Initiating Event and Licensing Basis Event Workshop Summary, ORNL/TM-2019/1246, July 2019: Accident Scenarios.

65. J. McMurray, N. D. Bull Ezell, D. Andersson, C. Jiang, T. Besmann, Molten Salt Reactor Chemistry, Properties, Database Development and Modeling, Molten Salt Reactor Workshop, October 2020.

66. Wang, Z.J., M. Chen and Z.Y. Guo, “A Nonequilibrium Molecular Dynamics Simulation of Evaporation,” Int. Conf. Passive and Low Energy Cooling for the Built Environment, May 2005.

67. Rosenthal, M.W., R.B. Briggs and P.R. Kosten, Molten-Salt Reactor Program, Semiannual Progress Report for Period Ending February 29, 1968, ORNL-4254, August 1968.

68. Ahlers, G., X. He, D. Funfschilling and E. Bodenschatz, "Heat Transport by Turbulent RayleighBénard Convection for $\operatorname{Pr} \approx 0.8$ and $3 \times 1012 \leq \mathrm{Ra} \leq 1015$ : Aspect Ratio," New Journal of Physics, Vol. 14, 2012. 
69. Dinh, T.N., Y.Z. Yang, J. P. Tu, R.R. Nougaliev and T.G. Theofanous, "Rayleigh-Bénard Natural Convection Heat Transfer: Pattern Formation, Complexity and Predictability," ICAPP 04, June 2004

70. Chaleff, E.S., T. Blue and P. Sagharwall, "Radiation Heat Transfer in the Molten Salt FLiNaK," Nuclear Technology, Vol. 196, pp 53-60, October 2016.

71. Beall, S., P. Haubenreich, R. Lindauer, J. Tallackson, MSRE Design and Operations Report, Part V, Reactor Safety Analysis Report, ORNL-TM-732, 1964.

72. Beeny, B., L. Humphries and D. Luxat, MELCOR Modeling Capabilities for Molten Salt Reactors, MSR Workshop 2019, October 2019.

73. Fei, T, B. Hua, F. Heidet and R. Hu, "MSRE Transient Benchmarks Using SAM," PHYSOR 2020, March 29 - April 2, 2020.

74. Benes O, Konings R. Thermodynamic Calculations of Molten Salt Reactor Fuel Systems. In: Frederic Lantelme, Henri Groult, editors. Molten Salts Chemistry - From Lab to Applications. Amsterdam (The Netherlands): Elsevier; 2013. p. 49 - 78. JRC83724

75. McFarlane, J., P. Taylor, D. Holcomb and W.P. Poore, Review of Hazards Associated with Molten Salt Reactor Fuel Processing Operations, ORNL/TM-2019/1195, June 2019.

76. US Nuclear Regulatory Commission, NRC Non-Light Water Reactor (Non-LWR) Vision and Strategy, Volume 3: Computer Code Development Plans for Severe Accident Progression, Source Term, and Consequence Analysis, ADAMS Accession Number: ML19093B404 (April 2019).

77. Brown, N.R., J.J. Powers, D.E. Mueller, and B.W. Patton, Complete Sensitivity/Uncertainty Analysis of LR-O Reactor Experiments with MSRE FLiBe Salt and Perform Comparison with Molten Salt Cooled and Molten Salt Fueled Reactor Models, ORNL/TM-2016/729, 2016.

78. Betzler, B.R., J.J. Powers, N.R. Brown and B.T. Rearden, "Implementation of Molten Salt Reactor Tools in SCALE," Int. Conf. on Math. and Comp. Methods Applied to Nucl. Science and Engineering, April 2017.

79. McMurray, J., et al., Multi-Physics Simulations for Molten Salt Reactor Evaluation: Chemistry Modeling and Database Development, ORNL/SPR-2018/864, June 2018.

80. A. N. Smith and M. Bell, Distribution of Decay Heat in the MSBR Off-Gas System, Section 7.2.2 of Molten-Salt Reactor Program Semi Annual Progress Report For Period Ending February 28, 1969 , ORNL-4396, August 1969. 
APPENDIX A. SCENARIO CATEGORY WORKSHEETS 



\section{APPENDIX A. SCENARIO CATEGORY WORKSHEETS}

This appendix contains the PIRT panel-identified phenomena for each scenario category presented at the start of the elicitation phase. The scenario categories for which accident phenomena (that may challenge a fundamental safety function) are identified include:

I. Salt spill accidents,

II. Dynamic system thermal/hydraulic/power response event,

III. Water-molten salt interactions,

IV. Accident criticality,

V. Emergency response system failures, and,

VI. Radwaste management system failures.

This initial list of scenario categories was developed by the PIRT technical integration team based on several MSR and accident analysis sources. During the elicitation process, two recommendations were made regarding the initially proposed list:

1. That Scenario Category III, "Water-molten salt interactions," be treated as a single phenomenon rather than a category containing multiple unique phenomena, and,

2. that Scenario Category V, "Emergency response system failures," be excluded from PIRT discussions because of the overwhelming significance of specific design information which has an impact on identifying phenomena related to this category, as well as an impact on the importance and knowledge level of any identified phenomena.

Therefore, the list of scenario categories for which the PIRT panel identified phenomena is shown in Table 14.

Table 14. Scenario categories

\begin{tabular}{|c|l|c|}
\hline ID\# & Scenario category & Page \\
\hline I & Salt spill accidents & A-4 \\
\hline II & Dynamic system thermal/hydraulic/power response event & A-9 \\
\hline IV & Accident criticality & A-11 \\
\hline VI & Radwaste management system failures & A-12 \\
\hline
\end{tabular}




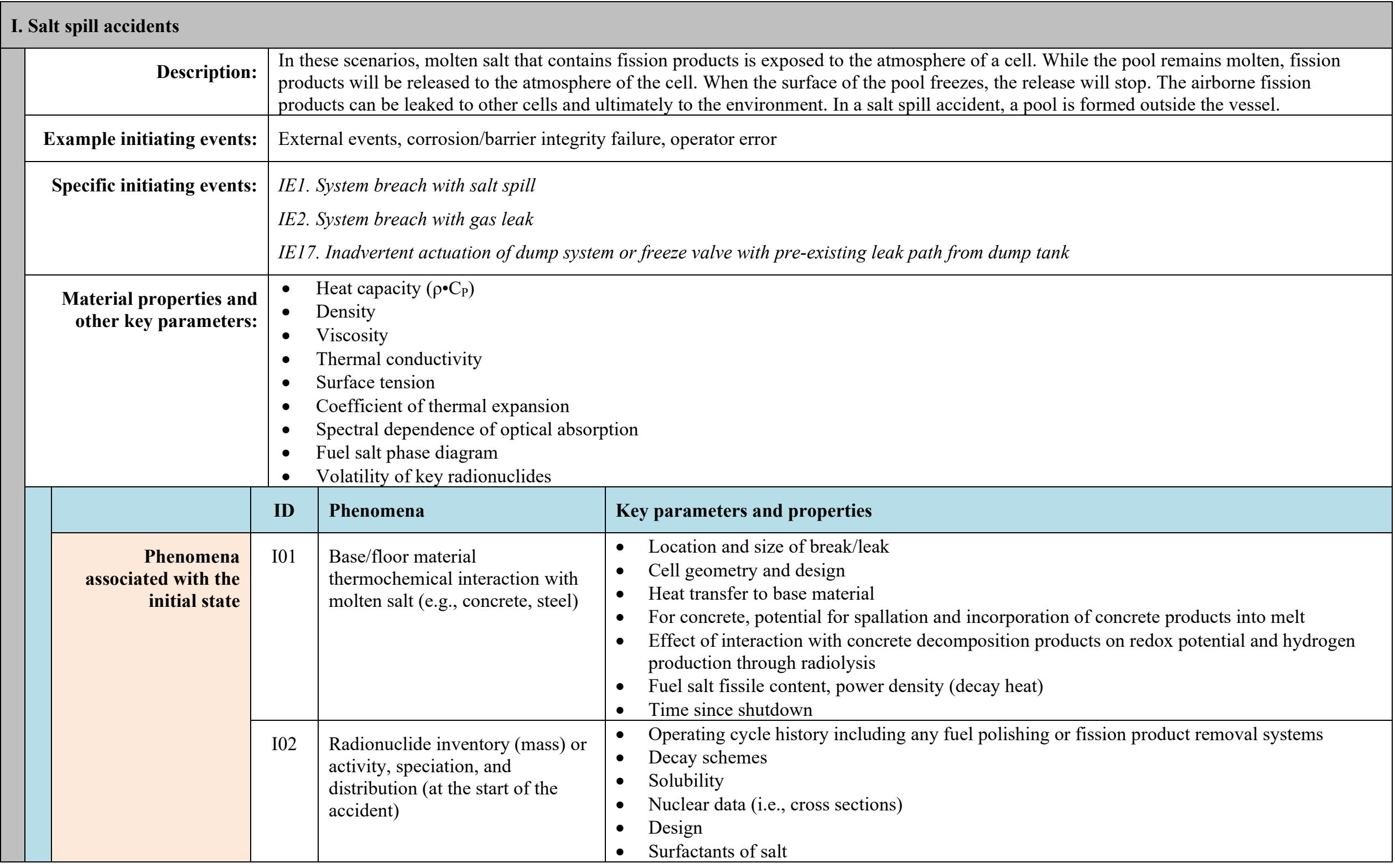




\begin{tabular}{|c|c|c|c|}
\hline \multicolumn{4}{|l|}{ I. Salt spill accidents } \\
\hline & $\mathrm{I} 03$ & $\begin{array}{l}\text { Mass/volume and energy of } \\
\text { molten salt (fueled salt) pool }\end{array}$ & $\begin{array}{l}\text { - Location and size of breach/leak } \\
\text { - } \quad \text { Cell geometry and design } \\
\text { - } \\
\text { - Health and condition of the system or the nature of the external event (e.g., seismic event) } \\
\text { - } \quad \text { Deposition of salt along leak path and potential for subsequent release }\end{array}$ \\
\hline & I04 & $\begin{array}{l}\text { Initial temperature of molten salt } \\
\text { pool and structures within the } \\
\text { volume }\end{array}$ & $\begin{array}{l}\text { - } \quad \text { Plant operating conditions } \\
\text { - } \quad \text { Cell geometry and design } \\
\text { - Heat transfer from the salt during initial spreading phase }\end{array}$ \\
\hline & $\mathrm{I} 05$ & Molten salt spreading & $\begin{array}{l}\text { - Fuel salt tends to flow like a low-viscosity fluid at high temperature } \\
\text { - Phase change can limit extent of spreading (i.e., increased viscosity and solidification at the } \\
\text { melt front, limiting progression) } \\
\text { - Location of break/leak relative to walls of compartment affects spreading } \\
\text { - } \begin{array}{l}\text { Cell geometry and design (if wall is contacted prior to solidification of melt front) affects } \\
\text { - The presence of oxides and contaminant could impact spreading }\end{array} \\
\text { - Fuel salt properties, particularly viscosity, surface tension, and solidification temperature affect } \\
\text { - Salt may "climb" walls due to capillary action (in which the adhesion force between the salt } \\
\text { and the wall exceeds the cohesive force of the salt, meniscus effect). Most likely observed for } \\
\text { small containers (with high circumference to surface area, such as small containers and lids) }\end{array}$ \\
\hline & I06 & Salt fragmentation & $\begin{array}{ll}\text { - } & \text { Break characteristics lead to mechanical fragmentation } \\
\text { - } & \text { Height of drop leads to splash droplets } \\
\text { - } & \text { Salt surface tension affects fragmentation } \\
& \text { Droplet size distribution is affected by level of fragmentation }\end{array}$ \\
\hline $\begin{array}{r}\text { Transient behavior } \\
\text { phenomena }\end{array}$ & I07 & $\begin{array}{l}\text { Generation of dross/crust layer on } \\
\text { surface of salt pool }\end{array}$ & $\begin{array}{ll}- & \text { Presence of contaminants within the salt } \\
\text { - } & \text { Oxidation of salt, fission products, and contaminates within salt } \\
\text { - } & \text { Density of dross } \\
\text { - } & \text { Freezing point of dross } \\
\end{array}$ \\
\hline
\end{tabular}




\begin{tabular}{|c|c|c|c|}
\hline \multicolumn{4}{|l|}{ I. Salt spill accidents } \\
\hline & $\mathrm{I} 08$ & $\begin{array}{l}\text { Vaporization and release of salt } \\
\text { components and radioactive } \\
\text { material from the surface of a } \\
\text { molten salt pool }\end{array}$ & $\begin{array}{l}\text { - } \\
\text { - } \\
\text { - } \\
\text { - } \\
\text { functivity coeffion of temperature, are being developed for key fission product species/fuel salt couples } \\
\text { return of vapors to the pool have been developed (although not for molten salts), which } \\
\text { indicates that empirical correction terms are required for emitted and returning vapors } \\
\text { - } \quad \text { Noble gases have low solubility and form bubbles in the molten salt pool } \\
\text { - Potential may exist for dross layer (such as products of oxidation by cell atmosphere or } \\
\text { concentration of insoluble particles such as graphite fragments at surface of molten pool) that } \\
\text { impacts heat transfer and transport of radionuclides to the cell atmosphere } \\
\text { - Freezing of salt effectively terminates release } \\
\text { Diffusive transport of radionuclides through boundary layer of cell atmosphere may retard } \\
\text { release to the atmosphere } \\
\text { Application of compartment cooling system could reduce the temperature of the atmosphere } \\
\text { and the surface temperature of the pool }\end{array}$ \\
\hline & $\mathrm{I} 10$ & $\begin{array}{l}\text { Reactions with fuel salt and } \\
\text { atmosphere }\end{array}$ & $\begin{array}{ll}\text { - } & \text { Oxygen and moisture content of cell atmosphere } \\
\text { - } & \text { Reaction rates and salt/atmosphere interfacial contact during release period } \\
\text { - } & \text { Imponvection within the cell atmosphere resulting in contact with salt surface } \\
\text { - } & \text { Greater potential impact on chloride salts } \\
\text { - } & \text { Impact on chemical forms of fission products and actinides }\left(\mathrm{UO}_{2}, \mathrm{PuO}_{2} \text { precipitation }\right) \\
\end{array}$ \\
\hline & I11 & $\begin{array}{l}\text { Bubble rupture and splash at the } \\
\text { surface of a molten salt pool }\end{array}$ & $\begin{array}{ll}\text { - } & \text { Bubble size and concentration of non-condensable gases within pool } \\
\text { - } & \text { Bubble rise velocity } \\
\text { - } & \text { Salt density, viscosity, surface tension } \\
\text { - } & \text { Bubble splash size distribution and quantity } \\
& \text { Bubble transport of noble gas parents of reactive fission products }\left({ }^{91} \mathrm{Kr},{ }^{91} \mathrm{Sr},{ }^{92} \mathrm{Kr},{ }^{92} \mathrm{Sr},{ }^{93} \mathrm{Kr},\right. \\
& \left.{ }^{137} \mathrm{Xe},{ }^{137} \mathrm{Cs},{ }^{139} \mathrm{Xe},{ }^{139} \mathrm{Ba},{ }^{140} \mathrm{Xe},{ }^{140} \mathrm{Ba}\right)\end{array}$ \\
\hline & $\mathrm{I} 12$ & Beta-recoil droplet release & $\begin{array}{ll} & \text { Droplet formation phenomenon observed in MSRE experiments leading to airborne droplets in } \\
\text { - } & \text { Surface tension } \\
\text { - } & \text { Surfactant layers }\end{array}$ \\
\hline
\end{tabular}




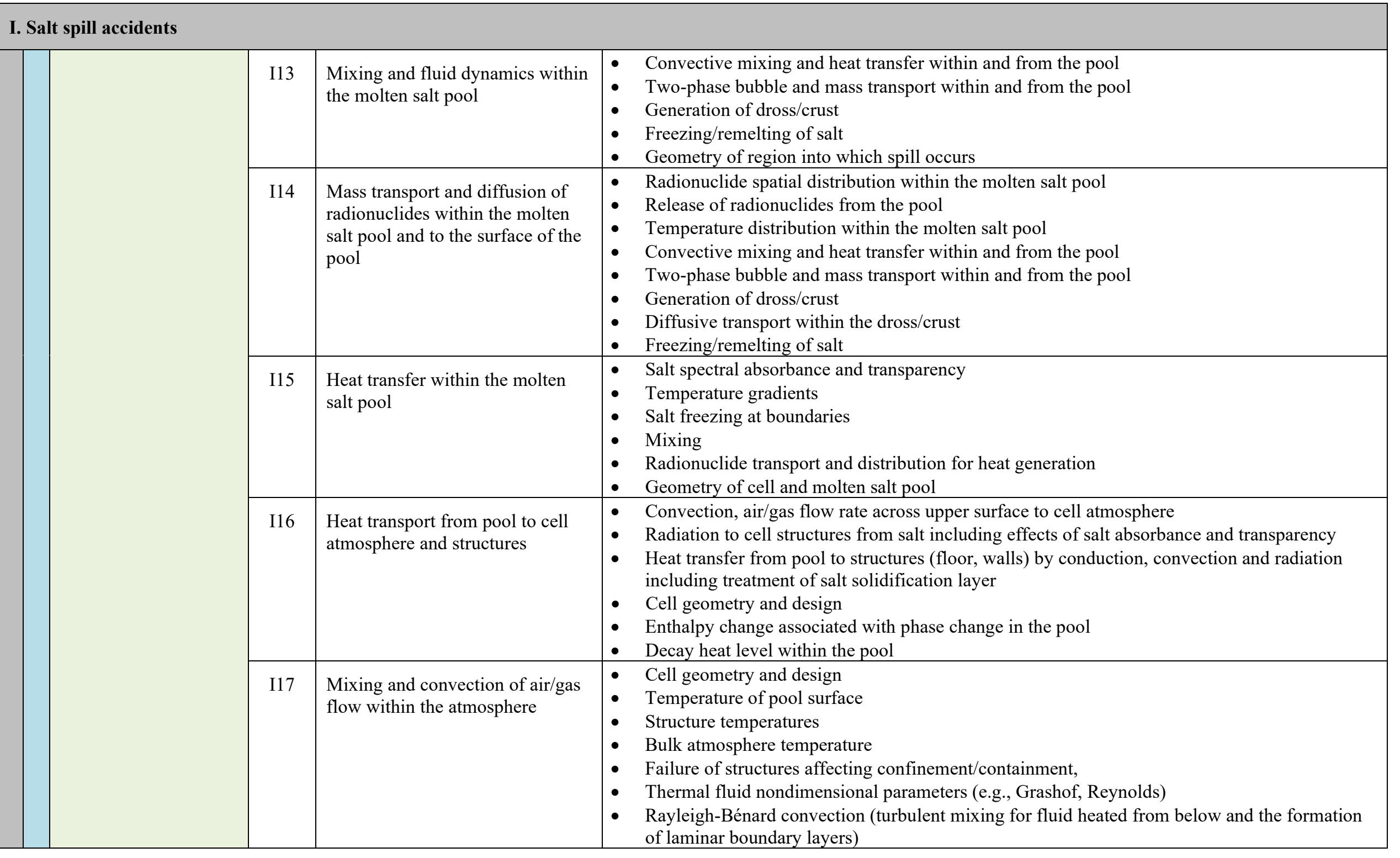




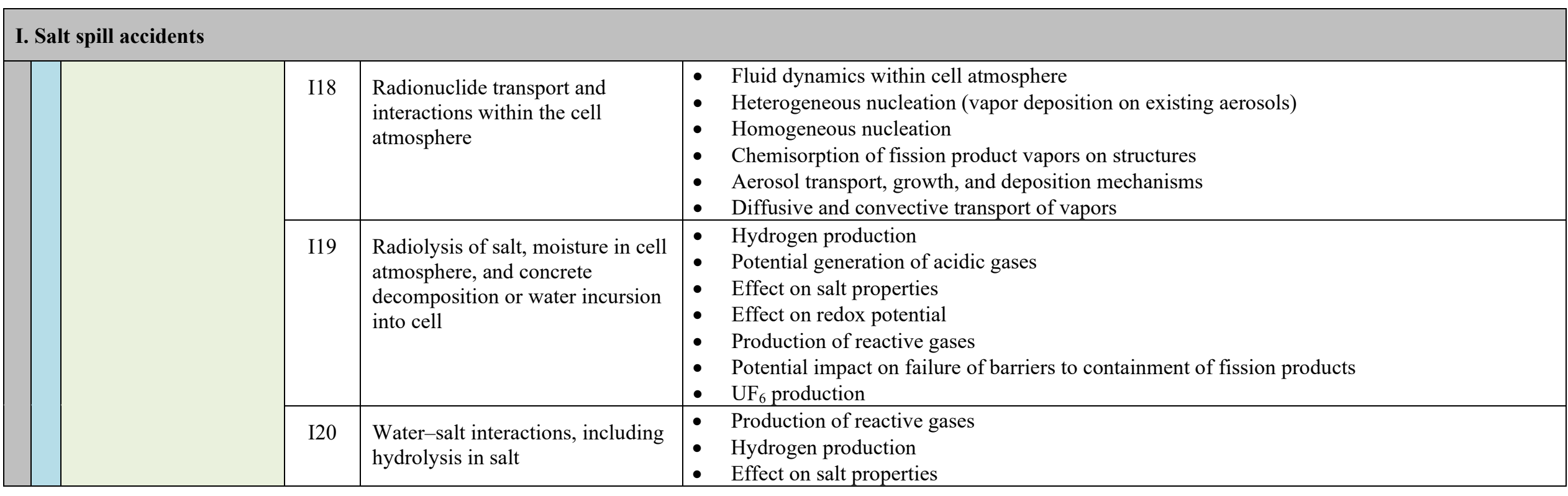




\begin{tabular}{|c|c|c|}
\hline Description: & \multicolumn{2}{|c|}{$\begin{array}{l}\text { These scenarios require the use/development of transient analysis codes that can predict thermal/hydraulic/nuclear/radionuclide behavior over } \\
\text { two-time scales (an operating cycle, as needed by the plant for fuel management) and over the time period of an accident (analogous to } \\
\text { RELAP5 or MELCOR). For a perturbation in component behavior, the accident analysis code must be capable of modeling the subsequent } \\
\text { response of the system. From the perspective of FOM1 (the most important FOM), it is essential to consider potential loss of primary system } \\
\text { integrity and the release of radioactive material. Thus, the potential for over-temperature/over-pressure conditions leading to a breach in the } \\
\text { system (including failure of seals) leading to the release of radioactive material to a secondary system or cell is an important consideration. } \\
\text { Unbalanced heat removal is represented by FOM2, and reactivity increase is represented in FOM3. These states represent vulnerabilities that } \\
\text { could result in a release of radioactive material at their extremes or in multi-fault accidents. The initial state critical parameters include all plant } \\
\text { operating conditions (e.g., temperature, pressure, system configuration, radionuclide distribution and chemical form.) at the start of the } \\
\text { scenario. Transient behavior includes the salt and system temperature, flow, pressure, and power responses due to some upset condition. } \\
\text { Potentially important sub-scenarios within this generic category include: } \\
\text { - Undercooling of the primary system, including decreased primary system flow, decreased secondary system flow, fouling of a } \\
\text { primary system heat exchanger, loss of pathway to the ultimate heat sink } \\
\text { - Overcooling of the primary system, including increased primary system flow, increased secondary system flow. } \\
\text { - Reactivity insertion events, including on-line fueling events, drain of non-fuel fluid in-core, reactivity control system failures, changes } \\
\text { in reflector effectiveness, changes in moderation, large redox shift (resulting in UC formation), graphite dimensional changes/fracture, } \\
\text { transport of graphite debris, accumulation and impact on other systems, and graphite tritium trap release }\end{array}$} \\
\hline Example initiating events: & \multicolumn{2}{|c|}{ External events, component failures, operator error } \\
\hline Specific initiating events: & \multicolumn{2}{|c|}{$\begin{array}{l}\text { IE3. High primary flow } \\
\text { IE4. Low primary flow } \\
\text { IE5. Flow blockage } \\
\text { IE13/IE16. Primary system overcooling } \\
\text { IE14. Primary system undercooling } \\
\text { IE27. Failures in salt property management } \\
\text { IE34. Graphite migration } \\
\text { IE35. Uncontrolled rod withdrawal }\end{array}$} \\
\hline $\begin{array}{r}\text { Material properties and } \\
\text { other key parameters: }\end{array}$ & \multicolumn{2}{|c|}{$\begin{array}{l}\text { - } \text { Parameters associated with the plant's operating state at the start of the transient or accident } \\
\text { - } \\
\text { - } \\
\text { - }\end{array}$} \\
\hline & Phenomena & Key parameters and properties \\
\hline
\end{tabular}




\section{Dynamic system thermal/hydraulic/power response}

\begin{tabular}{|c|c|c|c|}
\hline \multirow[t]{2}{*}{$\begin{array}{r}\text { Transient behavior } \\
\text { phenomena }\end{array}$} & II01 & $\begin{array}{l}\text { Over-temperature, over-pressure } \\
\text { conditions }\end{array}$ & $\begin{array}{l}\text { - State of heat transfer path to ultimate heat sink } \\
\text { - } \quad \text { Degradation and/or failure of passive systems, passive component reliability } \\
\text { - Heat capacity/storage of the system } \\
\text { - Temperature dependency and system performance } \\
\text { - Number of systems and start up times } \\
\text { - } \quad \text { Potential salt freezing in heat exchangers and core } \\
\text { System design and activation (normally running, etc.) }\end{array}$ \\
\hline & II02 & $\begin{array}{l}\text { Leak/rupture of primary heat } \\
\text { exchanger tube and radionuclide } \\
\text { release to secondary systems }\end{array}$ & $\begin{array}{l}\text { - } \\
\text { - } \quad \text { Fistivation products } \\
\text { - } \quad \text { Fuel salt leakage into the secondary coolant system } \\
\text { - Tritium transport and release } \\
\text { - Retention of radionuclides and release from graphite } \\
\text { - } \quad \text { Chemical compatibility of interfacing salts } \\
\text { - Thermophysical compatibility of interfacing salts (e.g., density and mechanical issues) }\end{array}$ \\
\hline
\end{tabular}




\begin{tabular}{|c|c|c|c|}
\hline \multicolumn{4}{|l|}{ IV. Accidental criticality } \\
\hline Description: & \multicolumn{3}{|c|}{ The initial state for this scenario is when fissile material accumulates in an accidental or uncontrolled manner which results in criticality. } \\
\hline Example initiating events: & \multicolumn{3}{|c|}{ External events, component failures, operator error } \\
\hline Specific initiating events: & \multicolumn{3}{|c|}{ IE18. Precipitation of fissile material in tank } \\
\hline \multirow[t]{2}{*}{$\begin{array}{l}\text { Material properties and } \\
\text { other key parameters: }\end{array}$} & \multicolumn{3}{|c|}{$\begin{array}{l}\text { In addition to those in scenario Categories I and II: } \\
\text { - Solubility of radionuclide species in salt }\end{array}$} \\
\hline & ID & Phenomena & Key parameters and properties \\
\hline \multirow[t]{2}{*}{$\begin{array}{r}\text { Transient behavior } \\
\text { phenomena }\end{array}$} & IV01 & $\begin{array}{l}\text { Unrecognized accumulation of } \\
\text { fissile material }\end{array}$ & $\begin{array}{ll} & \text { Speciation } \\
\text { - } & \text { Temperature-dependent joint solubility of actinides } \\
\text { - } & \text { Flow or deposition rate of accumulated fissile material to the point of criticality } \\
\text { - Geometry and location of accumulation }\end{array}$ \\
\hline & IV02 & $\begin{array}{l}\text { Overcooling leading to } \\
\text { precipitation and accumulation }\end{array}$ & $\begin{array}{l}\text { - Subcritical multiplication (unlikely to threaten confinement of radioactive material) } \\
\text { - Supercriticality resulting in increased temperature and pressure in system } \\
\text { - } \text { Feedback mechanisms } \\
\text { - } \quad \text { Geomponent failure mechanisms leading to radionuclide release } \\
\end{array}$ \\
\hline
\end{tabular}




\begin{tabular}{|c|c|c|c|}
\hline \multicolumn{4}{|c|}{ VI. Radwaste management system } \\
\hline Description: & \multicolumn{3}{|c|}{$\begin{array}{l}\text { Radionuclide sources for liquid-fueled MSRs are expected to span beyond just the core region and may include fission product removal and } \\
\text { other radwaste management systems. The initial state for these scenarios is highly dependent on the system design and the location of the } \\
\text { failure. }\end{array}$} \\
\hline Example initiating events: & \multicolumn{3}{|c|}{ External events, component failures, operator error } \\
\hline Specific initiating events: & \multicolumn{3}{|c|}{ IE38. Fuel processing system and radwaste storage system failures } \\
\hline \multirow[t]{2}{*}{$\begin{array}{r}\text { Material properties and } \\
\text { other key parameters: }\end{array}$} & \multicolumn{3}{|c|}{$\begin{array}{l}\text { In addition to the properties in other categories: } \\
\text { - Radwaste chemical and physical forms }\end{array}$} \\
\hline & ID & Phenomena & Key parameters and properties \\
\hline $\begin{array}{r}\text { Transient behavior } \\
\text { phenomena }\end{array}$ & VI01 & $\begin{array}{l}\text { Radwaste and other non-fuel } \\
\text { radioactive gas/fluid system } \\
\text { failures }\end{array}$ & $\begin{array}{ll}\text { - } & \text { Radwaste chemical and physical forms } \\
\text { - } & \text { Operating history, source magnitude } \\
\text { - } & \text { Failure modes } \\
\text { - } & \text { Design of the system and barriers to release }\end{array}$ \\
\hline
\end{tabular}


APPENDIX B. PHENOMENA RANKING WORKSHEETS 



\section{APPENDIX B. Phenomena Ranking Worksheets}

This appendix contains the worksheets for each phenomenon ranked during the elicitation phase of each PIRT meeting. A table of contents for this appendix is shown in Table 15.

For reference, the phenomena are ranked against the figures of merit (Table 16) according to the ranking values shown in 
Table 17.

Table 15. Ranked phenomena and page location

\begin{tabular}{|c|l|c|}
\hline ID\# & Phenomenon name & B-3 \\
\hline I01 & Base/floor material thermochemical interactions with molten salt (e.g., concrete, steel) & B-5 \\
\hline I02 & Radionuclide inventory (mass) or activity, speciation, and distribution & B-7 \\
\hline I03 & Mass/volume and energy of molten salt (fueled salt) pool & B-8 \\
\hline I04 & Initial temperature of molten salt pool and structures within the volume & B-9 \\
\hline I05 & Molten salt spreading & B-10 \\
\hline I06 & Salt fragmentation & B-11 \\
\hline I07 & Generation of dross/crust layer on surface of salt pool & B-13 \\
\hline I08 & $\begin{array}{l}\text { Vaporization and release of salt components and radioactive material from the surface of a } \\
\text { molten salt pool }\end{array}$ & B-15 \\
\hline I09 & Solubility of constituents within the salt pool & B-16 \\
\hline I10 & Reactions with fuel salt and atmosphere & B-18 \\
\hline I11 & Bubble rupture and splash at the surface of a molten salt pool & B-19 \\
\hline I12 & Beta-recoil droplet release & B-20 \\
\hline I13 & Mixing and fluid dynamics within the molten salt pool & B-21 \\
\hline I14 & $\begin{array}{l}\text { Mass transport and diffusion of radionuclides within the molten salt pool and to the surface of } \\
\text { the pool }\end{array}$ & B-22 \\
\hline I15 & Heat transfer within the molten salt pool & B-24 \\
\hline I16 & Heat transport from pool to cell atmosphere and structures & B-26 \\
\hline I17 & Mixing and convection of air/gas flow with the atmosphere & B-27 \\
\hline I18 & Radionuclide transport and interactions within the cell atmosphere & B-28 \\
\hline I19 & $\begin{array}{l}\text { Radiolysis of salt, moisture in cell atmosphere, and concrete decomposition or water incursion } \\
\text { into cell }\end{array}$ & B-30 \\
\hline I20 & Water-salt interactions, including hydrolysis in salt & B-32 \\
\hline II01 & Over-temperature, over-pressure conditions & B-34 \\
\hline II02 & Leak/rupture of primary heat exchanger tube and radionuclide release to secondary systems & B-35 \\
\hline IV01 & Unrecognized accumulation of fissile material & B-36 \\
\hline IV02 & Overcooling leading to precipitation and accumulation & B-37 \\
\hline VI01 & Radwaste and other non-fuel radioactive gas/fluid system failures &
\end{tabular}

Table 16. Figure of merit definitions (repeated for Appendix B)

\begin{tabular}{|l|l|}
\hline FOM-1 & Potential for release of fission products and/or barrier integrity failure \\
\hline FOM-2 & Potential for unbalanced heat removal \\
\hline FOM-3 & Potential for uncontrolled nuclear reaction \\
\hline
\end{tabular}


Table 17. Figure of merit ranking definitions (repeated for Appendix B)

\section{Importance $\quad$ State of knowledge}

\begin{tabular}{|l|l|l|l|}
\hline $\mathbf{H}$ & $\begin{array}{l}\text { High: The phenomenon has a controlling impact } \\
\text { on the FOM. }\end{array}$ & $\mathbf{3}$ & $\begin{array}{l}\text { Models exist, supported by validation experiments. } \\
\text { Data exist for the underlying properties over the } \\
\text { range of applications (e.g., thermophysical } \\
\text { properties). }\end{array}$ \\
\hline $\mathbf{M}$ & $\begin{array}{l}\text { Medium: The phenomenon has a moderate } \\
\text { impact on the FOM. }\end{array}$ & $\mathbf{2}$ & $\begin{array}{l}\text { Models exist that can be extended to the required } \\
\text { application but with the need for additional data, } \\
\text { theoretical development, or validation. }\end{array}$ \\
\hline $\mathbf{L}$ & $\begin{array}{l}\text { Low: The phenomenon has a minimal impact on } \\
\text { the FOM. }\end{array}$ & $\mathbf{1}$ & $\begin{array}{l}\text { Models either do not exist, are simplistic, or have } \\
\text { insufficient data. }\end{array}$ \\
\hline $\mathbf{I}$ & \multicolumn{2}{|l|}{ Insignificant: The phenomenon has insignificant or no impact on the FOM. } \\
\hline
\end{tabular}




\begin{tabular}{|c|c|c|}
\hline \multicolumn{2}{|c|}{ Scenario categories: } & I. Salt spill accident \\
\hline & Description: & In a salt spill accident, the molten salt lands on a surface or floor. Thermochemical interactions may occur. \\
\hline \multicolumn{2}{|c|}{ Key parameters and properties: } & $\begin{array}{ll}\text { 1. } & \text { Location and size of break/leak } \\
\text { 2. } & \text { Cell geometry and design } \\
\text { 3. Heat transfer to base material } \\
\text { 4. For concrete, potential for spallation and incorporation of concrete products into melt } \\
\text { 5. Effect of interaction with concrete decomposition products on redox potential and hydrogen production through radiolysis } \\
\text { 6. } & \text { Fuel salt fissile content, power density (decay heat) } \\
\text { 7. } & \text { Time since shutdown } \\
\end{array}$ \\
\hline \multicolumn{2}{|c|}{ Importance } & Considerations \\
\hline FOM-1 & $\begin{array}{c}\mathbf{M}-\mathbf{H} \\
\text { (Concrete) }\end{array}$ & $\begin{array}{l}\text { - Insulation layer may be provided between steel and concrete. } \\
\text { - Fission product release to cell volume/atmosphere could be significantly modified by concrete interaction; interaction with steel is } \\
\text { - } \\
\text { likely to be limited. } \\
\text { - } \text { - Fissich ins designs willes oxygen and water vapor. } \\
\text { - Heat load in gases along with spilled salt could impact barrier integrity. } \\
\text { - Possible hydrogen generation with interaction with concrete associated with the release of bound water. } \\
\text { - Japanese SFR (MONJU) accident involving spill of secondary sodium could have similar behavior to a molten salt spill. There has } \\
\text { also been significant research associated with molten } \mathrm{UO}_{2} / \text { zirconium mixtures with concrete. }\end{array}$ \\
\hline FOM-2 & $\mathbf{M}$ & $\begin{array}{l}\text { - } \quad \text { Warping of base/floor material could lead to interactions between fuel salt and underlying floor materials. } \\
\text { - } \quad \text { Temperatures of fuel salt and steel have a major impact on heat removal. } \\
\text { - } \quad \text { Location of spill also impacts heat removal. } \\
\text { - } \quad \text { Heatity of fuel salt spilled is directly related to energy released to compartment. } \\
\end{array}$ \\
\hline FOM-3 & $\mathbf{L}-\mathbf{M}$ & $\begin{array}{l}\text { - For low-enriched fuels there is a low potential for criticality; highly enriched fuels could have a moderate impact, depending on } \\
\text { geometry. } \\
\text { - For those designs with a breeder blanket salt, spill of breeder blanket salt (loss of absorption) could lead to a criticality accident. } \\
\text { Reflector blanket, if present, would not have an impact. }\end{array}$ \\
\hline
\end{tabular}




\begin{tabular}{|c|c|c|}
\hline \multicolumn{2}{|c|}{ Knowledge } & Considerations \\
\hline FOM-1 & $1-2$ & $\begin{array}{l}\text { - Some aspects of the interaction of the molten salt with the floor material are calculable, at least in a bounding sense, based on } \\
\text { available knowledge from fast reactor and LWR experience }(1,2) \text {. } \\
\text { - Salt property data are to a large degree now available, particularly for fluoride salts, because of the MSRE experience [4], but are not } \\
\text { as affected by concrete decomposition products. } \\
\text { - Thus, the state of knowledge of molten salt interaction with steel is higher than that of concrete. } \\
\text { Property data affecting fission product release from chloride salt spills are limited, particularly as related to the longer-term behavior } \\
\text { of the melt. }\end{array}$ \\
\hline FOM-2 & $1-2$ & $\begin{array}{l}\text { - Models exist that can be used to assess the thermal hydraulic behavior of spilled salt, but the associated uncertainties are large, } \\
\text { - Templicularly for a spill onto concrete. } \\
\text { - } \\
\text { associated with the magnitude of the spill, location within the compartment, and geometry of the compartment. } \\
\text { be applied, but major uncertainties exist regarding limitations of applicability. }\end{array}$ \\
\hline FOM-3 & $2-3$ & $\begin{array}{l}\text { - } \quad \text { Given a known configuration of material, nuclear data and physics tools have high certainty regarding ability to predict reactivity. } \\
\text { - The SCALE development program is well-focused on resolving residual uncertainties [4]. } \\
\text { - However, the ability to accurately predict the geometry and distribution of materials following the salt spill are very limited, } \\
\text { - } \begin{array}{l}\text { Unless the geometry of the comparterent is quite confined (such that the geometry has a small aspect ratio) and the amount of fissile } \\
\text { material release is large, criticality after a spill is quite unlikely. }\end{array}\end{array}$ \\
\hline Additio & $\begin{array}{l}\text { cription and } \\
\text { rationale: }\end{array}$ & Importance and knowledge for spills onto concrete may be substantially different for concrete than for steel. \\
\hline & References: & $\begin{array}{l}\text { [1] See Japanese SFR (MONJU) accident, which is a secondary sodium spill. } \\
\text { [2] B. R. Sehgal, "Nuclear Safety in Light Water Reactors," AP 2012. Molten core concrete interactions. } \\
\text { [3] R. R. Romatoski and L.W. Hu, "Fluoride Salt Coolant Properties for Nuclear Reactor Applications: A Review," Annals of Nuclear } \\
\text { Energy, 109, } 2017 \text { pp 635-647. } \\
\text { [4] See MSR PIRT presentation on SCALE. }\end{array}$ \\
\hline
\end{tabular}




\begin{tabular}{|c|c|c|}
\hline \multicolumn{2}{|c|}{ Scenario categories: } & I. Salt spill accidents \\
\hline \multicolumn{2}{|r|}{ Description: } & The initial inventory or activity, chemical form, and spatial distribution of the radionuclides present in the molten salt pool. \\
\hline \multicolumn{2}{|c|}{ Key parameters and properties: } & $\begin{array}{l}\text { 1. Operating cycle history, including any fuel polishing or fission product removal systems } \\
\text { 2. Decay schemes } \\
\text { 3. Solubility of radionuclides } \\
\text { 4. Nuclear data (i.e., cross sections) } \\
\text { 5. Salt thermochemistry } \\
\text { 6. Surfactants of salt }\end{array}$ \\
\hline \multicolumn{2}{|c|}{ Importance } & Considerations \\
\hline FOM-1 & $\mathbf{H}$ & $\begin{array}{l}\text { - Necessary precursor to release of radionuclides from salt spill. The potential for environmental release is to a degree proportional to } \\
\text { the inventory released from the vessel. } \\
\text { - The speciation of radioactive material (e.g., the formation of CsI vs. the formation of } \mathrm{I}_{2} \text { or the binding of I tightly to an element in the } \\
\text { salt) has a major impact on the volatility of the radionuclide. } \\
\text { - The presence of debris, surfactants, or material that forms a layer on the surface of the molten pool could substantially impact } \\
\text { radionuclide release from the pool. }\end{array}$ \\
\hline FOM-2 & $\mathbf{H}$ & $\begin{array}{l}\text { Radionuclide decay provides a continuing heat source, delaying freezing of the pool. The total mass of high-temperature salt spilled } \\
\text { directly affects the heat balance within the compartment. }\end{array}$ \\
\hline FOM-3 & H & $\begin{array}{l}\text { - The fissile inventory of released salt directly affects the potential for criticality. } \\
\text { MSRs operate with low excess reactivity. Unless the spilled salt has high fissile content and nearly optimized geometry, the potential } \\
\text { for criticality is small. }\end{array}$ \\
\hline \multicolumn{3}{|c|}{ Knowledge } \\
\hline FOM-1 & 2 & $\begin{array}{l}\text { - The analysis of design basis accidents generally uses a conservative profile for distribution and inventory to account for } \\
\text { uncertainties. } \\
\text { - Immediately following release, distribution of radionuclides is likely to be approximately uniform, depending on the location of the } \\
\text { breach and the quantity of fuel salt spilled. } \\
\text { Online systems and control provide data such that the operator knows the conditions within the reactor coolant system immediately } \\
\text { prior to the assumed event. Nevertheless, validated models (affecting all three FOMs) do not exist. } \\
\text { - Surfactants that affect radioactive material release from the pool may exist within the operating reactor that are released with the salt } \\
\text { or added as a contaminant from the compartment environment. } \\
\text { - If the release from the compartment is filtered, then the effectiveness of the filter will depend on the characteristics of released } \\
\text { radioactive material (as vapors or aerosols with filter efficiency, a function of aerosol size distribution). } \\
\text { - The extent to which a plant would be allowed to continue to operate with known leakage would be dependent on technical } \\
\text { specification restrictions determined at the time of licensing. Nevertheless, any persistent leak rates would have to be very small. }\end{array}$ \\
\hline
\end{tabular}




\begin{tabular}{|c|c|c|}
\hline FOM-2 & 2 & $\begin{array}{l}\text { - The state of knowledge of the quantity and distribution of material released as it affects heat distribution is similar to that for FOM1. } \\
\text { At the time of the assumed event, the operator knows the distribution of material within the reactor coolant system with reasonable } \\
\text { accuracy. }\end{array}$ \\
\hline FOM-3 & 2 & $\begin{array}{l}\text { - The state of knowledge of the quantity and distribution of fissile inventory is well known by the operator at the time of the assumed } \\
\text { event. The amount that is released to the spilled salt pool depends on the assumed break locations. }\end{array}$ \\
\hline \multicolumn{2}{|c|}{$\begin{array}{r}\text { Additional description and } \\
\text { rationale: }\end{array}$} & $\begin{array}{l}\text { This scenario is based on what is known at } \mathrm{t}=0 \text { (the start of the accident) and the assumed location of the break in the system. } \\
\text { Radionuclides, debris, surfactants, and other items that form a film on the surface of a spill were important to MSRE. } \\
\text { It is not clear whether interactions with the atmosphere could lead to development of an oxide crust. }\end{array}$ \\
\hline \multirow{5}{*}{\multicolumn{2}{|c|}{ References: }} & [1] See MSR PIRT presentation on SCALE. \\
\hline & & $\begin{array}{l}\text { [2] Betzler, B.R., J.J. Powers, N.R. Brown and B.T. Rearden, "Implementation of Molten Salt Reactor Tools in SCALE," Int. Conf. on } \\
\text { Math. and Comp. Methods Applied to Nucl. Science and Engineering, April } 2017 .\end{array}$ \\
\hline & & $\begin{array}{l}\text { [3] Brown, N.R., J.J. Powers, D.E. Mueller, and B.W. Patton, Complete Sensitivity/Uncertainty Analysis of LR-0 Reactor Experiments } \\
\text { with MSRE FLiBe Salt and Perform Comparison with Molten Salt Cooled and Molten Salt Fueled Reactor Models, ORNL/TM- } \\
\text { 2016/729, December } 2016 .\end{array}$ \\
\hline & & $\begin{array}{l}\text { [4] Chisholm, B., S. Krahn, A. Afzali, and E. Harvey, "Application of a Method to Estimate Risk in Advanced Nuclear Reactors - A } \\
\text { Case Study on the MSRE," Probabilistic Safety Assessment and Management, September } 2018 .\end{array}$ \\
\hline & & $\begin{array}{l}\text { [5] Piro, M.H.A., S. Simunovic, T. M. Besmann, B.J. Lewis and W.T. Thomson, "The Thermochemistry Library Thermochimica," } \\
\text { Computational Materials Science, Vol. 67, 2013, pp 266-272. }\end{array}$ \\
\hline
\end{tabular}




\begin{tabular}{|c|c|c|}
\hline \multicolumn{2}{|c|}{ Scenario categories: } & I. Salt spill accidents \\
\hline & Description: & In a salt spill accident, this is the quantity of salt (volume and mass) that is transported beyond the salt boundary. \\
\hline \multicolumn{2}{|c|}{ Key parameters and properties: } & $\begin{array}{l}\text { 1. Location and size of breach/leak } \\
\text { 2. Cell geometry and design } \\
\text { 3. Leak flow rate } \\
\text { 4. Health and condition of the system or the nature of the external event (e.g., seismic event) which leads to the break } \\
\text { 5. Deposition of salt along leak path and potential for subsequent release }\end{array}$ \\
\hline \multicolumn{2}{|c|}{ Importance } & Considerations \\
\hline FOM-1 & $\mathbf{H}$ & $\begin{array}{l}\text { - Magnitude of radionuclide release to environment is directly related to quantity released from the reactor coolant system to the salt } \\
\text { pool. } \\
\text { The height and mode of release from reactor coolant system could affect the formation and size of airborne droplets, mixing of air } \\
\text { with molten salt, and heat transfer to the compartment atmosphere. } \\
\text { - A non-fuel salt spill could also have some radioactive inventory. } \\
\text { - A pin-hole leak from the reactor coolant system could result in a high-velocity flow, the direct generation of salt droplets, and affect } \\
\text { the extent of chemical reaction with the compartment atmosphere and heat transfer to the atmosphere. }\end{array}$ \\
\hline FOM-2 & $\mathbf{H}$ & - Impact on heat imbalance effectively proportional to quantity and heat content of salt mass released from break/spill. \\
\hline FOM-3 & $\mathbf{H}$ & - $\quad$ Ability to form a critical mass directly impacted by mass spilled. \\
\hline \multicolumn{3}{|c|}{ Knowledge } \\
\hline FOM-1 & 2 & $\begin{array}{l}\text { - Given the location and characteristics of the break, properties of the salt are known sufficiently to reasonably predict the rate of } \\
\text { release, total release, and heat content of the released salt. } \\
\text { The potential for contaminants, such as the entrainment of insulation material, concrete decomposition products, and other materials } \\
\text { within the compartment could impact radionuclide release to the compartment atmosphere. The technical basis for assessing the } \\
\text { associated release of radionuclides from the salt pool requires further development and validation against prototypic integral effects } \\
\text { experiments. }\end{array}$ \\
\hline FOM-2 & 2 & $\begin{array}{l}\text { - The total release and heat content of the salt can be assessed using existing flow models and salt property data, but this requires } \\
\text { validation against prototypic integral experiments. }\end{array}$ \\
\hline FOM-3 & 2 & $\begin{array}{l}\text { - The total release and configuration of fissile material in the compartment can be predicted using available models. There is no direct } \\
\text { validation of ability to predict criticality, but the results of SCALE development activities indicate that this area is being adequately } \\
\text { addressed. }\end{array}$ \\
\hline \multicolumn{3}{|c|}{$\begin{array}{r}\text { Additional description and } \\
\text { rationale: }\end{array}$} \\
\hline & References: & \\
\hline
\end{tabular}




\begin{tabular}{|c|c|c|}
\hline \multicolumn{2}{|c|}{ Scenario categories: } & I. Salt spill accidents \\
\hline & Description: & The initial temperature of the molten salt, base/floor material, components, walls, and other structures impact the transient behavior. \\
\hline \multicolumn{2}{|c|}{ Key parameters and properties: } & $\begin{array}{ll}\text { 1. } & \text { Plant operating conditions } \\
\text { 2. } & \text { Cell geometry and design } \\
\text { 3. } & \text { Heat transfer from the salt during initial spreading phase }\end{array}$ \\
\hline \multicolumn{2}{|c|}{ Importance } & Considerations \\
\hline FOM-1 & $\mathbf{H}$ & $\begin{array}{l}\text { - Interaction of spilled salt with the salt atmosphere and surfaces will impact the initial temperature of the salt pool, as well as the } \\
\text { temperature of the compartment atmosphere. } \\
\text { - Conditions preceding failure of reactor coolant system (such as a reactivity excursion leading to failure of a component) could affect } \\
\text { the energy content of salt released from the reactor coolant system and the initial temperature of the salt pool. } \\
\text { - Thermal shock and/or warping of steel floor liner (or catch pan) could expose the concrete to the salt pool and impact the subsequent } \\
\text { release of radionuclides. } \\
\text { - Low temperature or a small quantity of spilled salt could lead to early freezing of salt and limited release of radionuclides. }\end{array}$ \\
\hline FOM-2 & $\mathbf{H}$ & - Temperature of salt has direct impact on the heat imbalance in the compartment. \\
\hline FOM-3 & $\mathbf{L}$ & - $\quad$ Mass of salt is more important than temperature on reactivity control. \\
\hline \multicolumn{3}{|c|}{ Knowledge } \\
\hline FOM-1 & 3 & $\begin{array}{l}\text { - The design organization has operating data to enable characterization of the temperature of the salt within the reactor coolant system } \\
\text { immediately prior to the event assumed to result in failure at a specified location of the reactor coolant system boundary. } \\
\text { The evolution of radioactive material from the pool is less sensitive to the initial temperature of the pool than it is to the longer-term } \\
\text { transport processes that bring the radionuclides to the surface of the pool, their evolution to the overlying atmosphere and transport } \\
\text { within the compartment atmosphere. }\end{array}$ \\
\hline FOM-2 & 2 & $\begin{array}{l}\text { - The state of knowledge of salt thermodynamic properties is either good or being addressed over the range of temperatures of } \\
\text { - } \\
\text { concern. } \\
\text { Depending on the mass of the salt spill relative to area of the compartment floor, the ability to predict the extent of salt spreading is } \\
\text { - } \quad \text { Dimited. } \\
\text { - Thermal interactions with a floor liner including the potential for warping or failure are not well modeled (lack validation). } \\
\text { Potential for formation of a crust or layer of frozen salt requires additional study. Such a layer would impact heat removal as well as } \\
\text { release of radionuclides. }\end{array}$ \\
\hline FOM-3 & 3 & $\begin{array}{l}\text { - The capability of SCALE tools to model reactivity (including temperature effects) is adequate given a defined configuration of fissile } \\
\text { material. }\end{array}$ \\
\hline \multicolumn{3}{|c|}{$\begin{array}{r}\text { Additional description and } \\
\text { rationale: }\end{array}$} \\
\hline & References: & $\begin{array}{l}\text { [1] Betzler, B.R., J.J. Powers, N.R. Brown and B.T. Rearden, "Implementation of Molten Salt Reactor Tools in SCALE," Int. Conf. on } \\
\text { Math. and Comp. Methods Applied to Nuclear Science and Engineering, April } 2017 . \\
\text { [2] Brown, N.R., J.J. Powers, D.E. Mueller, and B.W. Patton, Complete Sensitivity/Uncertainty Analysis of LR-0 Reactor Experiments } \\
\text { with MSRE FLiBe Salt and Perform Comparison with Molten Salt Cooled and Molten Salt Fueled Reactor Models, ORNL/TM- } \\
\text { 2016/729, December 2016. }\end{array}$ \\
\hline
\end{tabular}




\begin{tabular}{|c|c|c|}
\hline \multirow{2}{*}{\multicolumn{2}{|c|}{$\begin{array}{r}\text { Scenario categories: } \\
\text { Description: }\end{array}$}} & I. Salt spill accidents \\
\hline & & $\begin{array}{l}\text { After the molten salt impacts a surface, the spread of molten salt controls the geometry of the molten salt pool, which may } \\
\text { impact heat and radionuclide transport rates. }\end{array}$ \\
\hline \multicolumn{2}{|c|}{$\begin{array}{r}\text { Key parameters and } \\
\text { properties: }\end{array}$} & $\begin{array}{l}\text { 1. Fuel salt properties (viscosity, surface tension and solidification temperature) } \\
\text { - Viscosity of fuel salt is particularly important (salt tends to flow like a low-viscosity fluid at high temperature) } \\
\text { - Phase change can limit the extent of spreading (i.e., increased viscosity and solidification at the melt front, limiting } \\
\text { progression) } \\
\text { 2. Location of break/leak relative to walls of compartment } \\
\text { - Cell geometry and design (if wall is contacted prior to solidification of melt front) } \\
\text { 3. The presence of oxides and contaminants in the cell } \\
\text { 4. Capillary forces (salt may "climb" walls when the adhesion force between the salt and the wall exceeds the cohesive } \\
\text { force of the salt, meniscus effect); most likely observed for small containers (with high circumference to surface area, } \\
\text { such as small containers and lids. }\end{array}$ \\
\hline \multicolumn{2}{|c|}{ Importance } & Considerations \\
\hline FOM-1 & $\mathbf{M}$ & $\begin{array}{l}\text { - Under the most severe conditions, sufficient salt is released to spread to the boundary of the compartment, and } \\
\text { radioactive material evolves over a time from the pool. } \\
\text { - For more limited salt spills, the amount of radioactive material released is terminated by freezing. }\end{array}$ \\
\hline FOM-2 & $\mathbf{M}$ & $\begin{array}{l}\text { - Phase change on surface where the salt spreads form a high-insulation layer, limiting heat transfer in the downward } \\
\text { direction while the salt is flowing across the floor, and after spreading stops, affecting the energy content of the released } \\
\text { salt. } \\
\text { - In the longer term, a balance exists between decay heat and losses from the upper and lower surfaces of the pool. }\end{array}$ \\
\hline FOM-3 & $\mathbf{L}$ & - If a pool of substantial height is not formed, then accidental criticality cannot occur. \\
\hline \multicolumn{3}{|c|}{ Knowledge } \\
\hline FOM-1 & $1-2$ & $\begin{array}{l}\text { - The ability to predict fission product release is based on thermodynamic equilibrium assumptions. The amount of } \\
\text { transfer that would occur during the period of spreading is difficult to assess (but probably is not important). }\end{array}$ \\
\hline FOM-2 & $1-2$ & $\begin{array}{l}\text { - Thermal impacts during the spreading period can be assessed based on standard heat transfer models. The models are not } \\
\text { well validated for the expected conditions. }\end{array}$ \\
\hline FOM-3 & 2 & $\begin{array}{l}\text { - To the extent that the configuration of the spreading molten pool can be assessed, the ability to assess reactivity is likely } \\
\text { adequate. }\end{array}$ \\
\hline \multicolumn{3}{|c|}{$\begin{array}{r}\text { Additional description and } \\
\text { rationale: }\end{array}$} \\
\hline \multicolumn{2}{|c|}{ References: } & $\begin{array}{l}\text { [1] See MSR PIRT presentation on SCALE } \\
\text { [2] Farmer, M., "The MELTSPREAD Code for Modeling of Ex-Vessel Core Debris Spreading Behavior, ” ANL/NE-17/20, } \\
\text { Code Manual- Version 3-beta, September } 2017 .\end{array}$ \\
\hline
\end{tabular}




\begin{tabular}{|c|c|c|}
\hline \multicolumn{2}{|c|}{ Scenario categories: } & I. Salt spill accidents \\
\hline & Description: & The mechanical formation of airborne droplets as spray from the break or splash \\
\hline \multicolumn{2}{|c|}{$\begin{array}{r}\text { Key parameters and } \\
\text { properties: }\end{array}$} & $\begin{array}{l}\text { 1. Break characteristics leading to mechanical fragmentation } \\
\text { 2. Height of drop leading to splash droplets } \\
\text { 3. Salt surface tension } \\
\text { 4. Droplet size distribution }\end{array}$ \\
\hline \multicolumn{2}{|c|}{ Importance } & Considerations \\
\hline FOM-1 & $\mathbf{M}$ & $\begin{array}{l}\text { Fragmentation of fuel salt by mechanical means (jet release from vessel) or splash from impact with floor produces } \\
\text { droplets (aerosols) containing radioactive material. Typically, mechanically induced fragmentation produces large } \\
\text { droplets (e.g., 50-micron aerodynamic diameter or larger) which rapidly fall to the ground and are not respirable). The } \\
\text { fraction of the release in the range of } 10 \text { microns or less aerodynamic diameter are respirable and are removed slowly } \\
\text { from the atmosphere. }\end{array}$ \\
\hline FOM-2 & $\mathbf{L}$ & - The impact of splash on the thermal response of the system is expected to be small. \\
\hline FOM-3 & $\mathbf{L}$ & - The impact of splash on reactivity is negligible. \\
\hline \multicolumn{3}{|c|}{ Knowledge } \\
\hline FOM-1 & 1 & $\begin{array}{l}\text { - Although there are models that could be used to predict the size of droplets from splash or jet release from a high- } \\
\text { pressure system, applicability to molten salt is unvalidated. }\end{array}$ \\
\hline FOM-2 & 1 & - $\quad$ Same as above. \\
\hline FOM-3 & 3 & - The impact of salt fragmentation on accidental criticality is negligible and well understood. \\
\hline \multicolumn{2}{|c|}{$\begin{array}{r}\text { Additional description and } \\
\text { rationale: }\end{array}$} & $\begin{array}{l}\text { During the extended-release period of fission product vapors from the pool, aerosol behavior may be more important. The } \\
\text { fission product vapors could react with or condense on pre-existing aerosols and transport to the environment in the form of } \\
\text { aerosols. It is also possible that some insoluble radionuclides could be in the form of small particles on the surface of the salt } \\
\text { pool which could be released to the atmosphere by some mechanism. }\end{array}$ \\
\hline & References: & [1] See MSR PIRT presentation by Argonne on initial and planned salt splash tests. \\
\hline
\end{tabular}




\begin{tabular}{|c|c|c|}
\hline \multicolumn{2}{|c|}{ Scenario categories: } & I. Salt spill accidents \\
\hline & Description: & $\begin{array}{l}\text { Contaminants within the salt result in solid layers that may float on top of the salt surface, potentially impacting the heat or } \\
\text { radionuclide transport. }\end{array}$ \\
\hline \multicolumn{2}{|c|}{$\begin{array}{r}\text { Key parameters and } \\
\text { properties: }\end{array}$} & $\begin{array}{l}\text { 1. Presence of contaminants within the salt } \\
\text { 2. Oxidation of salt, fission products and contaminates within salt } \\
\text { 3. Density of dross } \\
\text { 4. Freezing point of dross } \\
\text { 5. Insulation materials } \\
\end{array}$ \\
\hline \multicolumn{2}{|c|}{ Importance } & Considerations \\
\hline FOM-1 & $\mathbf{M}-\mathbf{H}$ & $\begin{array}{l}\text { - Hydrocarbon oils have been found to affect the release of radionuclides (they react with or retard the diffusive release of } \\
\text { fission products). } \\
\text { - Chemical reactions may occur because of contaminants that lead to the production of a surface layer that provides a } \\
\text { diffusion barrier to the release of radionuclides. } \\
\text { - Small quantities of dross material relative to the volume of the pool could have a significant impact on radionuclide } \\
\text { release. }\end{array}$ \\
\hline FOM-2 & $\mathbf{M}$ & - A dross material layer on the surface of the pool could reduce heat transfer to the overlying atmosphere. \\
\hline FOM-3 & $\mathbf{L}$ & - The impact of contaminants reduces an already very low potential for a reactivity excursion. \\
\hline \multicolumn{2}{|c|}{ Knowledge } & \\
\hline FOM-1 & 1 & - Although some observations exist, data to support model development are minimal. \\
\hline FOM-2 & 1 & - Same as above. \\
\hline FOM-3 & 1 & - Same as above. \\
\hline Addition: & $\begin{array}{l}\text { cription and } \\
\text { rationale: }\end{array}$ & \\
\hline
\end{tabular}




\section{References:}




\begin{tabular}{|c|c|c|}
\hline \multicolumn{2}{|c|}{ Scenario categories: } & lents \\
\hline \multirow{2}{*}{\multicolumn{2}{|c|}{$\begin{array}{r}\text { Description: } \\
\text { Key parameters and properties: }\end{array}$}} & Transport of radioactive material (fission products and fuel salt) from a molten salt pool \\
\hline & & $\begin{array}{l}\text { 1. Chemical forms of radionuclides in key radionuclide groups affecting their volatility } \\
\text { 2. Activity coefficients or vapor pressure of chemical species, including fuel salt components as a function of temperature (being } \\
\text { developed for key fission product species/fuel salt couples) } \\
\text { 3. Langmuir-Knudsen coefficients describing the balance of vapors released from a pool and the return of vapors to the pool (these } \\
\text { have been developed for liquids other than molten salts, which indicates that empirical correction terms are required for emitted and } \\
\text { returning vapors) } \\
\text { 4. Noble gases with low solubility that form bubbles in molten salt pool, which can be released to the cell atmosphere } \\
\text { 5. Potential for dross layer (such as products of oxidation by cell atmosphere or concentration of insoluble particles such as graphite } \\
\text { fragments at surface of molten pool) that impacts heat transfer and transport of radionuclides to cell atmosphere } \\
\text { 6. Freezing point of salt (which effectively terminates release) } \\
\text { 7. Diffusive transport of radionuclides through boundary layer of cell atmosphere (which may retard release to the atmosphere) } \\
\text { 8. Design-specific application of compartment cooling system that could reduce the temperature of the atmosphere and the surface } \\
\text { temperature of the pool }\end{array}$ \\
\hline \multicolumn{2}{|c|}{ Importance } & Considerations \\
\hline FOM-1 & $\mathbf{H}$ & - $\quad$ Release of radioactive material to the compartment atmosphere provides the source term for environmental release. \\
\hline FOM-2 & $\mathbf{M}-\mathbf{H}$ & $\begin{array}{l}\text { - } \quad \text { Radionuclides released from pool provide a heat source to the compartment atmosphere. } \\
\text { - } \quad \text { Radionuclides released from pool could provide localized heat source, such as in a filter, which could lead to filter failure. }\end{array}$ \\
\hline FOM-3 & $\mathbf{L}$ & $\begin{array}{l}\text { - An impractical quantity of fissile species would have to be released from the pool and condense in cold location in a compact } \\
\text { geometry. }\end{array}$ \\
\hline \multicolumn{3}{|c|}{ Knowledge } \\
\hline FOM-1 & $1-2$ & $\begin{array}{l}\text { - Experiments with more combinations of fission product species and salts are needed for model development and validation. } \\
\text { - Experiments are ongoing using Knudsen cells to determine the equilibrium partial pressure of fission product species vapors released } \\
\text { from important fuel salts as a function of temperature. } \\
\text { - Experiments by Langmuir, Knudsen, and Hertz indicate that correction terms are required for assessing the release rate of vapors to } \\
\text { the atmosphere and return to the pool from the atmosphere. } \\
\text { - The behavior of the atmosphere above the pool (e.g., convective mixing, Rayleigh-Bénard instability) as well as the existence of a } \\
\text { boundary layer (laminar or turbulent) affect the release rate from the pool. } \\
\text { - The effects of irradiation of the salt and the radioactive nature of the fission product species are unknown. } \\
\text { - Prototypic experiments simulating molten pool conditions are necessary to have confidence in results. }\end{array}$ \\
\hline FOM-2 & 2 & $\begin{array}{l}\text { - Heat transfer correlations are available for Rayleigh-Bénard convective flow. Grashof numbers can also be determined for assessing } \\
\text { heat transfer coefficients to walls. }\end{array}$ \\
\hline FOM-3 & 3 & - $\quad$ These processes have little impact on the potential for accidental criticality. \\
\hline \multicolumn{3}{|c|}{$\begin{array}{r}\text { Additional description and } \\
\text { rationale: }\end{array}$} \\
\hline & References: & $\begin{array}{l}\text { [1] J. McMurray et al., "Molten Salt Reactor Chemistry, Properties, Database Development and Modeling," Molten Salt Reactor } \\
\text { Workshop, October } 2020 .\end{array}$ \\
\hline
\end{tabular}




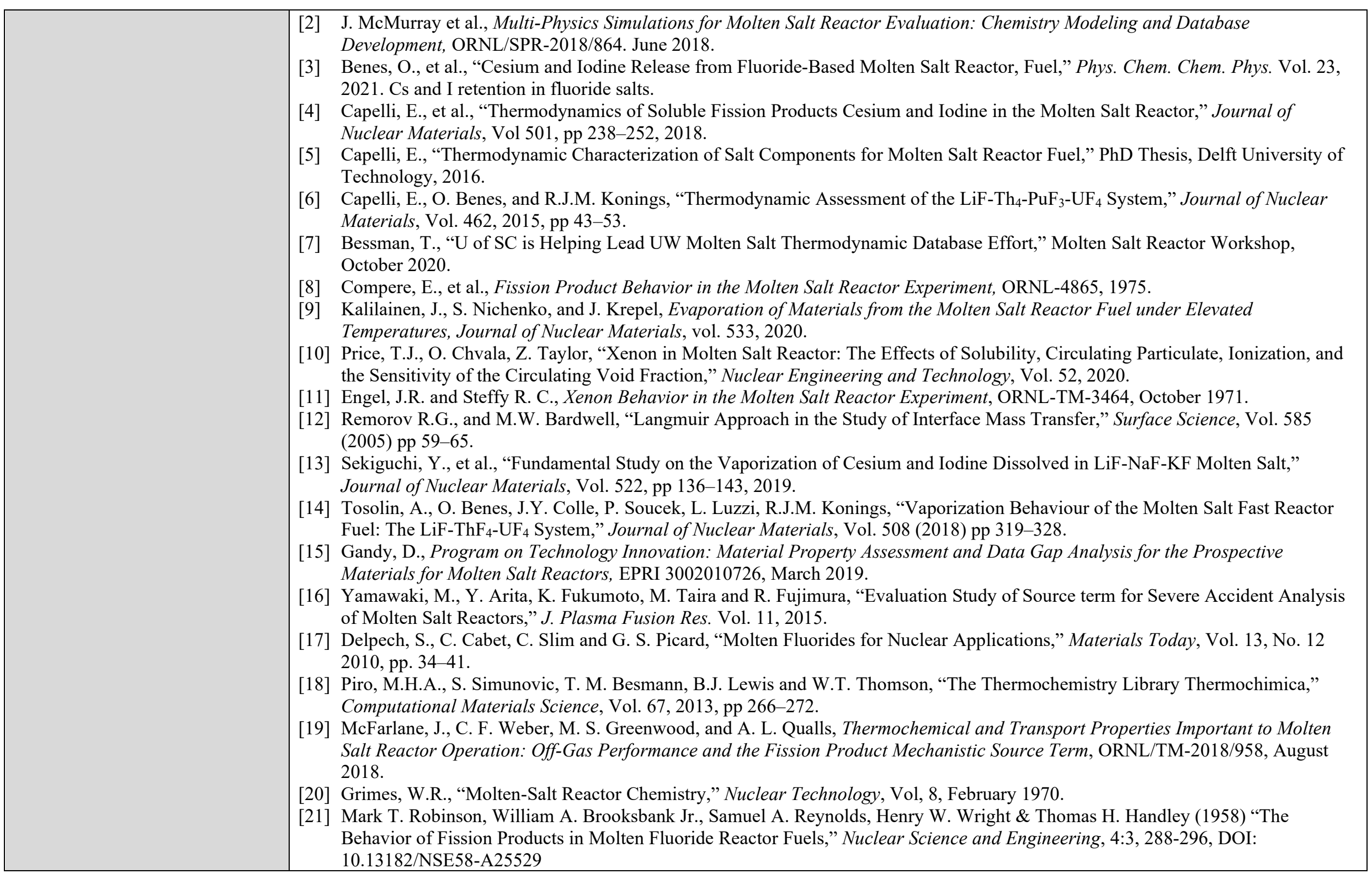




\begin{tabular}{|c|c|c|}
\hline \multirow{2}{*}{\multicolumn{2}{|c|}{$\begin{array}{r}\text { Scenario categories: } \\
\text { Description: }\end{array}$}} & I. Salt spill accidents \\
\hline & & Concentration of dissolved fission products, corrosion products, and other constituents within the salt pool \\
\hline \multicolumn{2}{|c|}{$\begin{array}{r}\text { Key parameters and } \\
\text { properties: }\end{array}$} & $\begin{array}{l}\text { 1. Condition of salt in core prior to release } \\
\text { 2. Presence and behavior of insoluble particles or immiscible phases within pool } \\
\text { 3. Solubility of noble gases } \\
\text { 4. Changes in redox potential and their impact on solubility of species } \\
\text { 5. Potential impact of metallic contaminants } \\
\text { 6. Bubble transport of noble gas parents of reactive fission products }\left({ }^{91} \mathrm{Kr},{ }^{91} \mathrm{Sr},{ }^{92} \mathrm{Kr},{ }^{92} \mathrm{Sr},{ }^{93} \mathrm{Kr},{ }^{93} \mathrm{Y},{ }^{137} \mathrm{Xe},{ }^{137} \mathrm{Cs},{ }^{139} \mathrm{Xe} \text {, }\right. \\
\end{array}$ \\
\hline \multicolumn{2}{|c|}{ Importance } & Considerations \\
\hline FOM-1 & $\mathbf{H}$ & $\begin{array}{l}\text { - From MSRE, insoluble solid particles (referred to as noble metals) were observed, which tended to form a layer at the } \\
\text { liquid surface in the pump bowl. } \\
\text { - Temperature dependance of solubility of noble gases is important. If temperature increases, more noble gases will come } \\
\text { out of solution and will potentially form bubbles which will then rise to the surface. } \\
\text { - Transport from the molten pool within bubbles is a mechanism by which some radiologically important isotopes that are } \\
\text { daughters of noble gas isotopes can escape the pool. }\end{array}$ \\
\hline FOM-2 & $\mathbf{M}$ & $\begin{array}{l}\text { - Precipitation and/or plate-out of radionuclides could lead to localized higher heat generation (e.g., adjacent to pool floor). } \\
\text { - } \quad \text { From the initial phase of salt spill, high heat generation could result from short-lived fission products. }\end{array}$ \\
\hline FOM-3 & $\mathbf{M}$ & $\begin{array}{l}\text { - } \quad \text { Precipitation and/or plate-out of fissile species could lead to high reactivity. } \\
\text { - } \quad \text { Contact of pool with air (oxygen) could enhance potential for precipitates with high fissile content to form: } \mathrm{UO}_{2}, \mathrm{PuO}_{2} \text {. }\end{array}$ \\
\hline \multicolumn{3}{|r|}{ 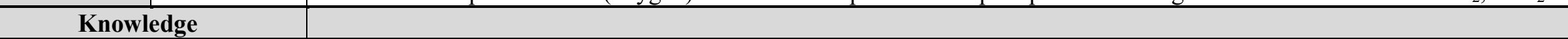 } \\
\hline FOM-1 & 2 & $\begin{array}{l}\text { - The initial condition and location of fission products should be well known for any hypothetical scenario. } \\
\text { - Some data are available on the solubility of noble gases in both fluoride and chloride salts as a function of temperature. } \\
\text { - Solubility of noble gases is low and decreases with temperature. }\end{array}$ \\
\hline FOM-2 & 1 & - Data are sparse on solubility of fission product chemical forms other than noble gases. \\
\hline FOM-3 & 1 & - Data are sparse on solubility of fissile isotope chemical forms. \\
\hline \multicolumn{3}{|c|}{$\begin{array}{r}\begin{array}{r}\text { Additional description and } \\
\text { rationale: }\end{array} \\
\end{array}$} \\
\hline & References: & $\begin{array}{l}\text { [1] Price, T.J., O. Chvala, Z. Taylor, "Xenon in Molten Salt Reactor: The Effects of Solubility, Circulating Particulate, } \\
\text { Ionization, and the Sensitivity of the Circulating Void Fraction," Nuclear Engineering and Technology, 52, } 2020 . \\
\text { [2] McFarlane, J., C. F. Weber, M. S. Greenwood, and A. L. Qualls, "Thermochemical and Transport Properties Important } \\
\text { to Molten Salt Reactor Operation: Off-Gas Performance and the Fission Product Mechanistic Source Term," ORNL/TM- } \\
\text { 2018/958, August } 2018 . \\
\text { [3] Kedl, R. J., The Migration of a Class of Fission Products (Noble Metals) in the Molten-Salt Reactor Experiment, ORNL- } \\
\text { TM-3884, December } 1972\end{array}$ \\
\hline
\end{tabular}




\begin{tabular}{|c|c|c|}
\hline \multirow{2}{*}{\multicolumn{2}{|c|}{$\begin{array}{r}\text { Scenario categories: } \\
\text { Description: }\end{array}$}} & I. Salt spill accidents \\
\hline & & Chemical reactions with the fuel salt and the gas in the volume containing the fuel salt breach \\
\hline \multicolumn{2}{|c|}{$\begin{array}{r}\text { Key parameters and } \\
\text { properties: }\end{array}$} & $\begin{array}{l}\text { 1. Oxygen and moisture content of cell atmosphere } \\
\text { 2. Reaction rates and salt/atmosphere interfacial contact during release period } \\
\text { 3. Convection within the cell atmosphere resulting in contact with salt surface } \\
\text { 4. Impact on redox potential of salt } \\
\text { 5. Greater potential impact on chloride salts } \\
\text { 6. Impact on chemical forms of fission products and actinides }\left(\mathrm{UO}_{2}, \mathrm{PuO}_{2} \text { precipitation) }\right.\end{array}$ \\
\hline \multicolumn{2}{|c|}{ Importance } & Considerations \\
\hline FOM-1 & $\mathbf{M}$ & $\begin{array}{l}\text { - Design differences are important. For most, if not all designs, salt spills are unlikely to occur into areas in which the } \\
\text { atmosphere is air: if oxygen is present, it could affect the chemical form of fission products. } \\
\text { - If air is present, then limited interaction with moisture in air could occur, thus affecting the chemical form of fission } \\
\text { products and production of hydrogen, but not to the extent that there is flooding contact of water with the molten pool. } \\
\text { - Humidity control within the containment/confinement is important and likely present for most, if not all designs. } \\
\text { - System design features and different operating modes (e.g., shutdown for maintenance) could impact whether a salt spill } \\
\text { could occur in a region in which air is present (e.g., external to fuel salt drain tanks). } \\
\text { - Production of HF, HCl with interaction with air (i.e., moisture/water) could impact integrity of instrumentation and thin- } \\
\text { metal components. } \\
\text { - Tritium getter systems could be impacted by production of hydrogen or corrosive gases such as HF and HCl. However, } \\
\text { the getter is likely to be located high in the containment/confinement cell. }\end{array}$ \\
\hline FOM-2 & $\mathbf{M}$ & - Oxides may settle, leading to high concentration of heat generation rate. \\
\hline FOM-3 & $\mathbf{M}$ & $\begin{array}{l}\text { - Air (with moisture contact) would not significantly impact criticality. } \\
\text { - } \quad \text { Reactions with the atmosphere may create oxides that may settle, increasing the potential for criticality. }\end{array}$ \\
\hline \multicolumn{2}{|c|}{ Knowledge } & \\
\hline FOM-1 & $1-2$ & $\begin{array}{l}\text { - Highly design dependent. If air is not present, then many hypothesized phenomena can be precluded. } \\
\text { - If air is present, then CFD tools are available to describe mixing phenomena, but reaction kinetics are not well-studied, } \\
\text { as they might affect the radiological source term. }\end{array}$ \\
\hline FOM-2 & $1-2$ & - Highly design dependent. If air is not present, then many hypothesized phenomena can be precluded. \\
\hline FOM-3 & $1-2$ & $\begin{array}{l}\text { - Highly design dependent. If air is not present, then many hypothesized phenomena can be precluded. However, the } \\
\text { potential for precipitation of fissile species leading to criticality is not well studied. However, the ability to predict } \\
\text { reactivity given a fissile configuration is strong based on capabilities within SCALE. }\end{array}$ \\
\hline Additior & $\begin{array}{r}\text { ription and } \\
\text { rationale: }\end{array}$ & \\
\hline
\end{tabular}


References: $[$ [1] Rubiolo, P.R. and M.T. Retamales, "Thermal-Hydraulics and CFD for Molten Salt Reactors," MSR Summer School, July 2-4, 2017, Lecco Italy. 


\begin{tabular}{|c|c|c|}
\hline \multicolumn{2}{|c|}{ Scenario categories: } & I. Salt spill accidents \\
\hline & Description: & $\begin{array}{l}\text { When a gas coalesces into a bubble within the molten salt pool, buoyancy brings it to the surface, leading to rupture and } \\
\text { splash. }\end{array}$ \\
\hline \multicolumn{2}{|c|}{$\begin{array}{r}\text { Key parameters and } \\
\text { properties: }\end{array}$} & $\begin{array}{l}\text { 1. Bubble size and concentration of non-condensable gases within pool } \\
\text { 2. Bubble rise velocity } \\
\text { 3. Salt density, viscosity, surface tension } \\
\text { 4. Bubble splash size distribution and quantity } \\
\text { 5. Bubble transport of noble gas parents of reactive fission products }\left({ }^{91} \mathrm{Kr},{ }^{91} \mathrm{Sr},{ }^{92} \mathrm{Kr},{ }^{92} \mathrm{Sr},{ }^{93} \mathrm{Kr},{ }^{93} \mathrm{Y},{ }^{137} \mathrm{Xe},{ }^{137} \mathrm{Cs},{ }^{139} \mathrm{Xe} \text {, }\right. \\
\left.{ }^{139} \mathrm{Ba},{ }^{140} \mathrm{Xe},{ }^{140} \mathrm{Ba}\right) \text {. }\end{array}$ \\
\hline \multicolumn{2}{|c|}{ Importance } & Considerations \\
\hline FOM-1 & Hн & $\begin{array}{l}\text { - Bubbles will form in the molten salt pool as a result of the generation of fission gases and the evolution of residual } \\
\text { sparging gas for designs that employ spargers. } \\
\text { When bubbles break the surface, they produce droplets of fuel salt (aerosols) in two size ranges: larger droplets } \\
\text { associated with a jet, and smaller droplets associated with breakup of a thin film. An issue to be resolved is the extent to } \\
\text { which these droplets would fall within the respirable size range. }\end{array}$ \\
\hline FOM-2 & $\mathbf{L L}$ & - Bubble rupture has little impact on heat balance. \\
\hline FOM-3 & II & - $\quad \mathrm{N} / \mathrm{A}$, bubble rupture has insignificant impact on criticality. \\
\hline \multicolumn{2}{|c|}{ Knowledge } & \\
\hline FOM-1 & 2 & $\begin{array}{l}\text { - Bubble rise (within a pool) is well characterized, particularly for air-water systems. Extension to noble gas/molten salt is } \\
\text { feasible. } \\
\text { - Poor understanding of aerosol formation from bubble rupture. }\end{array}$ \\
\hline FOM-2 & 2 & $\begin{array}{l}\text { - Bubble rise (within a pool) is well characterized, particularly for air-water systems. Extension to noble gas/molten salt is } \\
\text { feasible. }\end{array}$ \\
\hline FOM-3 & I & - $\quad$ N/A - Insignificant \\
\hline \multicolumn{2}{|c|}{$\begin{array}{r}\text { Additional description and } \\
\text { rationale: }\end{array}$} & \\
\hline & References: & $\begin{array}{l}\text { [1] D. C. Blanchard, and L. D. Syzdek, "Film Drop Production as a Function of Bubble Size," Journal of Geophysical Research, } \\
\text { 93, C4, pp. 3649-3654, (April 1988). } \\
\text { [2] C. F. Kientzler, A. B. Arons, D. C. Blanchard and A. H. Woodcock, "Photographic Investigation of the Projection of } \\
\text { Droplets by Bubbles Bursting at a Water Surface," Tellus, 6:1, 1-7, (1954). DOI: 10.3402/tellusa.v6i1.8717 } \\
\text { [3] Kohn, H.W. "Bubbles, Drops, and Entrainment in Molten Salts, " ORNL-TM-2373, December 1968. }\end{array}$ \\
\hline
\end{tabular}




\begin{tabular}{|c|c|c|}
\hline \multicolumn{2}{|c|}{ Scenario categories: } & I. Salt spill accidents \\
\hline & Description: & $\begin{array}{l}\text { Associated with irradiated fuel salt. When a beta-decay occurs near the salt surface, the recoiled ion momentum frees and } \\
\text { carriers a molten salt droplet away from the surface of the molten salt pool. }\end{array}$ \\
\hline \multicolumn{2}{|c|}{$\begin{array}{r}\text { Key parameters and } \\
\text { properties: }\end{array}$} & $\begin{array}{l}\text { 1. Droplet formation phenomenon observed in MSRE experiments leading to airborne droplets in the size range of } 35-80 \\
\text { Angstroms } \\
\text { 2. Surface tension } \\
\text { 3. Surfactant layers }\end{array}$ \\
\hline \multicolumn{2}{|c|}{ Importance } & Considerations \\
\hline FOM-1 & $\mathbf{M}$ & $\begin{array}{l}\text { - This is one mechanism identified for the generation of mist (respirable radioactive aerosols). The other mechanism is } \\
\text { bubbles bursting the surface. } \\
\text { - Alpha recoil and fission fragments could produce a similar type of mist }\end{array}$ \\
\hline FOM-2 & $\mathbf{L}$ & - Mist is expected to have a very low impact on heat transfer. \\
\hline FOM-3 & $\mathbf{I}$ & - N/A - Insignificant \\
\hline \multicolumn{3}{|c|}{ Knowledge } \\
\hline FOM-1 & $1-2$ & $\begin{array}{l}\text { - Phenomenon is based on MSRE observation of mist (by micrograph) in the vapor space above a salt sample. } \\
\text { - Interpretation of beta recoil as the mechanism is questioned because of the low energy of the recoiled atom and the } \\
\text { energy required to produce a droplet (based on the surface tension of the salt), even for very small droplets. } \\
\text { - The low MSRE inventory of alpha emitters and the length of time since withdrawal of the sample from the reactor } \\
\text { appear to rule out fission fragments and alpha recoil as the source of the mist. }\end{array}$ \\
\hline FOM-2 & $1-2$ & - Same as for FOM1. \\
\hline FOM-3 & $\mathbf{I}$ & - N/A - Insignificant \\
\hline \multicolumn{3}{|c|}{$\begin{array}{r}\text { Additional description and } \\
\text { rationale: }\end{array}$} \\
\hline & References: & $\begin{array}{l}\text { [1] M. W. Rosenthal, R. B. Briggs, and P. R., Kasten, Molten-Salt Reactor Program Semiannual Progress Report, Oak } \\
\text { Ridge National Laboratory, ORNL-4254, pp 102-111,(August 1968). }\end{array}$ \\
\hline
\end{tabular}




\begin{tabular}{|c|c|c|}
\hline \multicolumn{2}{|c|}{ Scenario categories: } & I. Salt spill accidents \\
\hline & Description: & $\begin{array}{l}\text { The fluid dynamics of the molten salt after a pool has formed and mixing occurs due to associated phenomena for heat and } \\
\text { mass transport }\end{array}$ \\
\hline \multicolumn{2}{|c|}{$\begin{array}{r}\text { Key parameters and } \\
\text { properties: }\end{array}$} & $\begin{array}{l}\text { 1. Convective mixing and heat transfer within and from the pool } \\
\text { 2. Two-phase bubble and mass transport within and from the pool } \\
\text { 3. Generation of dross/crust layer at pool surface } \\
\text { 4. Freezing/remelting of salt } \\
\text { 5. Design specific geometry of region into which spill occurs }\end{array}$ \\
\hline \multicolumn{2}{|c|}{ Importance } & Considerations \\
\hline FOM-1 & $\mathbf{M}$ & $\begin{array}{l}\text { Design dependent. Geometry of the pool could be determined by the geometry of the compartment into which spill } \\
\text { occurs (e.g., compartment could be a shield tank). Floors could be intentionally sloped. } \\
\text { Mass transport within pool affects the movement of radionuclides in the pool to the proximity of the surface from which } \\
\text { they are vaporized. }\end{array}$ \\
\hline FOM-2 & $\mathbf{M}$ & - Design dependent. Heat rejection from compartment could be enhanced by a cooling system. \\
\hline FOM-3 & $\mathbf{L}$ & $\begin{array}{l}\text { - Geometry of pool impacts potential for criticality. Fluid dynamics does not strongly impact low probability of accidental } \\
\text { criticality. }\end{array}$ \\
\hline \multicolumn{3}{|c|}{ Knowledge } \\
\hline FOM-1 & 2 & $\begin{array}{l}\text { - Understanding of key fuel salt properties affecting fluid dynamics - density, thermal conductivity, heat capacity, } \\
\text { viscosity and surface tension are good. Limitations are being addressed by programs at Argonne and ORNL. }\end{array}$ \\
\hline FOM-2 & 2 & $\begin{array}{l}\text { - Understanding of key fuel salt properties affecting fluid dynamics-density, thermal conductivity, heat capacity, } \\
\text { viscosity and surface tension-are good. Limitations are being addressed by programs at Argonne and ORNL. Heat } \\
\text { transfer correlations are available with generalized applicability. } \\
\text { - Computational fluid dynamics could be used if fluid properties are known. }\end{array}$ \\
\hline FOM-3 & 2 & $\begin{array}{l}\text { - Understanding of key fuel salt properties affecting fluid dynamics-density, thermal conductivity, heat capacity, } \\
\text { viscosity and surface tension - are good. Limitations are being addressed by programs at Argonne and ORNL. }\end{array}$ \\
\hline \multicolumn{2}{|c|}{$\begin{array}{r}\text { Additional description and } \\
\text { rationale: }\end{array}$} & \\
\hline & References: & \\
\hline
\end{tabular}




\begin{tabular}{|c|c|c|}
\hline \multirow{2}{*}{\multicolumn{2}{|c|}{$\frac{\text { Scenario categories: }}{\text { Descrintion: }}$}} & Salt spill accidents \\
\hline & & The mass transport and diffusion of radionuclides within the molten salt pool \\
\hline \multicolumn{2}{|c|}{ Key parameters and properties: } & $\begin{array}{l}\text { 1. Radionuclide spatial distribution within the molten salt pool } \\
\text { 2. Release of radionuclides from the pool } \\
\text { 3. Temperature distribution within the molten salt pool } \\
\text { 4. Convective mixing and heat transfer within and from the pool } \\
\text { 5. Two-phase bubble and mass transport within and from the pool } \\
\text { 6. Generation of dross/crust layer } \\
\text { 7. Diffusive transport within the dross/crust } \\
\text { 8. Freezing/remelting of salt }\end{array}$ \\
\hline \multicolumn{2}{|c|}{ Importance } & Considerations \\
\hline FOM-1 & $\mathbf{H}$ & $\begin{array}{l}\text { - Very dependent on the quantity of the spill. } \\
\text { - Once the salt at the surface freezes, the release of radionuclides to the confinement/containment atmosphere is significantly reduced. } \\
\text { - Convective mixing (see I13) will also transport radionuclides to the surface of the pool. }\end{array}$ \\
\hline FOM-2 & $\mathbf{M}$ & - The location of radioactive material within the pool has some impact on heat imbalance. \\
\hline FOM-3 & $\mathbf{L}$ & $\begin{array}{l}\text { - The potential for criticality could be impacted by a concentration of fissile species, but in general it is not impacted by the location of } \\
\text { fission products other than }{ }^{135} \mathrm{Xe} \text {. }\end{array}$ \\
\hline \multicolumn{3}{|c|}{ Knowledge } \\
\hline FOM-1 & 2 & $\begin{array}{l}\text { - Convective transport of fission product is expected to be the most important mechanism by which fission products migrate to the } \\
\text { surface of the pool. } \\
\text { - Convective transport can be modeled using computation fluid dynamics. The other important mechanism is diffusion, which is } \\
\text { important very close to the surface, through boundary layers, dross material or a thin layer of solidified salt. Because the chemical } \\
\text { forms are not well determined, diffusion coefficients are not well known. }\end{array}$ \\
\hline FOM-2 & 2 & - Convective mixing depends in part on heat transfer. Applicable generic heat transfer correlations are available. \\
\hline FOM-3 & 2 & $\begin{array}{l}\text { - Given a geometry of fissile, absorbing, and moderator material, the ability to predict criticality is good based the capabilities within } \\
\text { SCALE. }\end{array}$ \\
\hline \multicolumn{2}{|c|}{$\begin{array}{r}\text { Additional description and } \\
\text { rationale: }\end{array}$} & Release of radionuclides from the surface of the pool is addressed in I08. \\
\hline \multicolumn{2}{|r|}{ References: } & $\begin{array}{l}\text { [1] Taylor, Z., "Implementation of Multi-Phase Species Transport in VERA-CS for Molten Salt Reactor Analysis," MS, Nuclear } \\
\text { Engineering, University of Tennessee, Knoxville, } 2019 .\end{array}$ \\
\hline
\end{tabular}




\begin{tabular}{|c|c|c|}
\hline \multicolumn{2}{|c|}{ Scenario categories: } & I. Salt spill accidents \\
\hline \multirow{2}{*}{\multicolumn{2}{|c|}{ Key parameters and properties: }} & The integration of all relevant heat transport phenomena, convection, conduction, and radiation, within the molten salt pool \\
\hline & & 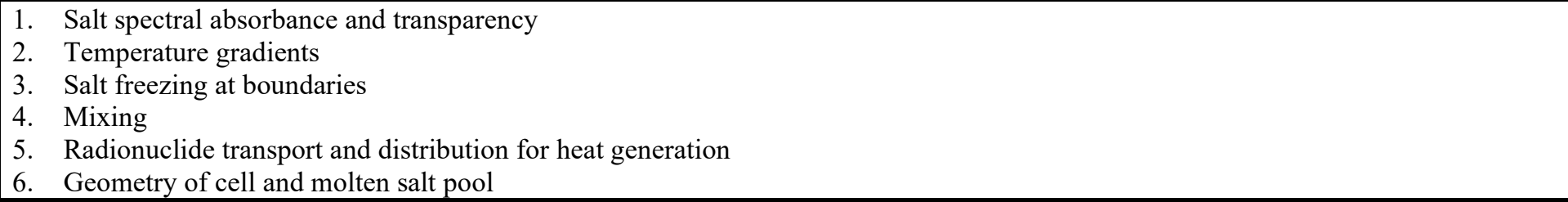 \\
\hline \multicolumn{2}{|c|}{ Importance } & Considerations \\
\hline FOM-1 & $\mathbf{L}$ & - $\quad$ Not directly applicable, but crust formation/dross could inhibit fission product release. \\
\hline FOM-2 & $\mathbf{H}$ & $\begin{array}{l}\text { - Several processes affect heat transfer within the pool, including convection, conduction and radiative heat transfer not only within } \\
\text { the molten salt, but also directly to external structures. } \\
\text { - } \quad \text { For lower temperature accidents and minor salt spills, radiative heat transfer may not be highly important. }\end{array}$ \\
\hline FOM-3 & $\mathbf{L}$ & - $\quad$ Not directly applicable. \\
\hline \multicolumn{3}{|c|}{ Knowledge } \\
\hline FOM-1 & 1 & - $\quad$ Not directly applicable. \\
\hline FOM-2 & 1 & $\begin{array}{l}\text { - } \quad \text { Very limited knowledge of emission and absorption coefficients of salts as a function of temperature. } \\
\text { - Theoretical basis for modeling and simulation is good, but the uncertainty and complexity of the geometry and limits in the database } \\
\text { - } \quad \text { Heat capacity and thermal conductivity may have high uncertainties. } \\
\text { - } \quad \text { Possible steep temperature gradients and potential crust formation may be difficult to predict. }\end{array}$ \\
\hline FOM-3 & 3 & $\begin{array}{l}\text { - Although the concentrations of fissile materials are uncertain within the pool, the effect of temperature is well understood on nuclear } \\
\text { data and should be a straightforward criticality calculation. }\end{array}$ \\
\hline \multicolumn{3}{|c|}{$\begin{array}{r}\text { Additional description and } \\
\text { rationale: }\end{array}$} \\
\hline & References: & \begin{tabular}{|l} 
[1] Ambrosek, J., M. Anderson, K. Sridharan and T. Allen, "Current Status of Knowledge of the Fluoride Salt (FLiNaK) Heat \\
Transfer," Nuclear Technology, Vol. 165, 2009. \\
[2] Chaleff, E.S., T. Blue and P. Sagharwall, "Radiation Heat Transfer in the Molten Salt FLiNaK," Nuclear Technology, Vol. 196, pp \\
53-60, October 2016. \\
[3] Derdeyn, W., M. A. Dbai, R. O. Scarlat, M. Trujillo, "FLiBe Radiative Heat Transfer," Trans ANS, Vol. 118, 2018. \\
[4] DiMarcello, V., A. Cammi, and L. Luzzi, "Analysis of Thermal-Hydraulic Behaviour of the Molten Salt Nuclear Fuel," Int. Conf. \\
on Nuclear Energy for New Europe 2008, September 2008. \\
Fiorina, C., A. Cammi, L. Luzzi, K. Mikityuk, H. Ninokata and M.E. Ricotti, "Thermal-Hydraulics of Internally Heated Molten \\
Salts and Application to the Molten Salt Fast Reactor," Journal of Physics: Conference Series, 501 012030, 2014. \\
[6] Betzler, B.R., F. Heidet, B. Fen, C. Rabiti, T. Sofu, and N.R. Brown, "Modeling and Simulation Needs for Molten Salt Reactor \\
Licensing," Nuclear Engineering and Design, Vol. 355, 2019. \\
[7] \\
Brown, N.R.., D. J. Diamond, S. Bajorek and R. Denning, "Thermal-Hydraulic and Neutronic Phenomena Important in Modeling \\
and Simulation of Liquid-Fuel Molten Salt Reactors," Nuclear Technology, 2019.
\end{tabular} \\
\hline
\end{tabular}


[8] Graham, A., B. Collins, R. Salko, Z. Taylor and C. Gentry, "Development of Molten Salt Reactor Modeling and Simulation Capabilities in VERA," GLOBAL 2019, Seattle, pp 1-9.

[9] Shahbazi, S. and D. Grabaskas, Functional Requirements for the Modeling and Simulation of Advanced (Non-LWR) Reactor Mechanistic Source Term, ANL/NSE-20/17, June 2020.

[10] Shahbazi, S., D. Grabaskas, S. Thomas (ANL) and N. Andrews, A. Clark, D. Luxat, M. Higgins, M. Smith (SNL), Survey and Assessment of Computational Capabilities for Advanced (non-LWR) Reactor Mechanistic Source Term Analysis, ANL/NSE20/39;SAND2021-3250 R, September 2020.

[11] Wang, Z.J., M. Chen and Z.Y. Guo, "A Nonequilibrium Molecular Dynamics Simulation of Evaporation," Int Conf Passive and Low Energy Cooling for the Built Environment, May 2005.

[12] Sohal, M.S., M. A. Ebner, P. Sabharwall and P. Sharpe, "Engineering Database of Liquid Salt Thermophysical and Thermochemical Properties," INL/EXT-10-18297, June 2013.

[13] Yoder, G. L. Jr., "Examination of Liquid Fluoride Salt Heat Transfer," Proceedings of ICAPP 2014, Charlotte USA April 6-9, 2014, Paper 14332 


\begin{tabular}{|c|c|c|}
\hline \multicolumn{2}{|c|}{ Scenario categories: } & I. Salt spill accidents \\
\hline & Description: & The integration of all relevant heat transport phenomena from the molten salt pool to the cell atmosphere and structures \\
\hline \multicolumn{2}{|c|}{ Key parameters and properties: } & $\begin{array}{l}\text { 1. Convection, air/gas flow rate across upper surface of the pool to cell atmosphere } \\
\text { 2. Radiation to cell structures from salt including effects of salt absorbance and transparency } \\
\text { 3. Heat transfer from pool to structures (floor, walls) by conduction, convection and radiation, including treatment of salt solidification } \\
\text { layer and aerosol formation in the cell atmosphere interfering with radiative heat transfer to structures } \\
\text { 4. Design-specific cell geometry } \\
\text { 5. Enthalpy change associated with phase change in the pool } \\
\text { 6. Decay heat level and distribution within the pool } \\
\end{array}$ \\
\hline \multicolumn{2}{|c|}{ Importance } & Considerations \\
\hline FOM-1 & $\mathbf{H}$ & $\begin{array}{l}\text { - Transfer of heat from the molten salt pool may damage barriers and structures, leading to release of fission products. } \\
\text { - Rate of heat removal from molten salt pool can affect the timeframe over which volatilization occurs. }\end{array}$ \\
\hline FOM-2 & $\mathbf{H}$ & - Heat transport from the pool can affect the integrity of structures. \\
\hline FOM-3 & $\mathbf{L}$ & - Although considered unlikely, freezing and phase separation could lead to a concentration of fissile precipitates. \\
\hline \multicolumn{3}{|c|}{ Knowledge } \\
\hline FOM-1 & $1-2$ & $\begin{array}{l}\text { - Uncertainties with pool geometry and parameters are associated with radiative heat transfer to structures from molten salts. } \\
\text { - } \quad \text { Presence of fog/mist/snow may prevent or significantly reduce radiative heat transfer to structures in the cell. } \\
\text { - Emission coefficients, absorption coefficients, reflectivity of surfaces and atmosphere are unknown. }\end{array}$ \\
\hline FOM-2 & 1 & - $\quad$ Same as above. \\
\hline FOM-3 & 2 & \\
\hline \multicolumn{3}{|c|}{$\begin{array}{r}\text { Additional description and } \\
\text { rationale: }\end{array}$} \\
\hline \multicolumn{2}{|r|}{ References: } & $\begin{array}{l}\text { [1] Chaleff, E.S., T. Blue and P. Sagharwall, "Radiation Heat Transfer in the Molten Salt FLiNaK," Nuclear Technology, Vol. 196, pp } \\
\text { 53-60, October } 2016 . \\
\text { [2] Derdeyn, W., M. A. Dbai, R. O. Scarlat, M. Trujillo, "FLiBe Radiative Heat Transfer," Trans ANS, Vol. 118, } 2018 \text {. } \\
\text { [3] Ahlers, G., X. He, D. Funfschilling and E. Bodenschatz, "Heat Transport by Turbulent Rayleigh-Bénard Convection for } \operatorname{Pr} \approx 0.8 \text { and } \\
3 \times 10^{12} \leq \text { Ra } \leq 10^{15}: \text { Aspect Ratio," New Journal of Physics, Vol. 14, } 2012 \text {. }\end{array}$ \\
\hline
\end{tabular}




\begin{tabular}{|c|c|c|}
\hline \multicolumn{2}{|c|}{ Scenario categories: } & I. Salt spill accidents \\
\hline & Description: & The fluid dynamics and associated heat transfer in the cell atmosphere \\
\hline \multicolumn{2}{|c|}{ Key parameters and properties: } & $\begin{array}{l}\text { 1. Design-specific cell geometry } \\
\text { 2. Temperature of pool surface } \\
\text { 3. Structure temperatures } \\
\text { 4. Bulk atmosphere temperature } \\
\text { 5. Failure of structures affecting confinement/containment } \\
\text { 6. Thermal fluid nondimensional parameters (Grashof, Reynolds, etc.) } \\
\text { 7. } \\
\end{array}$ \\
\hline \multicolumn{2}{|c|}{ Importance } & Considerations \\
\hline FOM-1 & $\mathbf{M}$ & $\begin{array}{l}\text { - Conditions within the cell atmosphere are associated with a well-known unstable condition, Rayleigh-Bénard instability, in which } \\
\text { convection patterns occur for a fluid heated from below. } \\
\text { - The associated high degree of mixing in the cell atmosphere can be predicted with CFD codes. } \\
\text { - Laminar boundary layer at the surface of the pool could impede the release of radioactive species. } \\
\text { - Convection carries fission products from the salt surface to the atmosphere and other surfaces in the containment/confinement, with a } \\
\text { potential for release with other barrier failures. }\end{array}$ \\
\hline FOM-2 & $\mathbf{M}$ & $\begin{array}{l}\text { - Major temperature drops expected to occur at boundary layer at surface of the pool and at the surface of the ceiling of the cell, with } \\
\text { the interior region being well mixed. } \\
\text { - Condensation of vaporized salt in the cell atmosphere could produce aerosols (snow), which could coat cooled surfaces, impede } \\
\text { radiative heat transfer, or plug a gas line. } \\
\text { - } \quad \text { Could impact salt spill mitigation strategies. } \\
\text { - Salt redox potential impacts release of zirconium fluoride ( } \mathrm{ZrF}) \text {. }\end{array}$ \\
\hline FOM-3 & I & - $\quad \mathrm{NA}$ - Insignificant \\
\hline \multicolumn{3}{|c|}{ Knowledge } \\
\hline FOM-1 & 2 & $\begin{array}{l}\text { - Impact of boundary layers on radioactive material transport uncertain. } \\
\text { - } \quad \text { Uncertainty in the vapor pressure of fission products in/just above the salt (assumed equilibrium), driving force for release. }\end{array}$ \\
\hline FOM-2 & 2 & $\begin{array}{l}\text { - Impact of boundary layers on heat transfer to atmosphere. } \\
\text { - } \quad \text { Uncertainty with snow formation, heat transfer to surfaces. }\end{array}$ \\
\hline FOM-3 & I & - $\quad \mathrm{NA}$ - Insignificant \\
\hline \multicolumn{3}{|c|}{$\begin{array}{r}\text { Additional description and } \\
\text { rationale: }\end{array}$} \\
\hline & References: & $\begin{array}{l}\text { [1] Dinh, T.N., Y.Z. Yang, J. P. Tu, R.R. Nougaliev and T.G. Theofanous, "Rayleigh-Bénard Natural Convection Heat Transfer: } \\
\text { Pattern Formation, Complexity and Predictability," ICAPP 04, June 2004. } \\
\text { [2] Shi, N., M.S. Emran and J. Schumaker, "Boundary Layer Structure in Turbulent Rayleigh-Bénard Convection," Journal of Fluid } \\
\text { Mechanics, 706, April 2012. }\end{array}$ \\
\hline
\end{tabular}




\begin{tabular}{|c|c|c|}
\hline \multicolumn{2}{|c|}{ Scenario categories: } & I. Salt spill accidents \\
\hline & Description: & $\begin{array}{l}\text { I08 addressed release of vapors including radioactive materials from the molten salt. This set of phenomena is associated with transport } \\
\text { within the cell atmosphere, aerosol formation and growth, vapor, and aerosol deposition mechanisms. }\end{array}$ \\
\hline \multicolumn{2}{|c|}{ Key parameters and properties: } & $\begin{array}{l}\text { 1. Fluid dynamics within cell atmosphere } \\
\text { 2. Heterogeneous nucleation (vapor deposition on existing aerosols) } \\
\text { 3. Homogeneous nucleation } \\
\text { 4. Chemisorption of fission product vapors on structures } \\
\text { 5. Aerosol transport, growth, and deposition mechanisms } \\
\text { 6. Diffusive and convective transport of vapors } \\
\end{array}$ \\
\hline \multicolumn{2}{|c|}{ Importance } & Considerations \\
\hline FOM-1 & $\mathbf{H}$ & $\begin{array}{l}\text { - Eventual release to the environment requires radionuclide transport within the cell atmosphere or wherever the salt spill or breach } \\
\text { occurs. } \\
\text { - Aerosol formation, growth, and deposition mechanisms significantly impact the potential for release. }\end{array}$ \\
\hline FOM-2 & M & - Radioactive material (aerosol or vapor) deposition on structures introduces a local heat load that could impact structural integrity. \\
\hline FOM-3 & $\mathbf{L}$ & - Very limited impact expected on potential for reactivity excursion \\
\hline \multicolumn{3}{|c|}{ Knowledge } \\
\hline FOM-1 & 3 & - Validated models and tools exist for gas and aerosol transport for other reactor designs. \\
\hline FOM-2 & 2 & - Some tools exist for heat generation associated with deposited radionuclides. \\
\hline FOM-3 & 2 & - Existing tools are adequate. \\
\hline \multicolumn{3}{|c|}{$\begin{array}{r}\text { Additional description and } \\
\text { rationale: }\end{array}$} \\
\hline & References: & $\begin{array}{l}\text { [1] Kalilainen, J., S. Nichenko, and J. Krepel, “Evaporation of Materials from the Molten Salt Reactor Fuel under Elevated } \\
\text { Temperatures," Journal of Nuclear Materials, 533, } 2020 .\end{array}$ \\
\hline
\end{tabular}




\begin{tabular}{|c|c|c|}
\hline \multicolumn{2}{|c|}{ Scenario categories: } & I. Salt spill accidents \\
\hline & Description: & Effect of radiation on chemical structures and induced chemical reactions. \\
\hline \multicolumn{2}{|c|}{ Key parameters and properties: } & $\begin{array}{ll}\text { 1. } & \text { Hydrogen production } \\
\text { 2. } & \text { Potential generation of acidic gases } \\
\text { 3. } & \text { Effect on salt properties } \\
\text { 4. } & \text { Effect on redox potential } \\
\text { 5. Production of reactive gases } \\
\text { 6. } & \text { Potential impact on failure of barriers to containment of fission products } \\
\text { 7. } & \mathrm{UF}_{6} \text { production } \\
\end{array}$ \\
\hline \multicolumn{2}{|c|}{ Importance } & Considerations \\
\hline FOM-1 & $\mathbf{M}$ & $\begin{array}{l}\text { - Introduction of other materials into salt is necessary to have impact of radiolysis } \\
\text { - Water is a concern if the cell atmosphere has moisture content, if there is concrete decomposition, or if there is water intrusion as } \\
\text { from failure of a cooling system. } \\
\text { - Production of hydrogen and potentially } \mathrm{HF} / \mathrm{HCl} / \mathrm{UF}_{6} \text {. }\end{array}$ \\
\hline FOM-2 & $\mathbf{L}$ & - Unlikely to impact heat generation or removal. \\
\hline FOM-3 & $\mathbf{M}$ & $\begin{array}{ll} & \text { Rate of } \mathrm{UF}_{6} \text { production, especially a concern with HALEU or HEU fuels. } \\
\text { - } & \text { Uranium tetrafluoride }\left(\mathrm{UF}_{4}\right) \text { is the preferred state. } \\
\text { - } & \text { Recombination will likely match radiolysis while in liquid phase. } \\
\end{array}$ \\
\hline \multicolumn{3}{|c|}{ Knowledge } \\
\hline FOM-1 & 3 & - $\quad$ For ionic liquid, radiolysis is well known. \\
\hline FOM-2 & 3 & - $\quad$ Same as above. \\
\hline FOM-3 & 2 & - Uranium hexafluoride $\left(\mathrm{UF}_{6}\right)$ production requires a deeply frozen salt; this is a long-term accident issue. \\
\hline \multicolumn{3}{|c|}{$\begin{array}{r}\text { Additional description and } \\
\text { rationale: }\end{array}$} \\
\hline & References: & 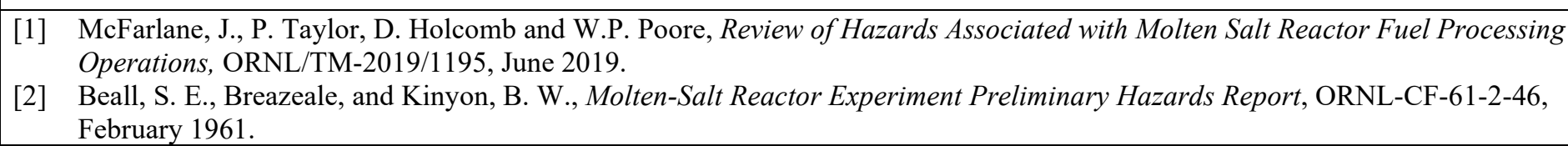 \\
\hline
\end{tabular}


[3] Beall, S. E., Briggs, R. B., and Westsik, J. H. Addendum to ORNL CF-61-2-46, Molten-Salt Reactor Experiment Preliminary Hazards Report, ORNL-CF-61-2-46 Addendum 1, 1961. DOI:10.2172/1399897.

[4] Staff of the Molten Salt Reactor Program, Molten-Salt Reactor Experiment Preliminary Hazards Report, Addendum 2, ORNL-CF61-2-46, 1962, DOI: $10.2172 / 1399900$ 


\begin{tabular}{|c|c|c|}
\hline \multicolumn{2}{|c|}{ Scenario categories: } & I. Salt spill accidents \\
\hline \multicolumn{2}{|r|}{ Description: } & $\begin{array}{l}\text { Water salt interactions either associated with water ingress or moisture in the compartment atmosphere. Potential for energetic reactions. } \\
\text { Water disassociation leading to the production of chemically reactive gases and potential impact on fission product barriers. }\end{array}$ \\
\hline \multicolumn{2}{|c|}{ Key parameters and properties: } & $\begin{array}{ll}\text { 1. } & \text { Steam production } \\
\text { 2. } & \text { Production of reactive gases } \\
\text { 3. } & \text { Hydrogen production } \\
\text { 4. } & \text { Effect on salt properties } \\
\end{array}$ \\
\hline \multicolumn{2}{|c|}{ Importance } & Considerations \\
\hline FOM-1 & $\mathbf{M}$ & $\begin{array}{l}\text { - Energetic reactions are unlikely because of low probability of salt spilling into a pre-existing pool of water, such as could occur with } \\
\text { a prior water line leak into cell (design specific). } \\
\text { - Most likely scenarios are with restricted quantities of water (e.g., humid air, small water line/spray). } \\
\text { - A major water incursion could result in steam production with the potential to over-pressurize confinement barriers. } \\
\text { - Any event with water-salt interaction has the potential for hydrolysis; quantities would be limited, but uncertain and design } \\
\text { dependent. } \\
\text { - Could produce a corrosive salt (oxide formation), leading to a barrier integrity failure; however, this is a slow process (relative to } \\
\text { accident timescales). } \\
\text { Heat exchanger and thin wall components would more likely be affected by corrosion than thicker walled components like a vessel; } \\
\text { highly dependent on where the water-salt interactions occur. }\end{array}$ \\
\hline FOM-2 & $\mathbf{L}$ & - Hydrolysis and its effects are unlikely to impact heat generation or removal. \\
\hline FOM-3 & $\mathbf{M}$ & - $\quad$ Depends on quantities of salt (fissile content). \\
\hline \multicolumn{3}{|c|}{ Knowledge } \\
\hline FOM-1 & 2 & $\begin{array}{l}\text { - Variability in accident conditions, quantities, locations, and materials. } \\
\text { - Some relevant corrosion experiments have been performed. }\end{array}$ \\
\hline FOM-2 & 2 & - Same as above. \\
\hline FOM-3 & 2 & - $\quad$ Same as above. \\
\hline \multicolumn{2}{|c|}{$\begin{array}{r}\text { Additional description and } \\
\text { rationale: }\end{array}$} & \\
\hline
\end{tabular}


Scenario categories:

Description:

Key parameters and properties:

\begin{tabular}{|c|c|}
\hline \multicolumn{2}{|c|}{ Importance } \\
\hline FOM-1 & $\mathbf{M}$ \\
\hline FOM-2 & $\mathbf{M}$ \\
\hline FOM-3 & $\mathbf{M}$ \\
\hline
\end{tabular}

II. Dynamic system thermal/hydraulic/power response

In the safety analysis report, the ability to withstand a variety of upset conditions must be demonstrated. From the perspective of the current study, the only scenarios of concern are those that challenge the integrity of the primary system from over-temperature or overpressure conditions with the potential for release of radioactive material.

1. Failure modes of components, creep rupture of structures, failure modes of seals

2. Heat generation (power level), heat rejection, heat capacity

- Transient analysis tools should determine if barrier integrity is challenged.

- Increased fission gas production in a reactivity transient could lead to burping of the salt and transport to cover gas systems.

- The quantity of fission gases produced may not be significant enough to challenge a barrier or cover gas systems.

- Fission products retained in graphite could be released because of temperature excursions, including tritium.

- Impact on creep is not likely to be significant for challenging a barrier but could be a potential economic concern for shutting down the reactor.

- Over-temperature/over-pressure conditions may be caused by overpower or power excursion events; insufficient heat removal could lead to barrier integrity challenges.

- Possible increased voids caused by increased fission gases could affect absorption/moderation.

- If mass flow increases/decreases in the event, then delayed neutron precursor distribution through the system changes, changing the effective delayed neutron fraction and the transient response (relative to a fixed delayed neutron fraction assumption).

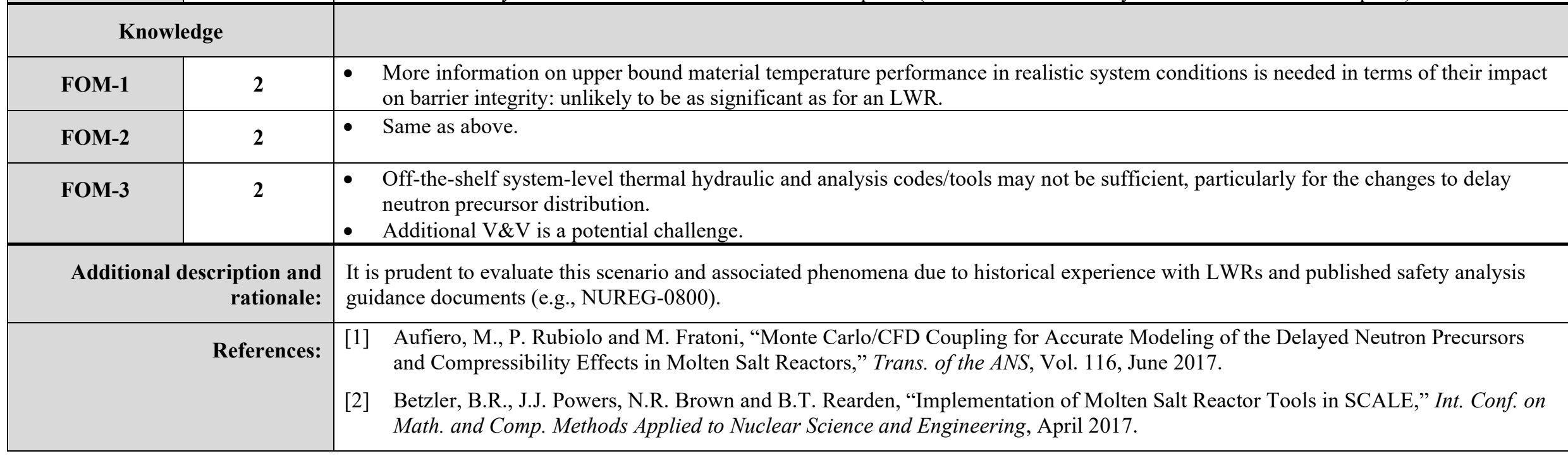




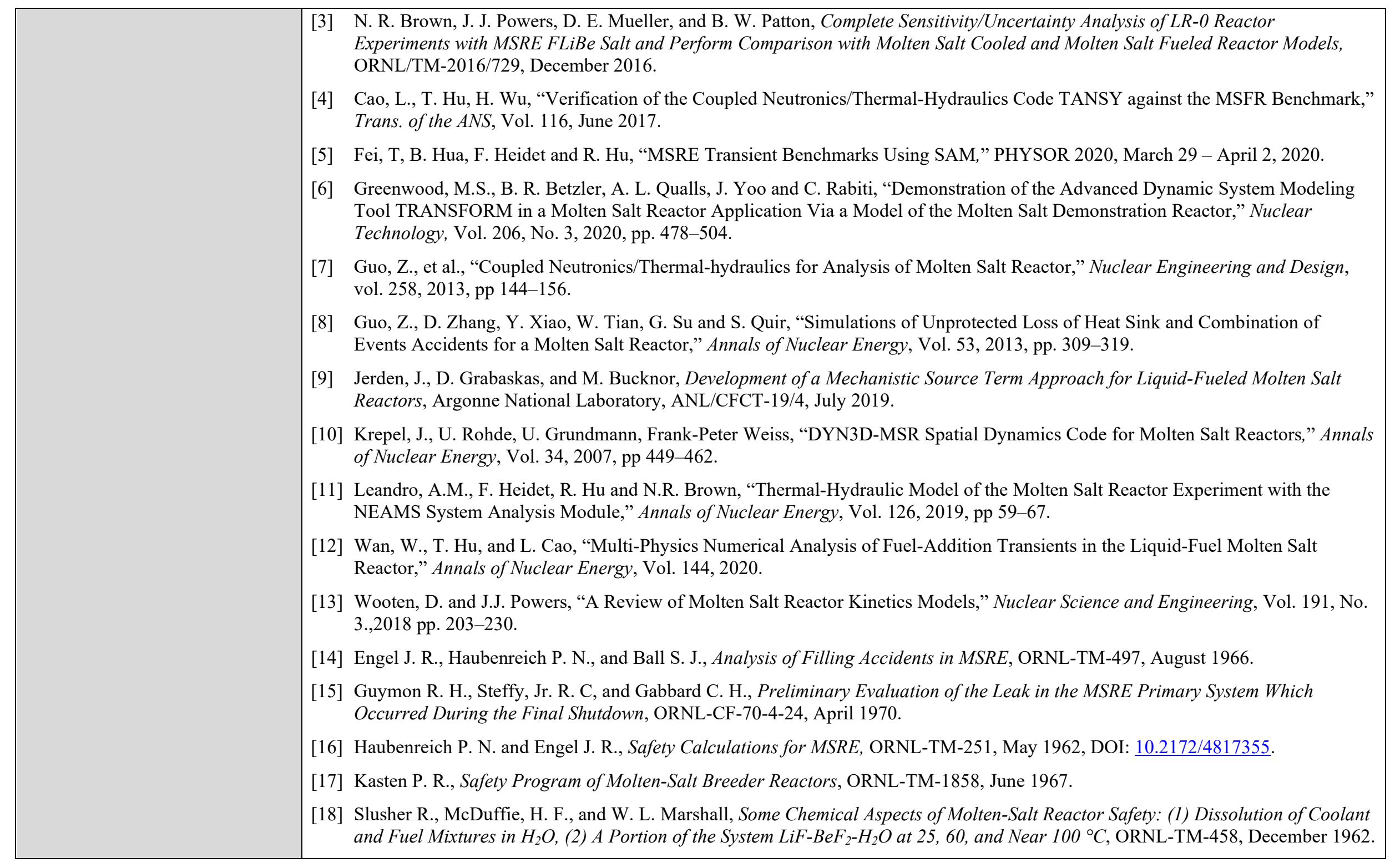


Scenario categories:

Description:

Key parameters and properties:

1. Activation products

2. Fission product migration, corrosion of heat exchanger

3. Fuel salt leakage into the secondary coolant system (for primary pressure exceeding secondary pressure)

4. Secondary coolant leakage into primary system (for primary pressure less than secondary pressure)

5. Tritium transport and release

6. Retention of radionuclides and release from graphite

7. Chemical compatibility of interfacing fuel salt and secondary coolant

8. Thermophysical compatibility of interfacing primary salt and secondary coolant (e.g., density and mechanical issues)

\begin{tabular}{|c|c|c|}
\hline \multicolumn{2}{|c|}{ Importance } & Considerations \\
\hline FOM-1 & $\mathbf{M}$ & $\begin{array}{l}\text { - Unlikely that the secondary system is a power conversion loop; most if not all have contained secondary loop. } \\
\text { Most if not all designs have a higher pressure on the secondary side so that it leaks inward to the primary side, with detection and } \\
\text { primary control mechanisms (isolation values). } \\
\text { - Reactor designs have some flexibility to control leak characteristics. }\end{array}$ \\
\hline FOM-2 & $\mathbf{M}$ & - Depends on the reactor heat removal system design. \\
\hline FOM-3 & $\mathbf{L}$ & - Could increase moderation, but unlikely to have a significant reactivity impact. \\
\hline \multicolumn{3}{|c|}{ Knowledge } \\
\hline FOM-1 & 2 & $\begin{array}{l}\text { - Isolation valves on the primary system are not at a high technology readiness level (TRL) for MSRs. } \\
\text { Tube break mechanisms have been widely studied. However, some uncertainty exists in the range of potential heat exchanger } \\
\text { designs. }\end{array}$ \\
\hline FOM-2 & 2 & - $\quad$ Same as above. \\
\hline FOM-3 & 2 & - $\quad$ Same as above. \\
\hline \multicolumn{2}{|c|}{$\begin{array}{r}\text { Additional description and } \\
\text { rationale: }\end{array}$} & \\
\hline & erences: & \\
\hline
\end{tabular}




\begin{tabular}{|c|c|c|}
\hline \multicolumn{2}{|c|}{ Scenario categories: } & IV. Accidental criticality \\
\hline & Description: & $\begin{array}{l}\text { There are two possible scenarios with similar phenomena and impacts: (1) inside a tank or vessel designed to contain fuel salt, and (2) in } \\
\text { a location where fuel salt is not intended to accumulate. }\end{array}$ \\
\hline \multicolumn{2}{|c|}{ Key parameters and properties: } & $\begin{array}{l}\text { 1. Speciation of fissile elements } \\
\text { 2. Temperature dependent, joint solubility of actinides } \\
\text { 3. Flow or deposition rate of accumulated fissile material to the point of criticality } \\
\text { 4. Geometry and location of accumulation }\end{array}$ \\
\hline \multicolumn{2}{|c|}{ Importance } & Considerations \\
\hline FOM-1 & $\mathbf{M}$ & $\begin{array}{l}\text { - For scenario 1, MSRs will be designed with criticality requirements and thus unlikely to have an accidental criticality event with } \\
\text { significant impact on barrier integrity or a potential for the release of radionuclides. } \\
\text { - Accumulation depends on fissile material (uranium or plutonium) speciation, extent of reflection, and extent of moderation. } \\
\text { - In a spent fuel tank, absorbers and controls will likely be present; in-core may be a greater concern. }\end{array}$ \\
\hline FOM-2 & $\mathbf{M}$ & - Could have an impact on heat removal capability, which would exceed design level. \\
\hline FOM-3 & $\mathbf{H}$ & - This phenomenon is directly related to the FOM and thus is highly important. \\
\hline \multicolumn{3}{|c|}{ Knowledge } \\
\hline FOM-1 & 2 & - Ingress of oxygen, radiolysis, formation of volatiles could be transported to unintended locations. \\
\hline FOM-2 & 2 & $\begin{array}{l}\text { - Rate of localized heat generation depends on the accumulation and neutronic parameters; however, sufficient thermal analysis tools } \\
\text { exist if initial conditions can be well-defined. }\end{array}$ \\
\hline FOM-3 & $1-2$ & $\begin{array}{l}\text { - There is a potential need for more data on joint solubility; some data exist. } \\
\text { - Possible reintroduction of fissile material that has precipitated but flows back into active core region is a principal concern. }\end{array}$ \\
\hline \multicolumn{3}{|c|}{$\begin{array}{r}\text { Additional description and } \\
\text { rationale: }\end{array}$} \\
\hline \multicolumn{2}{|r|}{ References: } & $\begin{array}{l}\text { [1] Betzler, B.R., J.J. Powers, N.R. Brown and B.T. Rearden, "Implementation of Molten Salt Reactor Tools in SCALE," Int. Conf. on } \\
\text { Math. and Comp. Methods Applied to Nuclear Science and Engineering, April } 2017 . \\
\text { [2] Brown, N.R., J.J. Powers, D.E. Mueller, and B.W. Patton, Complete Sensitivity/Uncertainty Analysis of LR-0 Reactor Experiments } \\
\text { with MSRE FLiBe Salt and Perform Comparison with Molten Salt Cooled and Molten Salt Fueled Reactor Models, ORNL/TM- } \\
\text { 2016/729, December 2016. }\end{array}$ \\
\hline
\end{tabular}




\begin{tabular}{|c|c|c|}
\hline \multicolumn{2}{|c|}{ Scenario categories: } & IV. Accidental criticality \\
\hline & Description: & $\begin{array}{l}\text { Like the "cold slugging" reactor experiment for the MSRE, this occurs when the heat removal systems suddenly increase in cooling } \\
\text { capability, leading to a precipitation of fissile material. }\end{array}$ \\
\hline \multicolumn{2}{|c|}{ Key parameters and properties: } & $\begin{array}{l}\text { 1. Likelihood of excursion depends on reactor control system response to overcooling event (whether control mechanisms) shut down } \\
\text { the reactor } \\
\text { 2. Precipitation of fissile species could lead to increase in reactivity and excursion } \\
\text { 3. Supercriticality resulting in increased temperature and pressure in system } \\
\text { 4. Feedback mechanisms tend to decrease reactivity } \\
\text { 5. Component failure mechanisms due to over-temperature/over-pressure leading to radionuclide release } \\
\text { 6. Geometry and location of overcooling could affect the potential for precipitation of fissile material and increased reactivity }\end{array}$ \\
\hline \multicolumn{2}{|c|}{ Importance } & Considerations \\
\hline FOM-1 & $\mathbf{M}$ & $\begin{array}{l}\text { - Highly dependent on event scenario characteristics and design features for potential impact on FOM. Effect could be to decrease } \\
\text { reactivity as to increase reactivity. }\end{array}$ \\
\hline FOM-2 & $\mathbf{M}$ & - $\quad$ Same as above. \\
\hline FOM-3 & $\mathbf{M}$ & $\begin{array}{l}\text { - This is likely a short-lived transient. } \\
\text { - Identified as part of IV01 for a potential for reactivity addition resulting from flow back into the active core region. }\end{array}$ \\
\hline \multicolumn{3}{|c|}{ Knowledge } \\
\hline FOM-1 & 2 & $\begin{array}{l}\text { - Likely able to be treated through conservative analysis. However, detailed analysis depends on the event scenario characteristics and } \\
\text { design features. }\end{array}$ \\
\hline FOM-2 & 2 & - Same as above. \\
\hline FOM-3 & 2 & - Same as above. \\
\hline \multicolumn{3}{|c|}{$\begin{array}{r}\text { Additional description and } \\
\text { rationale: }\end{array}$} \\
\hline \multicolumn{2}{|r|}{ References: } & $\begin{array}{l}\text { [1] Betzler, B.R., J.J. Powers, N.R. Brown and B.T. Rearden, "Implementation of Molten Salt Reactor Tools in SCALE," Int. Conf. on } \\
\text { Math. and Comp. Methods Applied to Nucl. Science and Engineering, April } 2017 . \\
\text { [2] Brown, N.R., J.J. Powers, D.E. Mueller, and B.W. Patton, Complete Sensitivity/Uncertainty Analysis of LR-0 Reactor Experiments } \\
\text { with MSRE FLiBe Salt and Perform Comparison with Molten Salt Cooled and Molten Salt Fueled Reactor Models, ORNL/TM- } \\
\text { 2016/729, December 2016. }\end{array}$ \\
\hline
\end{tabular}




\begin{tabular}{|c|c|c|}
\hline \multicolumn{2}{|c|}{ Scenario categories: } & VI. Radwaste management system \\
\hline & Description: & $\begin{array}{l}\text { Possible sources include graphite beds, cover gas systems, part of the balance of plant, and waste generated from maintenance system } \\
\text { (filters). This assumes that gases from fuel salt prior to filters or other treatment operations are part of a fuel salt spill accident. }\end{array}$ \\
\hline \multicolumn{2}{|c|}{ Key parameters and properties: } & \begin{tabular}{ll|} 
1. & Radwaste chemical and physical forms \\
2. Operating history, source magnitude \\
3. Failure modes \\
4. Design of the system and barriers to release \\
\end{tabular} \\
\hline \multicolumn{2}{|c|}{ Importance } & Considerations \\
\hline FOM-1 & $\mathbf{H}$ & $\begin{array}{l}\text { - } \quad \text { Post-filters, could be in a separate containment, possible different gas environment, different hazards. } \\
\text { - } \quad \text { Radwaste management systems could be very different across the reactor designs. } \\
\text { - } \quad \text { Cryogenic long-term storage of gases is unlikely as a result of loss of power, loss of cooling issues. }\end{array}$ \\
\hline FOM-2 & $\mathbf{M}$ & - Off-gases have a high heat load. \\
\hline FOM-3 & $\mathbf{M}$ & - If the fluid contains fissile material, then there is a potential for criticality; however, this is highly design dependent. \\
\hline \multicolumn{3}{|c|}{ Knowledge } \\
\hline FOM-1 & 2 & $\begin{array}{l}\text { Although MSR radwaste systems have been successfully employed previously, an exhaustive list of failure modes and the overall } \\
\text { knowledge level is highly design dependent and may not exist for some novel or advanced systems. }\end{array}$ \\
\hline FOM-2 & 2 & - Same as above. \\
\hline FOM-3 & 2 & - $\quad$ Same as above. \\
\hline \multicolumn{2}{|c|}{$\begin{array}{r}\text { Additional description and } \\
\text { rationale: }\end{array}$} & The cover gas system may warrant another study of phenomena and possible accidents with design-specific information. \\
\hline & References: & \\
\hline
\end{tabular}


APPENDIX C. PANEL COMPOSITION AND PRESENTERS 



\section{APPENDIX C. Panel Composition and Presenters}

Table 18. Panel composition

\begin{tabular}{|c|c|c|c|}
\hline Name & Affiliation & Role & Organization \\
\hline Amanda Lines & PNNL & Panelist & National Lab \\
\hline David LeBlanc & Terrestrial Energy, Inc. & Panelist & Developer \\
\hline Tommy Cisneros & TerraPower & Panelist & Developer \\
\hline Kurt Harris & Flibe Energy, Inc. & Panelist & Developer \\
\hline Dane Wilson & ThorCon US, Inc. & Panelist & Developer \\
\hline Ed Pheil & Elysium Industries & Panelist & Developer \\
\hline Aslak Stubsgaard & Copenhagen Atomics & Panelist & Developer \\
\hline Guy Anderson & Moltex Energy & Panelist & Developer \\
\hline Wendy Reed & NRC & Panelist & Developer \\
\hline Christopher VanWert & NRC & Panelist & Developer \\
\hline Tony Hill & Natura Resources, LLC & Panelist & Developer \\
\hline Fred Gelbard & SNL & Panelist & National Lab \\
\hline Joanna McFarlane & ORNL & Panelist & National Lab \\
\hline Melissa Rose & Argonne & Panelist & National Lab \\
\hline Shayan Shahbazi & Argonne & Participant & National Lab \\
\hline Toni Karlsson & INL & Participant & National Lab \\
\hline Matthew Bucknor & Argonne & Participant & National Lab \\
\hline Markus Piro & Ontario Tech University & Participant & Tool Developer \\
\hline George Flanagan & ORNL & Peer Reviewer & National Lab \\
\hline Richard Denning & Consultant & Co-LTI \& Panelist & Private \\
\hline Michael Muhlheim & ORNL & Co-LTI & National Lab \\
\hline Alexander Huning & ORNL & Co-LTI & National Lab \\
\hline David Holcomb & ORNL & LTI \& Panelist & National Lab \\
\hline
\end{tabular}


Table 19. PIRT presenters

\begin{tabular}{|c|c|c|}
\hline Name & Affiliation & PIRT Presentation \\
\hline Guy Anderson & Moltex Energy & Overview of SSR-W Reactor Design \\
\hline Kurt Harris & Flibe Energy, Inc. & Overview of Lithium Fluoride Thorium Reactor (LFTR) \\
\hline Dane Wilson & ThorCon US, Inc. & ThorCon's Implementation of Control, Cool and Contain \\
\hline Tony Hill & Natura Resources, LLC & Introductions, Licensing Pathway and Technical Summary \\
\hline Aslak Stubsgaard & Copenhagen Atomics & Copenhagen Atomics Reactor Design Overview \\
\hline Jake McMurray & ONRL & Molten Salt Thermophysical Properties Database \\
\hline Tommy Cisneros & TerraPower & MCFR System Description \\
\hline David LeBlanc & Terrestrial Energy, Inc. & Overview of the IMSR $\AA$ \\
\hline Wendy Reed & NRC & Phenomena Identification and Ranking Tables: US NRC Perspective \\
\hline Ed Pheil & Elysium Industries & Molten Chloride Salt Fast Reactor PIRT Presentation \\
\hline Sara Thomas & Argonne & Salt Spill Experiments \\
\hline Joanna McFarlane & ORNL & Molten Salt Chemistry and Off-Gas Monitoring \\
\hline David Holcomb & ORNL & Current Status of Fuel Salt Qualification Guidance Development \\
\hline Dave Luxat & SNL & MELCOR for non-LWR Analysis \\
\hline Melissa Rose & Argonne & Quality Aspects Of Molten Salt Property Measurements \\
\hline Rui Hu & Argonne & SAM Overview for MSR Analyses \\
\hline Scott Greenwood & ORNL & TRANSFORM: Description and Application \\
\hline Will Wieselquist & ORNL & Overview of MSR Capabilities in SCALE \\
\hline
\end{tabular}




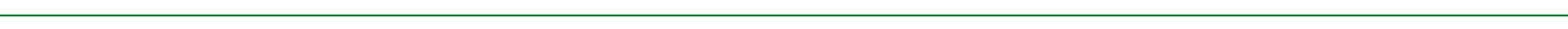

